Boise State University

ScholarWorks

Management Faculty Publications and

Presentations

Spring 2019

\title{
Leaders and Followers Behaving Badly: A Meta-Analytic Examination of Curvilinear Relationships Between Destructive Leadership and Followers' Workplace Behaviors
}

\author{
Jeremy D. Mackey \\ Auburn University \\ Charn P. McAllister \\ Northeastern University \\ Liam P. Maher \\ Boise State University \\ Gang Wang \\ Florida State University
}

This is the peer reviewed version of the following article:

J.D. Mackey; C.P. McAllister; L.P. Maher; \& G. Wang. (2019). Leaders and Followers Behaving Badly: A Meta-Analytic Examination of Curvilinear Relationships Between Destructive Leadership and Followers' Workplace Behaviors. Personnel Psychology, 72(1), 3-47.

which has been published in final form at doi: 10.1111/peps.12286. This article may be used for non-commercial purposes in accordance with Wiley Terms and Conditions for Self-Archiving. 


\title{
Leaders and Followers Behaving Badly: A Meta-Analytic Examination of Curvilinear Relationships Between Destructive Leadership and Followers' Workplace Behaviors
}

\author{
Jeremy D. Mackey \\ Auburn University \\ Charn P. McAllister \\ Northeastern University
}

\author{
Liam P. Maher \\ Boise State University \\ and \\ Gang Wang \\ Florida State University
}

\begin{abstract}
We draw from social psychological and resource-based theories to meta-analytically examine the existence, form, and magnitude of curvilinear relationships between destructive leadership and followers' workplace behaviors (i.e., job performance, organizational citizenship behaviors, and workplace deviance). Overall, our meta-analytic results demonstrate weak evidence of curvilinear relationships between destructive leadership and followers' workplace behaviors. However, we did find some support for the application of social psychological theories when examining the curvilinear effects of destructive leadership on followers' workplace behaviors at extreme levels of destructive leadership (i.e., two standard deviations below and above the mean). Our findings are important because they (1) provide support for prior research that has examined the linear effects of destructive leadership on followers' workplace outcomes and (2) refine our knowledge of the effects of destructive leadership on followers' workplace outcomes by demonstrating the existence, form, and magnitude of curvilinear effects at extreme levels of destructive leadership. Overall, this study's meta-analytic regression, relative weight, and semipartial correlation results have important implications for (1) how to interpret the conclusions drawn from prior destructive leadership research, (2) how to conduct future studies that examine destructive leadership, and (3) practitioners' attempts to deter destructive leadership and limit its harmful effects on followers.
\end{abstract}

Keywords: destructive leadership; meta-analysis; performance; OCB; deviance; abusive supervision; social undermining

Destructive leadership has received a great deal of scholarly and practitioner attention in recent years due to its prevalence and impact in organizations (Krasikova, Green, \& LeBreton, 2013; Schyns \& Schilling, 2013). Destructive leadership is defined as volitional leader behavior that has the intent or potential to harm leaders' organizations and/or followers (Einarsen, Aasland, \& Skogstad, 2007; Krasikova et al., 2013). Typically, destructive leaders use harmful methods of influencing followers that encourage followers to violate their organizations' interests (Krasikova et al., 2013). Destructive leadership is a broad construct comprised of many forms of hostility leaders direct toward followers (e.g., abusive supervision, supervisor undermining) that have negative consequences for followers' workplace behaviors (e.g., job performance, organizational citizenship behaviors [OCBs], workplace deviance). Job performance (i.e., in-role performance) and OCBs (i.e., contextual performance) are considered essential to proper organizational functioning (Cascio \& Aguinis, 2008; Podsakoff, MacKenzie, Paine, \& Bachrach, 2000), whereas workplace deviance consists of behaviors that violate organizational norms while harming organizations and/or their members (Berry, Ones, \& Sackett, 2007). Thus, it is important to understand the existence, form, and magnitude of the relationships between destructive leadership and followers' workplace behaviors because job performance, OCBs, and workplace deviance all affect how well organizations operate. 
This is an author-produced, peer-reviewed version of this article. The final, definitive version of this document can be found online at Personnel Psychology, published by Wiley Periodicals, Inc.. Copyright restrictions may apply. doi: 10.1111/peps.12286

Prior destructive leadership research has almost exclusively examined linear relationships between destructive leadership and followers' workplace behaviors. However, recent calls for examining curvilinear relationships in organizational research advocate that important curvilinear relationships may exist (e.g., Pierce \& Aguinis, 2013). Surprisingly little destructive leadership research has examined curvilinear relationships between destructive leadership and followers' workplace behaviors. Further, when curvilinear relationships have been examined in prior research, they often have either been used as control variables rather than substantive variables (e.g., Mackey, Ellen, Hochwarter, \& Ferris, 2013) or in the examination of specific types of workplace behaviors (e.g., creativity; Lee, Yun, \& Srivastava, 2013). Additionally, curvilinear relationships have not been replicated by subsequent research (Tepper, Simon, \& Park, 2017). It is possible that examining curvilinear relationships in prior destructive leadership studies would uncover meaningful curvilinear relationships that have important implications for how to interpret the findings from prior studies, how researchers conduct destructive leadership research moving forward, and how practitioners limit the impact of destructive leadership on followers' workplace behaviors.

Our motivation for this study is to provide the theoretical and empirical foundation necessary for research to examine curvilinear relationships between destructive leadership and followers' workplace behaviors. We draw from competing theoretical perspectives (i.e., social psychological and resource-based theoretical perspectives) to investigate and understand the potential curvilinear relationships between destructive leadership and followers' workplace outcomes in order to advance knowledge concerning the existence, form, and magnitude of these relationships. Extending our current understanding of curvilinear relationships generates knowledge in a nuanced perspective that can address some of the inconsistent and/or modest effects prior research has found between destructive leadership and followers' workplace behaviors. Thus, we use meta-analytic techniques (Hunter \& Schmidt, 2004) to cumulate empirical research on destructive leadership and followers' workplace behaviors. Our meta-analytic results contribute much needed depth to the extant meta-analyses that examine destructive leadership by including curvilinear effects and drawing from a much larger sample of primary studies than prior meta-analyses (i.e., current study: $54 \leq k \leq 83$; Mackey, Frieder, Brees, \& Martinko, 2017: $13 \leq k \leq 22$; Schyns \& Schilling, 2013: $7 \leq k \leq 13$ ).

Our study makes two important contributions to destructive leadership research. First, we make a theoretical contribution by explaining why curvilinear relationships between destructive leadership and followers' workplace behaviors may exist. Specifically, we examine competing social psychological and resource-based theoretical explanations of curvilinear destructive leadership effects in order to provide a novel and compelling theoretical explanation for the existence, form, and magnitude of potential curvilinear relationships between destructive leadership and followers' workplace outcomes. Thus, our study makes an incremental improvement to our theoretical understanding of linear and curvilinear effects in a stream of research that lacks a unifying theoretical framework. Second, we make a methodological contribution by conducting the first direct meta-analytic test of curvilinear relationships that utilizes curvilinear data from prior research. We examine the relative contributions of linear and curvilinear effects via regression, relative weight, and semipartial correlation analyses, which enables us to assess the incremental validity of curvilinear effects (Cortina, 1993). Our methodological contribution provides an immediate opportunity to make incremental advancements to research in numerous literatures if researchers use our study as an example for future meta-analytic efforts that examine the incremental contribution of curvilinear effects above linear effects.

\section{Workplace Behaviors}

In this study, we examine three widely studied workplace behaviors in destructive leadership research: job performance, OCBs, and workplace deviance. Below, we describe our conceptualizations of each of these workplace behaviors and provide an overview of how each of these behaviors has been examined in destructive leadership research. Then, we develop competing hypotheses that pit the predictions of social psychological theories against the predictions of resource-based theories regarding the existence and form of curvilinear relationships between destructive leadership and followers’ workplace behaviors.

\section{$\underline{\text { Job Performance }}$}

First, job performance is defined as "the aggregated value to the organization of the discrete behavioral episodes that an individual performs over a standard interval of time” (Motowidlo, Borman, \& Schmit, 1997, p. 71). Prior destructive leadership research demonstrates that destructive leadership is negatively associated with followers' selfrated (e.g., Wang, Harms, \& Mackey, 2015), coworker-rated (e.g., Peng, Schaubroeck, \& Li, 2014), leader-rated (e.g., 
This is an author-produced, peer-reviewed version of this article. The final, definitive version of this document can be found online at Personnel Psychology, published by Wiley Periodicals, Inc.. Copyright restrictions may apply. doi: 10.1111/peps.12286

Tepper, Moss, \& Duffy, 2011), and objectively rated (e. g., Walter, Lam, van der Vegt, Huang, \& Miao, 2015) job performance. Although job performance is considered an important behavioral outcome in most organizational research because it captures in-role performance, it is especially important for destructive leadership research because the negative association between job performance and destructive leadership affects numerous raters' assessments of followers' performance.

\section{Organizational Citizenship Behaviors}

Next, OCBs are discretionary behaviors that are not formally required, but nonetheless support "the social and psychological environment in which task performance takes place” (Organ, 1997, p. 95). Organ (1988) initially proposed altruism, civic virtue, conscientiousness, courtesy, and sportsmanship as the five specific dimensions of OCBs, but recent conceptualizations and operationalizations of OCBs capture a wide array of discretionary, extra-role behaviors that impact employee and organizational functioning. Researchers often describe OCBs as contextual performance (Hoffman, Blair, Meriac, \& Woehr, 2007; Podsakoff, Whiting, Podsakoff, \& Blume, 2009) directed toward organizations (i.e., OCB-Os) or individuals within organizations (i.e., OCB-Is; McNeely \& Meglino, 1994). Prior destructive leadership research has found a negative association between destructive leadership and general OCBs, OCB-Is, and OCB-Os (e.g., Aryee, Chen, Sun, \& Debrah, 2007; Zhang, Kwan, Zhang, \& Wu, 2014). Thus, OCBs are an important behavioral outcome to examine because destructive leadership adversely affects a wide array of followers' discretionary behaviors that benefit organizations and the individuals within them.

\section{Workplace Deviance}

Finally, workplace deviance is defined as "voluntary behavior that violates significant organizational norms and in so doing threatens the well-being of an organization, its members, or both" (Robinson \& Bennett, 1995, p. 556). Behaviors that violate significant organizational norms may vary by organization, but workplace deviance typically includes stealing workplace property, intentionally working slow, and taking unacceptably long breaks, whereas interpersonal deviance typically includes verbal harassment, sexual harassment, and assault (Bennett \& Robinson, 2000). Meta-analytic evidence demonstrates that workplace deviance, which includes both organizational and interpersonal deviance, is associated with harmful effects on an array of organizational and personal phenomena (Berry et al., 2007). Prior research has demonstrated evidence that destructive leadership is positively associated with organization-, interpersonal-, and leader-directed deviance (e.g., Mawritz, Mayer, Hoobler, Wayne, \& Marinova, 2012; Mitchell \& Ambrose, 2007; Vogel \& Mitchell, 2017). Thus, workplace deviance is an important behavioral outcome to examine in destructive leadership research due to its harmful impacts on organizations and their members.

\section{Theoretical Foundations and Hypothesis Development}

\section{Social Psychological Theories}

Numerous social psychological theories have been used in prior research to explain the linear effects of destructive leadership on followers' workplace behaviors. For example, Tepper's (2000) seminal study on abusive supervision drew from justice theory (Folger \& Cropanzano, 2001), which advocates that employees use cognitive comparisons to evaluate the fairness of the treatment they receive from their leaders relative to the way they treat their leaders. Since then, primary studies (e.g., Tepper, Duffy, Henle, \& Lambert, 2006), meta-analyses (e.g., Mackey et al., 2017), and conceptual reviews (e.g., Chan \& McAllister, 2014; Klaussner, 2014) have drawn from justice theory to explain that followers' perceptions of destructive leadership typically begin as perceptions of supervisory injustice, then evolve to account for social exchange processes between leaders and followers. Thus, it is not surprising that social exchange theory is the theoretical rationale used in many recent destructive leadership studies because it shares some theoretical foundations with justice theory (Cropanzano \& Mitchell, 2005).

Social exchange theory explains why and how relationships between leaders and followers develop over time through interdependent interactions (Cropanzano, Anthony, Daniels, \& Hall, 2017; Cropanzano \& Mitchell, 2005). Specifically, the tenets of social exchange theory argue that exchange relationships generate obligations for the parties involved because reciprocity norms compel individuals to respond in kind to the treatment they receive without knowing whether, when, or to what extent the other party may reciprocate (Cropanzano \& Mitchell, 2005; Gouldner, 1960). Social exchange parties establish social standards that govern their current exchange relationships (e.g., felt obligations, reciprocity norms). Ultimately, these social reinforcement standards (i.e., the rate of past social rewards 
This is an author-produced, peer-reviewed version of this article. The final, definitive version of this document can be found online at Personnel Psychology, published by Wiley Periodicals, Inc.. Copyright restrictions may apply. doi: 10.1111/peps.12286

in exchange relationships; Baron, 1966) create internal frames of reference that individuals use when engaging in social exchange relationships (Baron, 1966; Emerson, 1976). Social reinforcement standards are important because they provide a baseline for future social exchange expectations (Baron, 1966) that differs across followers because each follower has unique perceptions of their exchanges with their leaders.

Curvilinear relationships between destructive leadership and in-role performance (i.e., job performance) and extrarole performance (i.e., OCBs) likely exist because followers adjust their social reinforcement standards in accordance with their sustained perceptions of leaders' downward-directed hostility. However, we argue it is unlikely that followers continue to de-escalate their job performance and OCBs past a point identified by their social reinforcement standards due to floor effects (Wang, Zhang, McArdle, \& Salthouse, 2008) that regulate the lowest acceptable standard for job performance and OCBs. Specifically, followers' social psychological assessments of their exchange relationships serve as ways of identifying unfairness in order to protect against further adverse social exchange interactions. Thus, social psychological theories advocate that destructive leadership is negatively associated with job performance and OCBs, but that this negative relationship is stronger from lower to moderate levels of destructive leadership than it is from moderate to higher levels of destructive leadership because it is subject to a floor effect that restricts the relationship to be weak or nonexistent between moderate and higher levels of destructive leadership. In summary, social psychological theories predict asymptotic (i.e., U-shaped) curvilinear relationships between destructive leadership and job performance and OCBs whereby the rate of the negative association between destructive leadership and job performance and OCBs weakens as destructive leadership increases.

In contrast, we theorize it is unlikely that followers continue to escalate their deviant behaviors in an exponential manner because harmful behaviors that violate organizational norms likely are subject to ceiling effects (Wang et al., 2008) that limit social psychological boundaries of fairness in order to protect against adverse social exchange consequences. Specifically, social psychological theories advocate that destructive leadership is positively associated with workplace deviance from lower to moderate levels of destructive leadership, but that this positive relationship is subject to a ceiling effect that restricts the relationship to weak or nonexistent effects between moderate and higher levels of destructive leadership. As a result, we hypothesize an asymptotic (i.e., inverted U-shaped) curvilinear relationship between destructive leadership and workplace deviance whereby the rate of the positive association between destructive leadership and workplace deviance weakens as destructive leadership increases. Thus, we propose the following hypothesis:

Hypothesis 1a-c: Destructive leadership will demonstrate asymptotic curvilinear relationships with (a) job performance, (b) OCBs, and (c) workplace deviance that weaken as destructive leadership increases.

\section{Resource-Based Theories}

Although social psychological theories offer a useful theoretical basis from which to understand the curvilinear effects of destructive leadership, recent destructive leadership research (e.g., Mawritz, Greenbaum, Butts, \& Graham, 2017) has drawn from the valuable explanations offered by resource-based theories (e.g., conservation of resources theory, ego depletion theory). For instance, the conservation of resources theory (Hobfoll, 1989, 2001) posits that individuals try to protect, retain, and build their valuable resources in order to guard against potential or actual resource loss due to addressing demands in their work environments. Resources include "anything perceived by the individual to help attain his or her goals" (Halbesleben, Neveu, Paustian-Underdahl, \& Westman, 2014, p. 1338). Ego depletion theory (Baumeister, Bratslavsky, Muraven, \& Tice, 1998; Baumeister, Muraven, \& Tice, 2000) builds on the conservation of resources theory by positing that self-regulation is a valuable resource with a limited supply for each individual. The tenets of ego depletion theory argue that ego depletion (i.e., "a temporary reduction in the self's capacity or willingness to engage in volitional action”; Baumeister et al., 1998, p. 1253) likely results when perceived demands in the work environment (e.g., responding to destructive leadership) consume followers' self-regulatory resources. Thus, followers may become increasingly ego depleted as destructive leadership increases, which results in decreasing abilities to regulate behavioral responses to destructive leadership.

Together, resource-based theories advocate that asymptotic (i.e., inverted U-shaped) curvilinear relationships likely exist between destructive leadership and in-role (i.e., job performance) and extra-role performance (i.e., OCBs) because destructive leadership increasingly depletes followers' egos and self-regulatory resources. The depletion of followers' egos and self-regulatory resources likely renders followers increasingly unable or unwilling to engage in 
This is an author-produced, peer-reviewed version of this article. The final, definitive version of this document can be found online at Personnel Psychology, published by Wiley Periodicals, Inc.. Copyright restrictions may apply. doi: 10.1111/peps.12286

the volitional action necessary to engage in performance and OCBs. As a result, we hypothesize asymptotic curvilinear relationships between destructive leadership and job performance and OCBs whereby destructive leadership is negatively associated with job performance and OCBs, but that this negative relationship is stronger between moderate and higher levels of destructive leadership than it is between lower and moderate levels of destructive leadership. Thus, we posit that resource-based theories predict that the magnitude of the relationship between destructive leadership and job performance and OCBs becomes increasingly stronger as destructive leadership increases because followers' resources become increasingly depleted.

In contrast, we hypothesize an asymptotic (i.e., U-shaped) curvilinear relationship between destructive leadership and workplace deviance whereby the magnitude of the relationship between destructive leadership and workplace deviance increases as destructive leadership increases because followers' egos and self-regulatory capabilities are progressively depleted. Specifically, resource-based theories suggest that destructive leadership is positively associated with job performance and OCBs, but that this positive relationship is stronger between moderate and higher levels of destructive leadership than it is between lower and moderate levels of destructive leadership because followers' egos and self-regulatory resources become progressively less able to inhibit them from engaging in deviant behaviors in response to perceptions of destructive leadership. Thus, we propose the following competing hypothesis:

Hypothesis 2a-c: Destructive leadership will demonstrate asymptotic curvilinear relationships with (a) job performance, (b) OCBs, and (c) workplace deviance that strengthen as destructive leadership increases.

\section{Method}

\section{$\underline{\text { Literature Search }}$}

We conducted an extensive literature search for studies that reported empirical data on destructive leadership and followers' workplace behaviors that were available as of November 2017. First, we located studies that were cited in recent reviews (e.g., Krasikova et al., 2013; Martinko, Harvey, Brees, \& Mackey, 2013; Tepper et al., 2017) and metaanalyses (e.g., Mackey et al., 2017; Schyns \& Schilling, 2013) of destructive leadership and interpersonal mistreatment research. Then, we searched through academic databases (e.g., Google Scholar, PsycINFO, Proquest Dissertations \& Theses) for journal articles, dissertations, conference papers, book chapters, reports, and other published and unpublished studies. Next, we used Google Scholar to identify studies that cited prominent measures of destructive leadership (e.g., Duffy, Ganster, \& Pagon, 2002; Shaw, Erickson, \& Harvey, 2011; Tepper, 2000; Thoroughgood, Tate, Sawyer, \& Jacobs, 2012). Then, we searched for in press articles on numerous websites for academic journals that have published destructive leadership research (e.g., Personnel Psychology). Additionally, we searched individual researchers' websites and ResearchGate profiles for studies, as well as the titles of each study's list of references.

In addition to searching the sources listed above, we searched the conference programs of the Society for Industrial and Organizational Psychology, Academy of Management (AOM), and AOM's affiliates (i.e., Eastern AOM, Midwest AOM, Southern Management Association, Southwest AOM, and Western AOM) for the programs available from 2000-2017. Ultimately, we contacted authors of the 49 conference papers we identified as potentially meeting the inclusion criteria below to request copies of the conference papers. Most conference papers were excluded from this study because they were not available or shared data with other studies that were included in the meta-analysis.

Finally, we contacted the first and/or corresponding author of every study included in this meta-analysis to request the information necessary to conduct the curvilinear analyses because the information required for these analyses was not available in any of the primary studies we found. Specifically, we sent personalized emails with custom SPSS syntax files used to calculate curvilinear terms and create correlation matrices with linear and curvilinear terms to the authors of each primary study. Ultimately, we contacted authors of 126 studies that included a total of 176 samples with 352 workplace behavior variables. Our efforts resulted in responses from the authors of 74 studies with partial or full data (i.e., 59\%), the authors of 4 studies whose data were not available (i.e., 3\%), and the authors of 48 studies who did not respond to the request or responded to the request without data (i.e., 38\%). Overall, 56 studies with 79 independent samples ( $k=79, N=22,531$ ) were included in the curvilinear analyses because they provided full information (i.e., bivariate zero-order correlations and descriptive statistics) and met the inclusion criteria noted below. 
This is an author-produced, peer-reviewed version of this article. The final, definitive version of this document can be found online at Personnel Psychology, published by Wiley Periodicals, Inc.. Copyright restrictions may apply. doi: 10.1111/peps.12286

We obtained complete information for 293 workplace behavior variables for the linear analyses and 129 workplace behavior variables for the curvilinear analyses. Full lists of the studies and main codes included in the linear and curvilinear analyses are shown in Appendices A, B, and C. For the linear analyses (see Table 1), 54 studies examined job performance ( $k=54, N=14,029), 64$ studies examined OCBs $(k=64, N=16,415)$, and 83 studies examined workplace deviance ( $k=83, N=22,759$ ). For the curvilinear analyses (see Appendix D), 31 studies examined job performance ( $k=31, N=8,427)$, 32 studies examined OCBs $(k=32, N=8,232)$, and 32 studies examined workplace deviance $(k=32, N=9,542)$.

\section{$\underline{\text { Inclusion Criteria }}$}

We required that studies meet five inclusion criteria to be included in the final analyses. We describe the inclusion criteria and explain the rationale for each of the inclusion criteria below in order to facilitate the interpretation of our results (Kepes, McDaniel, Brannick, \& Banks, 2013), enhance the transparency of our study (Aytug, Rothstein, Zhou, \& Kern, 2012; Gonzalez-Mulé \& Aguinis, in press), and enable replicability of our meta-analysis (Aguinis, Dalton, Bosco, Pierce, \& Dalton, 2011).

First, we required that all studies were written in English. Second, we required that destructive leadership and at least one workplace behavior consistent with the definitions of job performance, OCBs, and workplace deviance provided earlier in this study were empirically measured. The coders and first author of this study reviewed the description of the destructive leadership and workplace behavior measures to ensure that the variables were operationalized in a manner that was consistent with prior theory, prior research, and the objectives of this study. Our study contains numerous forms of destructive leadership, including abusive supervision, aversive leadership, despotic leadership, petty tyranny, supervisor bullying, supervisor incivility, supervisor narcissism, and supervisor undermining. Third, we required that destructive leadership and workplace behaviors were measured and reported at the individual level (i.e., we excluded studies that reported variables at the group or organization level). Fourth, we required that workplace behaviors pertained to actual employees, rather than hypothetical employees or experimental participants. Fifth, we required that followers were the referent for the workplace behaviors variable.

We ensured that each sample of data was included in the analyses only once because meta-analytic procedures require an assumption of sample independence (Hunter \& Schmidt, 2004; Wood, 2008). Specifically, we reviewed the description of each sample to ensure that we avoided data overlap. We defaulted to including published studies when data overlapped between published (e.g., journal articles) and unpublished (e.g., conference papers) studies. Also, we defaulted to the earliest published study for journal articles that shared data. Finally, we created composite variables when there were multiple effect sizes reported in a single study. We used Mosier's (1943) Equation 8 to assess the internal consistency of composite variables and calculate correlations.

\section{Coding}

The first three authors met to develop a coding protocol and pilot test several versions of the coding form used to report data to ensure that coders were consistent in their assessments of studies and judgment calls made (Aguinis et al., 2011; Geyskens, Krishnan, Steenkamp, \& Cunha, 2009). Then, two authors independently coded information from each study. The coders reported numerous characteristics of study designs. First, coders recorded information about the type of publication (e.g., journal article, dissertation), whether destructive leadership was measured using an agreement or frequency scale, the sample size (i.e., $n$ ) of the study, and the internal consistency (i.e., $\alpha$ ) of the destructive leadership measure. Finally, the coders recorded the general type of workplace behavior (i.e., job performance, OCBs, or workplace deviance), the specific type of workplace behavior (e.g., OCB-Is, OCB-Os), the rater of the workplace behavior measure (e.g., leader, follower), the internal consistency (i.e., $\alpha$ ) of the workplace behavior measure, and the correlations $(r$ ) between destructive leadership and the workplace behavior measure. For the curvilinear analyses, the coders reported the correlations $(r)$ between linear and curvilinear terms for destructive leadership and workplace behaviors (i.e., three total correlations: $r_{\text {Destructive Leadership \& Destructive Leadership }}{ }^{2} ; r_{\text {Destructive Leadership }}$ \& Behavior; $r_{\text {Destructive Leadership }}^{2}$ \& Behavior $)$.

The first author of this study reviewed all of the information reported in the coding forms, checked for errors and discrepancies between coders, finalized the coding results by consulting the original studies to resolve all discrepancies between coders, and calculated inter-rater agreement statistics. Generally, there were high levels of agreement between the coders for the information reported in the coding form. For the linear information, agreement ranged from $89 \%$ 
This is an author-produced, peer-reviewed version of this article. The final, definitive version of this document can be found online at Personnel

Psychology, published by Wiley Periodicals, Inc.. Copyright restrictions may apply. doi: 10.1111/peps.12286

for the correlations between destructive leadership and the workplace behavior measures to $100 \%$ for the type of publication. The coders agreed at least $90 \%$ of the time for most coding categories (i.e., 8/9 categories). The raters agreed about $99 \%$ of the time when recording the curvilinear correlations that the authors of the primary studies provided.

\section{$\underline{\text { Sub-Group Analyses for Moderators }}$}

In addition to conducting overall analyses for job performance, OCBs, and workplace deviance, we also provide analyses for specific forms of these behaviors that have been widely examined in prior destructive leadership research. Specifically, we examined OCB-Os, OCB-Is, organization-directed deviance, interpersonal-directed deviance, and leader-directed deviance. Also, we conduct sub-group analyses within each of the specific forms of workplace behaviors noted above in order to examine the differences in results across studies that stem from theoretical and study design choices described below (i.e., publication status, source of behavioral rating, type of scale points, abusive supervision versus other forms of destructive leadership). We set the minimum number of primary studies for inclusion in the moderator analyses to 20 because 20 is the threshold for obtaining proper confidence intervals in random effects meta-analyses that assume approximate normality of effect sizes while using the Hunter and Schmidt (2004) metaanalytic technique (Aguinis, Gottfredson, \& Wright, 2011; Field, 2005). We describe the moderators we examined in this study below.

Publication Status. We examined whether there were differences between published (i.e., journal articles) and unpublished (i.e., dissertations, conference papers, book chapters, and reports) studies. Examining publication status effects is a recommended and important practice for meta-analysis (Aytug et al., 2012) because non-significant results and/or small effect sizes are less likely to be published than significant results and/or large effect sizes (i.e., the file drawer problem; Rothstein, Sutton, \& Borenstein, 2005).

Source of Behavioral Rating. Prior research demonstrates that the source of behavioral ratings can impact their measurement (e.g., Carpenter, Rangel, Jeon, \& Cottrell, 2017; Viswesvaran, Ones, \& Schmidt, 1996). Destructive leadership researchers have assessed followers' workplace behaviors via responses from leaders, peers, organizational records, and even the followers themselves. Thus, we examine differences between self- and other-ratings of followers' workplace behaviors as a moderator in our study.

Type of Scale Points. Many measures of destructive leadership were developed using frequency scale points (e.g., Duffy et al., 2002; Tepper, 2000; Thoroughgood et al., 2012). However, researchers have used a combination of various frequency and agreement scale points across subsequent studies. Examining the type of scale points used for the destructive leadership measure is important because prior research demonstrates that measurement ratings can differ when utilizing agreement scale points versus frequency scale points (e.g., Spector, Bauer, \& Fox, 2010). Thus, we examine the effects of the type of scale points (i.e., agreement or frequency) as a moderator of the findings obtained in our study.

Type of Destructive Leadership. We examined the type of destructive leadership as a moderator. Abusive supervision was the most widely studied form of destructive leadership included in our study, which was expected because Schyns \& Schilling's (2013) meta-analysis of destructive leadership was comprised of mostly abusive supervision studies. Thus, we conducted moderator analyses that examined the results from abusive supervision studies versus the collective results from all other forms of destructive leadership in our study.

\section{$\underline{\text { Analyses }}$}

We used Hunter and Schmidt's (2004) psychometric meta-analytic procedures to analyze the data and calculate results for the linear effects. Specifically, we used the "Hunter \& Schmidt Meta-Analysis Program" (Schmidt \& Le, 2004) to run random-effects models that weighted the results by sample size. We report the number of studies included in each analysis $(k)$, the total number of respondents in each analysis $(N)$, weighted mean bivariate correlations $(\vec{r})$ of uncorrected correlations $\left(r_{\mathrm{i}}\right)$, standard deviations for weighted mean bivariate correlations $\left(S D_{r}\right)$, population correlation estimates that were corrected for measurement unreliability and sampling error $(\rho)$, standard deviations for population correlation estimates $\left(S D_{\rho}\right)$, and the percentage of variance that was attributable to artifacts for population correlation estimates. Also, we report the $80 \%$ credibility intervals (CV) and the $95 \%$ confidence intervals (CI) for population correlation estimates. The $80 \%$ credibility intervals indicate that $80 \%$ of the values in the estimated $\rho$ 
This is an author-produced, peer-reviewed version of this article. The final, definitive version of this document can be found online at Personnel Psychology, published by Wiley Periodicals, Inc.. Copyright restrictions may apply. doi: 10.1111/peps.12286

distribution fell within the interval identified, whereas the 95\% confidence intervals indicate that we can be 95\% certain the true value of an estimated population correlation fell within the interval identified (Hunter \& Schmidt, 2004).

We were interested in bivariate relationships at the construct level (Hunter \& Schmidt, 2004), so we corrected the observed correlations for measurement error. Specifically, we used Cronbach's alpha $(\alpha)$ as a measure of internal consistency for the destructive leadership and workplace behavior variables. We used the median internal consistency estimate from other studies for each specific workplace behavior if Cronbach's alpha was not reported in a particular study. Also, we used the median internal consistency estimate for studies that used two-item measures in order to avoid overly correcting the correlations in a manner that would upwardly bias the estimates due to the low internal consistency estimates typical of short measures. Median reliability estimates generally are preferred to mean reliability estimates in meta-analyses because they are less susceptible to systematic sources of error due to outlier values (Aguinis, Gottfredson, \& Joo, 2013). We assumed perfect reliability (i.e., $\alpha=1.00$ ) for objective performance reported from organizational records. Finally, we followed Viswesvaran et al.'s (1996) recommendation to use .52 as the reliability estimate for leader ratings and .42 for coworker ratings.

Next, we meta-analytically examined curvilinear relationships. To do this, we used the correlations that primary study authors provided us to meta-analytically estimate population correlation estimates $(\rho)$ and their standard deviations $\left(S D_{\rho}\right)$ for the curvilinear terms. We used Dimitruk, Schermelleh-Engel, Kelava, and Moosbrugger's (2007) Equation 12 to estimate the reliability of curvilinear terms (i.e., we used the squared value of the reliability estimate for the linear term).

Prior to estimating population correlation estimates, we used the means and standard deviations of the linear and curvilinear terms to transform the correlations we received from primary study authors to reflect the values we would have obtained if the linear terms were mean-centered prior to estimating the curvilinear terms (see Appendix E). It was important to transform the correlations in our study due to multicollinearity concerns that arose because the linear and curvilinear terms were highly correlated, so we followed prior researchers' recommendations (Disatnik \& Sivan, 2016; Echambadi \& Hess, 2007; Shieh, 2011) for examining curvilinear effects in a manner that facilitates the interpretation of curvilinear effects.

Then, we used the population correlation estimates (i.e., $\rho$ ) and their corresponding standard deviations (i.e., $S D_{\rho}$ ) to generate meta-analytic correlation matrices (Roth, Switzer, Van Iddekinge, \& Oh, 2011). We used the meta-analytic correlation matrices to run Viswesvaran and Ones' (1995) regression-based procedure using an online utility created by Yu, Downes, Carter, and O’Boyle (2016; https://mgmt.shinyapps.io/masem/). Yu et al.’s utility uses the lavaan package (Rosseel, 2011) of R (R Core Team, 2017). We used Yu et al.'s utility because its procedures build on recent meta-analytic structural equation modeling practices that incorporate the effects of heterogeneity into the obtained results (Cheung, 2008, 2013a, 2013b, 2015). We used the attenuated weight (i.e., sample size) due to corrections for unreliability for the analyses (i.e., Adjusted $N=n \times \alpha_{\text {Destructive Leadership }} \times \alpha_{\text {Behavior }}$ ) and ran 500 iterations of the simulations. We report the results for Viswesvaran and Ones' (1995) regression-based procedure from Yu et al.'s utility. The regression results we report examine the incremental contribution of the curvilinear terms while controlling for the effects of the linear terms (Cortina, 1993).

Next, we created .csv files that mirrored each of the meta-analytic correlation matrices from the regression analyses in order to use the relaimpo package (Groemping, 2015) in the R program (R Core Team, 2017) to conduct relative weight analyses (Johnson, 2000; Johnson \& LeBreton, 2004; Tonidandel \& LeBreton, 2015). We conducted relative weight analyses to estimate the percentage of variance in the criterion variable that each predictor variable (i.e., linear and curvilinear destructive leadership terms) explained, as well as to examine the results of the curvilinear effects while controlling for the effects of linear terms. One of the benefits of relative weight analyses is that it helps with interpreting the results when multicollinearity is a concern, which likely is the case when examining linear and curvilinear terms in tandem because the linear terms were used to create the curvilinear terms.

Then, we used Jeremy Dawson's plotter for quadratic regression effects (http://www.jeremydawson.co.uk/slopes.htm) to plot the curvilinear relationships for each of the overall regression analyses across lower and higher levels of the independent variables (Aguinis \& Gottfredson, 2010). We plotted lower and higher levels at one and two standard deviation(s) below and above the mean. Specifically, we entered the unstandardized regression coefficient for the independent variable and the unstandardized regression coefficient for the squared independent variable that we 
This is an author-produced, peer-reviewed version of this article. The final, definitive version of this document can be found online at Personnel

Psychology, published by Wiley Periodicals, Inc.. Copyright restrictions may apply. doi: 10.1111/peps.12286

obtained from the regression analyses. We retained the default setting for the mean (i.e., zero) and changed the standard deviation to one or two for each figure. We used a seven-point scale for the y-axis when job performance and OCBs were the dependent variables because this was the most frequently used set of scale points in the studies we examined. We used a five-point scale for the workplace deviance analyses due to the low means for workplace deviance variables across studies.

Finally, we meta-analyzed the semipartial correlation of the curvilinear destructive leadership terms by conducting weighted least squares regression (Cohen, Cohen, West, \& Aiken, 2003; Lipsey \& Wilson, 2001). The random-effects results of the semipartial correlation procedure report the correlation between the curvilinear destructive leadership term and each criterion variable that is independent of the effects of the linear destructive leadership term. Thus, we used semipartial correlation analyses to (1) examine the consistency and robustness of our results across meta-analytic techniques and (2) identify the unique variance (i.e., incremental validity) accounted for by the curvilinear terms (Cortina, 1993).

\section{Results}

\section{Linear Results}

A summary of the meta-analytic results for the linear analyses is shown in Table 1 . The studies included in the linear analyses are listed in Appendix A, whereas the main coding values we used to conduct the linear meta-analyses are shown in Appendix B. Overall, the linear meta-analyses yielded results of the expected magnitudes and directions. Our results were similar to the meta-analytic results obtained by Mackey et al. (2017) and Schyns and Schilling (2013), but with at least twice as many samples across all analyses.

The moderators we examined tended to demonstrate modest effects on the obtained results. However, there were a few notable exceptions. For example, the agreement $\left(\rho=-.32,95 \% \mathrm{CI}_{\rho}=[-.37,-.27], S D_{\rho}=.12, k=33, N=7,370\right)$ and frequency $\left(\rho=-.18,95 \% \mathrm{CI}_{\rho}=[-.22,-.14], S D_{\rho}=.10, k=30, N=8,922\right)$ scale points for destructive leadership demonstrated different results for overall OCBs. Overall, the linear results demonstrated that the primary studies we found likely were representative of the extant research available. Thus, we proceeded to examine the curvilinear results.

\section{Curvilinear Results}

The main coding values we used to conduct the curvilinear meta-analyses are shown in Appendix C. The meta-analytic inputs for the curvilinear regression analyses are reported in Appendix D. The results of the regression analyses are reported in Table 2, and the corresponding relative weight analyses results are reported in Table 3 . Finally, the results of the semipartial correlation analyses are reported in Table 4. Below, we briefly describe the key findings for the curvilinear results. A visual summary of the results with $95 \%$ CIs is shown in the forest plot depicted in Figure 1.

Job Performance. Hypothesis 1a predicted that destructive leadership would demonstrate an asymptotic (i.e., Ushaped) curvilinear relationship with job performance whereby the rate of the negative association between destructive leadership and job performance would weaken as destructive leadership increased. In contrast, Hypothesis 2a predicted that destructive leadership would demonstrate an asymptotic (i.e., inverted U-shaped) curvilinear relationship with job performance whereby the rate of the negative association between destructive leadership and job performance would strengthen as destructive leadership increased. As shown in Tables 2, 3, and 4, the curvilinear destructive leadership term significantly predicted overall job performance via the regression analyses $(B=.099$, 95\% $\mathrm{CI}=[.062, .136], R W=0.9 \%, 13.8 \%$ of model $\left.R^{2}\right)$, but not the semipartial correlation analyses $(s r=.033,95 \% \mathrm{CI}=$ $[-.001, .067])$. The asymptotic curvilinear relationships depicted in Figures 2 and 3 are consistent with the predictions in Hypothesis 1a. Thus, Hypothesis 1a was partially supported, whereas Hypothesis 2a was not supported.

Organizational Citizenship Behaviors. Hypothesis 1b predicted that destructive leadership would demonstrate an asymptotic (i.e., U-shaped) curvilinear relationship with OCBs whereby the rate of the negative association between destructive leadership and OCBs would weaken as destructive leadership increased. In contrast, Hypothesis $2 \mathrm{~b}$ predicted that destructive leadership would demonstrate an asymptotic (i.e., inverted U-shaped) curvilinear relationship with OCBs whereby the rate of the negative association between destructive leadership and OCBs would strengthen as destructive leadership increased. As reported in Tables 2, 3, and 4, the curvilinear destructive leadership 
This is an author-produced, peer-reviewed version of this article. The final, definitive version of this document can be found online at Personnel Psychology, published by Wiley Periodicals, Inc.. Copyright restrictions may apply. doi: 10.1111/peps.12286

term significantly predicted overall OCBs via the regression $(B=.122,95 \% \mathrm{CI}=[.087, .157], R W=0.9 \%, 11.2 \%$ of model $\left.R^{2}\right)$ and the semipartial correlation $(s r=.054,95 \% \mathrm{CI}=[.015, .093])$ analyses. The asymptotic curvilinear relationships depicted in Figures 4 and 5 are consistent with the predictions in Hypothesis $1 \mathrm{~b}$. Thus, Hypothesis $1 \mathrm{~b}$ was supported, whereas Hypothesis 2b was not supported.

Workplace Deviance. Hypothesis 1c predicted that destructive leadership would demonstrate an asymptotic (i.e., inverted U-shaped) curvilinear relationship with workplace deviance whereby the rate of the positive association between destructive leadership and OCBs would weaken as destructive leadership increased. In contrast, Hypothesis 2c predicted that destructive leadership would demonstrate an asymptotic (i.e., U-shaped) curvilinear relationship with workplace deviance whereby the rate of the positive association between destructive leadership and OCBs would strengthen as destructive leadership increased. The curvilinear destructive leadership term significantly predicted overall workplace deviance via the regression analyses $(B=-.175,95 \% \mathrm{CI}=[-.210,-.140], R W=6.9 \%, 27.8 \%$ of model $R^{2}$ ). Further, the asymptotic curvilinear relationships depicted in Figures 6 and 7 are consistent with the predictions in Hypothesis 1c. However, the semipartial correlation analyses did not demonstrate evidence of a curvilinear relationship between destructive leadership and workplace deviance ( $s r=-.041,95 \%$ CI $=[-.091, .009]$ ). Thus, Hypothesis 1c was partially supported, whereas Hypothesis 2c was not supported.

\section{Discussion}

Overall, we found some evidence of curvilinear relationships between destructive leadership and followers' workplace outcomes. Specifically, our findings provide partial support for Hypotheses 1a and 1c, full support for Hypothesis 1b, and no support for Hypotheses 2a, 2b, and 2c. However, we caution that even the support we found for Hypotheses $1 \mathrm{a}$ and $1 \mathrm{c}$ was weak. For example, the results of the overall relative weight analyses demonstrated that the linear terms predicted the majority of the explained variance in followers' workplace outcomes (i.e., range: $72.2 \%$ to $88.8 \%$; see Table 3), whereas the curvilinear terms only accounted for a modest percentage of the explained variance (i.e., range: $11.2 \%$ to $27.8 \%)$. Further, the results of the partial correlations analyses demonstrated weak evidence for the incremental ability of the curvilinear terms to predict followers' outcomes beyond the linear effects $\left(-.041 \leq \operatorname{Sr}_{\mathrm{DL}}{ }^{2} \leq\right.$ .054; see Table 4).

Despite our modest findings, we did find some meta-analytic evidence of curvilinear relationships at extreme values of destructive leadership (i.e., two standard deviations below and above the mean; see Figures 3, 5, and 7). The existence and form of the curvilinear relationships we found conformed with the predictions of social psychological theories (e.g., justice theory, social exchange theory) rather than resource-based theories (e.g., conservation of resources theory, ego depletion theory). Overall, we advocate for researchers to continue to emphasize linear conceptualizations and operationalizations of destructive leadership in studies that examine job performance, OCBs, and/or workplace deviance because our results primarily lend support to the linear perspective. However, we also advocate for future research to examine the curvilinear effects of followers' destructive leadership perceptions at extreme levels and explore the potential for curvilinear relationships between destructive leadership and organizational phenomena not examined in this study.

The mixed support for a curvilinear relationship between destructive leadership and job performance is important to note. This finding likely stems from the complete lack of support for a curvilinear relationship between abusive supervision and job performance $\left(B=.017,95 \% \mathrm{CI}=[-.030, .064], R W=1.1 \%, 23.3 \%\right.$ of model $\left.R^{2}\right)$ because a majority (i.e., 83.9\%) of the studies included in the curvilinear job performance analyses examined abusive supervision instead of other forms of destructive leadership. Further, job performance typically is directly monitored and rewarded by organizations, whereas OCBs and workplace deviance are voluntary behaviors that likely are more susceptible to fluctuations because they are not formally monitored or required for employment. Thus, it makes conceptual sense that curvilinear relationships between destructive leadership and discretionary workplace behaviors (e.g., OCBs) exist, whereas curvilinear relationships between destructive leadership and formally required workplace behaviors (e.g., job performance) do not.

Also, the mixed support for a curvilinear relationship between destructive leadership and workplace deviance is worth noting. This finding likely stems from the highly correlated predictors (i.e., linear and curvilinear destructive leadership terms; $.83 \leq \rho_{\mathrm{DL}} \& \mathrm{DL}^{2} \leq .85$; see Appendix D) across all of the workplace deviance analyses. It is possible that the similarly negative connotations in destructive leadership and workplace deviance assessments led to empirical confounding. For example, the correlation between the linear and curvilinear destructive leadership terms for the 
This is an author-produced, peer-reviewed version of this article. The final, definitive version of this document can be found online at Personnel Psychology, published by Wiley Periodicals, Inc.. Copyright restrictions may apply. doi: 10.1111/peps.12286

overall workplace deviance $(\rho=.84)$ analyses was notably higher than the correlations between the linear and curvilinear destructive leadership terms for the overall job performance $(\rho=.68)$ and overall OCBs $(\rho=.63)$ analyses. Thus, the ability of the curvilinear destructive leadership term to predict incremental variance above the linear destructive leadership term was more limited in the overall workplace deviance analyses than the overall job performance and OCBs analyses. Perhaps this feature of the analyses explains why we found evidence of curvilinear relationships between destructive leadership and workplace deviance via regression analyses, but not via semipartial correlation analyses.

Ultimately, our meta-analytic study enabled us to cumulate empirical knowledge (Hunter \& Schmidt, 2004) on the relationships between destructive leadership and followers' workplace behaviors that would not otherwise be available. Further, our population estimates based on psychometric correction for sampling and measurement error are of considerable scholarly and practical interest. Finally, contacting authors to gather correlations between linear destructive leadership terms, curvilinear destructive leadership terms, and followers' workplace behavior terms enabled us to conduct a novel meta-analytic examination of curvilinear relationships that provides breadth and depth to our understanding of the effects of destructive leadership on followers' workplace outcomes.

\section{Contributions to Theory and Research}

We make two important contributions to theory and research. First, we make a theoretical contribution that explains why curvilinear relationships between destructive leadership and followers' workplace behaviors exist. Our novel examination of competing social psychological and resource-based theoretical explanations for curvilinear relationships provides nuanced insight into the theoretical explanations that could be used to predict different forms of curvilinear relationships in destructive leadership research. Our theoretical contribution is important because the lack of a unifying theoretical framework for destructive leadership research has created a gap in knowledge that has limited inferences about curvilinear effects in destructive leadership research. The absence of extant research that examines the curvilinear effects of destructive leadership limits our knowledge of the effects of destructive leadership on followers' workplace outcomes, so our study contributes to extant research by identifying the relevant theoretical foundations for understanding the existence, form, and magnitude of the curvilinear relationships between destructive leadership and followers' workplace behaviors.

Overall, our results challenge the prevailing wisdom that assumes there are strictly linear relationships between destructive leadership and followers' workplace behaviors by demonstrating that curvilinear relationships may exist, especially in extreme cases of destructive leadership (i.e., at two standard deviations below and above the mean). The asymptotic curvilinear effects depicted in Figures 2-7 are consistent with the predictions of the social psychological theoretical perspective rather than the resource-based theoretical perspective, so our results have important implications for the application of social psychological to destructive leadership research. Overall, the results provide support for the notion that followers likely use social reinforcement standards to manage behavioral responses throughout their social exchange interactions with leaders, rather than simply react to the depletion of their egos and/or self-regulatory resources throughout the leadership process.

Second, we make an important methodological contribution by using curvilinear data from prior research to conduct a direct meta-analytic test of curvilinear relationships and their relative and incremental contributions to explaining workplace behaviors above and beyond linear effects. Our approach to meta-analytically examining curvilinear relationships required substantial time and effort because we had to contact authors to request data for every primary study included in our meta-analysis. We hope that the rigor and depth of this study can serve as an example for future meta-analytic studies that examine curvilinear relationships because our study design has the potential to fundamentally reshape the scope and depth of future meta-analytic efforts that examine the existence, form, and magnitude of curvilinear relationships across an array of phenomena.

\section{$\underline{\text { Limitations }}$}

We discuss this study's limitations below and identify the limitations' implications for the validity of inferences drawn from our findings (Brutus, Aguinis, \& Wassmer, 2013). First, we were limited by the quality and availability of data from primary studies, which restricts the quality of the meta-analytic data (Hunter \& Schmidt, 2004). The self-report and cross-sectional nature of much of destructive leadership has been well documented (Schyns \& Schilling, 2013), so we caution against drawing causal conclusions from this study. Also, studies that were not available to us may 
This is an author-produced, peer-reviewed version of this article. The final, definitive version of this document can be found online at Personnel Psychology, published by Wiley Periodicals, Inc.. Copyright restrictions may apply. doi: 10.1111/peps.12286

demonstrate systematic patterns of differences from the studies included in the meta-analysis (e.g., file drawer problem; Kepes, Banks, McDaniel, \& Whetzel, 2012; Rothstein et al., 2005), though we have no direct evidence that this is the case. In fact, some research demonstrates that inflation bias likely poses a minimal threat to the validity of inferences drawn from meta-analyses (Dalton, Aguinis, Dalton, Bosco, \& Pierce, 2012), so our considerable efforts to locate unpublished studies likely enabled us to minimize the effects of publication bias.

Many of the limitations noted above are common to meta-analyses. However, our study also faced the unique challenge of examining linear and curvilinear terms. For example, we were limited by the quantity of data available for curvilinear analyses because we were reliant on primary study authors to provide supplementary information for every study we included in the curvilinear analyses. Also, multicollinearity is an important limitation of our study because the linear and curvilinear destructive leadership terms were highly correlated. Although we attempted to address multicollinearity by transforming the obtained correlations, the correlation between the linear and curvilinear destructive leadership terms was still high across all of the overall analyses (i.e., $.63 \leq \rho_{\mathrm{DL}} \& \mathrm{DL}^{2} \leq .84$ ). Thus, inferences from our findings should account for multicollinearity concerns and future research should explicitly address multicollinearity concerns that stem from examining linear and curvilinear terms in tandem (Disatnik \& Sivan, 2016; Echambadi \& Hess, 2007; Shieh, 2011).

\section{$\underline{\text { Actionable Agenda for Future Research }}$}

One of our goals is to provide an actionable agenda for future research that describes immediate and incremental opportunities for scholars to advance theory and research (Brutus et al., 2013). To that end, we advocate for future destructive leadership research to incorporate curvilinear relationships directly into study designs so researchers can examine the extent to which curvilinear relationships affect the obtained results. It is possible that there are curvilinear relationships between destructive leadership and workplace attitudes, perceptions, and behaviors that we did not examine in this study, so we encourage future research to explore this possibility.

Next, we encourage researchers to continue to examine the relationships between destructive leadership and workplace outcomes. Although we found numerous studies that already examine these relationships, the large $S D_{\rho}$ values we obtained for many of our meta-analytic estimates demonstrate heterogeneity in the obtained findings that could be improved by future research. In their review of meta-analytic findings, Carlson and Ji (2011) found that the average obtained $S D_{\rho}$ value across meta-analyses was .106, which is lower than many of the $S D_{\rho}$ values we obtained. Further, Carlson and Ji suggested that $S D_{\rho}$ values above .05 indicate enough heterogeneity to warrant additional research attention. Thus, we hope our findings spur additional research that examines the relationship between destructive leadership and followers' workplace behaviors so that future meta-analytic efforts can use advanced meta-analytic techniques without violating the assumptions necessary to meaningfully conduct the analyses (e.g., limited heterogeneity). Additionally, the predominance of abusive supervision studies within destructive leadership research (Schyns \& Schilling, 2013) means that there is still much room for future research to examine the effects of specific types of destructive leadership (e.g., aversive leadership, despotic leadership) on followers' workplace outcomes.

Also, we encourage researchers to directly measure theoretical mechanisms through which curvilinear destructive leadership effects likely impact workplace outcomes. Our results support the predictions of social psychological theories, so we encourage future research that examines how followers' perceptions of justice and social exchange relationship quality with their leaders mediate the relationship between destructive leadership and followers' workplace behaviors. Additionally, we advocate for continued efforts to examine moderators of the relationship between destructive leadership and followers' workplace behaviors because we only found weak evidence of the more parsimonious explanation that relies on the existence of curvilinear relationships (Cortina, 1993).

Finally, future meta-analytic efforts can use our data collection and analysis procedures as an example when metaanalytically testing curvilinear relationships between a wide variety of organizational phenomena. For example, the regression analyses, relative weight analyses, and semipartial correlation analyses we conducted could be used in future meta-analyses that examine relative differences and the incremental validity/explanatory power for various dimensions of multi-dimensional variables, or any other set of competing predictor variables. We hope the methodological contribution we make enables scholars in a wide array of research areas to cumulate empirical knowledge that makes immediate and incremental advancements to theory and research across a variety of domains. 
This is an author-produced, peer-reviewed version of this article. The final, definitive version of this document can be found online at Personnel Psychology, published by Wiley Periodicals, Inc.. Copyright restrictions may apply. doi: 10.1111/peps.12286

\section{$\underline{\text { Implications for Practice }}$}

We make several inferences from this study's results that can meaningfully inform practice (Le, Oh, Shaffer, \& Schmidt, 2007). First, although destructive leadership tends to demonstrate universally harmful effects on followers' behaviors (Schyns \& Schilling, 2013), we found evidence that curvilinear relationships subject to floor and ceiling effects at extreme values (i.e., two standard deviations below and above the mean) may limit the extent to which destructive leadership is associated with followers' workplace behaviors. We advocate for practitioners' awareness that even small increases in destructive leadership from lower to moderate levels can be associated with notable decreases in OCBs and increases in workplace deviance. Further, our results indicate that most followers who report lower levels of destructive leadership than others likely demonstrate little or no deviant behaviors. Thus, the presence of any workplace deviance can be evidence of a social psychological imbalance between followers and their leaders. Additionally, we advocate that practitioners likely can identify followers who share constructive social relationships with their leaders by identifying employees who engage in higher levels of OCBs than others.

Also, we encourage organizational leaders to look beyond in-role (i.e., job performance) and extra-role (i.e., OCBs) assessments when evaluating ways of identifying poor social relationships between leaders and their followers. We found moderate correlations between destructive leadership and job performance $\left(\rho=-.23, S D_{\text {p }}=.16, k=54, N=\right.$ $14,029)$ and overall OCBs $\left(\rho=-.23, S D_{\mathrm{p}}=.13, k=64, N=16,415\right)$, but a high correlation between destructive leadership and workplace deviance $\left(\rho=.45, S D_{\mathrm{p}}=.14, k=83, N=22,759\right)$. Thus, it likely is more beneficial for practitioners to examine changes in destructive behaviors (i.e., workplace deviance) than constructive behaviors (i.e., job performance, OCBs) when monitoring for the effects of destructive leadership. Ultimately, we advocate for organizational leaders to ensure that organizational environments contribute to constructive social relationships at work by monitoring followers' workplace behaviors and perceptions of destructive leadership, especially when extreme levels of destructive leadership may be present and/or perceived.

\section{Conclusion}

The results from our meta-analytic examination of curvilinear relationships between destructive leadership and followers' workplace behaviors (i.e., job performance, OCBs, and workplace deviance) demonstrated that linear effects dominate the prediction of followers' workplace behaviors. However, our results also demonstrate that the curvilinear effect of destructive leadership on followers' workplace behaviors may have meaningful implications at extreme values of destructive leadership (i.e., two standard deviations below and above the mean). We make an important theoretical contribution by examining competing social psychological and resource-based theories in a novel way that demonstrates support for social psychological theoretical explanations for why curvilinear relationships between destructive leadership and followers' workplace behaviors exist at extreme values. Also, we make an important methodological contribution by providing an example for future meta-analyses that examine curvilinear relationships via regression, relative weight, and semipartial correlation analyses. We hope this study's results, the actionable agenda for future research we provide, and the implications for practice we identify enable researchers and practitioners to meaningfully advance theory and research on destructive leadership, as well as deter the presence and impact of destructive leadership in organizations.

\section{References}

Aguinis, H., Dalton, D. R., Bosco, F. A., Pierce, C. A., \& Dalton, C. M. (2011). Meta-analytic choices and judgment calls: Implications for theory building and testing, obtained effect sizes, and scholarly impact. Journal of Management, 37(1), 5-38.

Aguinis, H., \& Gottfredson, R. K. (2010). Best-practice recommendations for estimating interaction effects using moderated multiple regression. Journal of Organizational Behavior, 31, 776-786.

Aguinis, H., Gottfredson, R. K., \& Joo, H. (2013). Best-practice recommendations for defining, identifying, and handling outliers. Organizational Research Methods, 16(2), 270-301.

Aguinis, H., Gottfredson, R. K., \& Wright, T. A. (2011). Best-practice recommendations for estimating interaction effects using meta-analysis. Journal of Organizational Behavior, 32, 1033-1043.

Aryee, S., Chen, Z. X., Sun, L.-Y., \& Debrah, Y. A. (2007). Antecedents and outcomes of abusive supervision: Test of a trickle-down model. Journal of Applied Psychology, 92(3), 191-201. 
This is an author-produced, peer-reviewed version of this article. The final, definitive version of this document can be found online at Personnel Psychology, published by Wiley Periodicals, Inc.. Copyright restrictions may apply. doi: 10.1111/peps.12286

Aytug, Z. G., Rothstein, H. R., Zhou, W., \& Kern, M. C. (2012). Revealed or concealed? Transparency of procedures, decisions, and judgment calls in meta-analyses. Organizational Research Methods, 15(1), 103133.

Baron, R. M. (1966). Social reinforcement effects as a function of social reinforcement history. Psychological Review, 73(6), 527-539.

Baumeister, R. F., Bratslavsky, E., Muraven, M., \& Tice, D. M. (1998). Ego depletion: Is the active self a limited resource? Journal of Personality and Social Psychology, 74(5), 1252-1265.

Baumeister, R. F., Muraven, M., \& Tice, D. M. (2000). Ego depletion: A resource model of volition, self-regulation, and controlled processing. Social Cognition, 18(2), 130-150.

Bennett, R. J., \& Robinson, S. L. (2000). Development of a measure of workplace deviance. Journal of Applied Psychology, 85(3), 349-360.

Berry, C. M., Ones, D. S., \& Sackett, P. R. (2007). Interpersonal deviance, organizational deviance, and their common correlates: A review and meta-analysis. Journal of Applied Psychology, 92, 410-424.

Brutus, S., Aguinis, H., \& Wassmer, U. (2013). Self-reported limitations and future directions in scholarly reports: Analysis and recommendations. Journal of Management, 39(1), 48-75.

Carlson, K. D., \& Ji, F. X. (2011). Citing and building on meta-analytic findings: A review and recommendations. Organizational Research Methods, 14(4), 696-717.

Carpenter, N. C., Rangel, B., Jeon, G., \& Cottrell, J. (2017). Are supervisors and coworkers likely to witness employee counterproductive work behavior? An investigation of observability and self-observer convergence. Personnel Psychology, 70, 843-889.

Cascio, W. F., \& Aguinis, H. (2008). Research in industrial and organizational psychology from 1963 to 2007: Changes, choices, and trends. Journal of Applied Psychology, 93(5), 1062-1081.

Chan, M. L. E., \& McAllister, D. J. (2014). Abusive supervision through the lens of employee state paranoia. Academy of Management Review, 39(1), 44-66.

Cheung, M.W.-L. (2008). A model for integrating fixed-, random-, and mixed-effects meta-analyses into structural equation modeling. Psychological Methods, 13(3), 182-202.

Cheung, M.W.-L. (2013a). Implementing restricted maximum likelihood estimation in structural equation models. Structural Equation Modeling, 20, 157-167.

Cheung, M.W.-L. (2013b). Multivariate meta-analysis as structural equation models. Structural Equation Modeling, 20, 429-454.

Cheung, M.W.-L. (2015). metaSEM: An R package for meta-analysis using structural equation modeling. Frontiers in Psychology, 5, 1-7.

Cohen, J., Cohen, P., West, S. G., \& Aiken, L. S. (2003). Applied multiple regression/correlation analysis for the behavioral sciences (3rd ed.). Hillsdale, NJ: Erlbaum.

Cortina, J. (1993). Interaction, nonlinearity, and multicollinearity: Implications for multiple regression. Journal of Management, 19, 915-922.

Cropanzano, R., Anthony, E., Daniels, S., \& Hall, A. (2017). Social exchange theory: A critical review with theoretical remedies. Academy of Management Annals, 11(1), 479-516.

Cropanzano, R., \& Mitchell, M. (2005). Social exchange theory: An interdisciplinary review. Journal of Management, 31(6), 874-900.

Dalton, D. R., Aguinis, H., Dalton, C. M., Bosco, F. A., \& Pierce, C. A. (2012). Revisiting the file drawer problem in meta-analysis: An assessment of published and nonpublished correlation matrices. Personnel Psychology, 65, 221-249.

Dimitruk, P., Schermelleh-Engel, K., Kelava, A., \& Moosbrugger, H. (2007). Challenges in nonlinear structural equation modeling. Methodology, 3(3), 100-114.

Disatnik, D., \& Sivan, L. (2016). The multicollinearity illusion in moderated regression analysis. Marketing Letters, 27, 403-408.

Duffy, M. K., Ganster, D. C., \& Pagon, M. (2002). Social undermining at work. Academy of Management Journal, 45, 331-351.

Echambadi, R., \& Hess, J. D. (2007). Mean-centering does not alleviate collinearity problems in moderated multiple regression models. Marketing Science, 26(3), 438-445.

Einarsen, S., Aasland, M. S., \& Skogstad, A. (2007). Destructive leadership behaviour: A definition and conceptual model. The Leadership Quarterly, 18, 207-216.

Emerson, R. M. (1976). Social exchange theory. Annual Review of Sociology, 2, 335-362.

Field, A. P. (2005). Is the meta-analysis of correlation coefficients accurate when population correlations vary? Psychological Methods, 10(4), 444-467. 
This is an author-produced, peer-reviewed version of this article. The final, definitive version of this document can be found online at Personnel Psychology, published by Wiley Periodicals, Inc.. Copyright restrictions may apply. doi: 10.1111/peps.12286

Folger, R., \& Cropanzano, R. (2001). Fairness theory: Justice as accountability. In J. Greenberg \& R. Cropanzano (Eds.), Advances in organizational justice (pp. 1-55). Stanford, CA: Stanford University Press.

Geyskens, I., Krishnan, R., Steenkamp, J.-B. E. M., \& Cunha, P. V. (2009). A review and evaluation of metaanalysis practices in management research. Journal of Management, 35(2), 393-419.

Gonzalez-Mulé, E., \& Aguinis, H. (in press). Advancing theory by assessing boundary conditions with metaregression: A critical review and best-practice recommendations. Journal of Management. doi: 10.1177/0149206317710723

Gouldner, A. W. (1960). The norm of reciprocity: A preliminary statement. American Sociological Review, 25(2), 161-178.

Groemping, U. (2015). Package 'relaimpo'. Retrieved from https://cran.rproject.org/web/packages/relaimpo/relaimpo.pdf

Halbesleben, J. R. B., Neveu, J.-P., Paustian-Underdahl, S. C., \& Westman, M. (2014). Getting to the "COR": Understanding the role of resources in conservation of resources theory. Journal of Management, 40(5), 1334-1364.

Hobfoll, S. E. (1989). Conservation of resources: A new attempt at conceptualizing stress. American Psychologist, 44(3), 513-524.

Hobfoll, S. E. (2001). The influence of culture, community, and the nested-self in the stress process: Advancing conservation of resources theory. Applied Psychology: An International Review, 50, 337-370.

Hoffman, B. J., Blair, C. A., Meriac, J. P., \& Woehr, D. J. (2007). Expanding the criterion domain? A quantitative review of the OCB literature. Journal of Applied Psychology, 92(2), 555-566.

Hunter, J. E., \& Schmidt, F. L. (2004). Methods of meta-analysis: Correcting error and bias in research findings (2nd ed.). Thousand Oaks, CA: Sage Publications, Inc.

Johnson, J. W. (2000). A heuristic method for estimating the relative weight of predictor variables in multiple regression. Multivariate Behavioral Research, 35(1), 1-19.

Johnson, J. W., \& LeBreton, J. M. (2004). History and use of relative importance indices in organizational research. Organizational Research Methods, 7(3), 238-257.

Kepes, S., Banks, G. C., McDaniel, M., \& Whetzel, D. L. (2012). Publication bias in the organizational sciences. Organizational Research Methods, 15(4), 624-662.

Kepes, S., McDaniel, M. A., Brannick, M. T., \& Banks, G. C. (2013). Meta-analytic reviews in the organizational sciences: Two meta-analytic schools on the way to MARS (the meta-analytic reporting standards). Journal of Business and Psychology, 28, 123-143.

Klaussner, S. (2014). Engulfed in the abyss: The emergence of abusive supervision as an escalating process of supervisor-subordinate interaction. Human Relations, 67(3), 311-332.

Krasikova, D. V., Green, S. G., \& LeBreton, J. M. (2013). Destructive leadership: A theoretical review, integration, and future research agenda. Journal of Management, 39(5), 1308-1338.

Le, H., Oh, I. S., Shaffer, J., \& Schmidt, F. (2007). Implications of methodological advances for the practice of personnel selection: How practitioners benefit from meta-analysis. Academy of Management Perspectives, 21(3), 6-15.

Lee, S., Yun, S., \& Srivastava, A. (2013). Evidence for a curvilinear relationship between abusive supervision and creativity in South Korea. The Leadership Quarterly, 24(5), 724-731.

Lipsey, M. W., \& Wilson, D. B. (2001). Practical meta-analysis. Thousand Oaks, CA: Sage.

Mackey, J. D., Ellen III, B. P., Hochwarter, W. A., \& Ferris, G. R. (2013). Subordinate social adaptability and the consequences of abusive supervision perceptions in two samples. The Leadership Quarterly, 24(5), 732746.

Mackey, J. D., Frieder, R. E., Brees, J. R., \& Martinko, M. J. (2017). Abusive supervision: A meta-analysis and empirical review. Journal of Management, 43(6), 1940-1965.

Martinko, M. J., Harvey, P., Brees, J. R., \& Mackey, J. (2013). A review of abusive supervision research. Journal of Organizational Behavior, 34, S120-S137.

Mawritz, M. B., Greenbaum, R. L., Butts, M. M., \& Graham, K. (2017). I just can’t control myself: A selfregulation perspective on the abuse of deviant employees. Academy of Management Journal, 60(4), 14821503.

Mawritz, M. B., Mayer, D. M., Hoobler, J. M., Wayne, S. J., \& Marinova, S. V. (2012). A trickle-down model of abusive supervision. Personnel Psychology, 65, 325-357.

McNeely, B. L., \& Meglino, B. M. (1994). The role of dispositional and situational antecedents in prosocial organizational behavior: An examination of the intended beneficiaries of prosocial behavior. Journal of Applied Psychology, 79(6), 836-844. 
This is an author-produced, peer-reviewed version of this article. The final, definitive version of this document can be found online at Personnel Psychology, published by Wiley Periodicals, Inc.. Copyright restrictions may apply. doi: 10.1111/peps.12286

Mitchell, M. S., \& Ambrose, M. L. (2007). Abusive supervision and workplace deviance and the moderating effects of negative reciprocity beliefs. Journal of Applied Psychology, 92(4), 1159-1168.

Mosier, C. I. (1943). On the reliability of a weighted composite. Psychometrika, 8(3), 161-168.

Motowidlo, S. J., Borman, W. C., \& Schmit, M. J. (1997). A theory of individual differences in task and contextual performance. Human Performance, 10, 71-83.

Organ, D. W. (1988). Organizational citizenship behavior: The good soldier syndrome. Lexington, MA: Lexington Books.

Organ, D. W. (1997). Organizational citizenship behavior: It's construct clean-up time. Human Performance, 10(2), 85-97.

Peng, A. C., Schaubroeck, J. M., \& Li, Y. (2014). Social exchange implications of own and coworkers' experiences of supervisory abuse. Academy of Management Journal, 57, 1385-1405.

Pierce, J. R., \& Aguinis, H. (2013). The too-much-of-a-good-thing effect in management. Journal of Management, 39(2), 313-338.

Podsakoff, P. M., MacKenzie, S. B., Paine, J. B., \& Bachrach, D. G. (2000). Organizational citizenship behaviors: A critical review of the theoretical and empirical literature and suggestions for future research. Journal of Management, 26(3), 513-563.

Podsakoff, N. P., Whiting, S. W., Podsakoff, P. M., \& Blume, B. D. (2009). Individual- and organizational-level consequences of organizational citizenship behaviors: A meta-analysis. Journal of Applied Psychology, 94(1), 122-141.

R Core Team. (2017). R: A language and environment for statistical computing. Vienna, Austria: R Foundation for Statistical Computing.

Robinson, S. L., \& Bennett, R. J. (1995). A typology of deviant workplace behaviors: A multidimensional scaling study. Academy of Management Journal, 38(2), 555-572.

Rosseel, Y. (2011). Lavaan: An R package for structural equation modeling and more. Retrieved from http://byrneslab.net/classes/lavaan_materials/lavaanIntroduction4-9.pdf

Roth, P. L., Switzer, F. S., Van Iddekinge, C. H., \& Oh, I.-S. (2011). Toward better meta-analytic matrices: How input values can affect research conclusions in human resource management simulations. Personnel Psychology, 64, 899-935.

Rothstein, H. R., Sutton, A. J., \& Borenstein, M. (2005). Publication bias in meta-analysis: Prevention, assessment and adjustments. West Sussex, England: John Wiley and Sons, Ltd.

Schmidt, F. L., \& Le, H. (2004). Software for the Hunter-Schmidt meta-analysis methods. Iowa City: Department of Management and Organizations, University of Iowa.

Schyns, B., \& Schilling, J. (2013). How bad are the effects of bad leaders? A meta-analysis of destructive leadership and its outcomes. The Leadership Quarterly, 24(1), 138-158.

Shaw, J. B., Erickson, A., \& Harvey, M. (2011). A method for measuring destructive leadership and identifying types of destructive leaders in organizations. The Leadership Quarterly, 22(4), 575-590.

Shieh, G. (2011). Clarifying the role of mean centering in multicollinearity of interaction effects. British Journal of Mathematical and Statistical Psychology, 64, 462-477.

Spector, P. E., Bauer, J. A., \& Fox, S. (2010). Measurement artifacts in the assessment of counterproductive work behavior and organizational citizenship behavior: Do we know what we think we know? Journal of Applied Psychology, 95(4), 781-790.

Tepper, B. J. (2000). Consequences of abusive supervision. Academy of Management Journal, 43(2), 178-190.

Tepper, B. J., Duffy, M. K., Henle, C. A., \& Lambert, L. S. (2006). Procedural injustice, victim precipitation, and abusive supervision. Personnel Psychology, 59, 101-123.

Tepper, B. J., Moss, S. E., \& Duffy, M. K. (2011). Predictors of abusive supervision: Supervisor perceptions of deep-level dissimilarity, relationship conflict, and subordinate performance. Academy of Management Journal, 54(2), 279-294.

Tepper, B. J., Simon, L., \& Park, H. M. (2017). Abusive supervision. Annual Review of Organizational Psychology and Organizational Behavior, 4, 123-152.

Thoroughgood, C. N., Tate, B. W., Sawyer, K. B., \& Jacobs, R. (2012). Bad to the bone: Empirically defining and measuring destructive leader behavior. Journal of Leadership \& Organizational Studies, 19(2), 230-255.

Tonidandel, S., \& LeBreton, J. M. (2015). RWA Web: A free, comprehensive web-based, and user-friendly tool for relative weight analyses. Journal of Business and Psychology, 30, 207-216.

Viswesvaran, C., \& Ones, D. S. (1995). Theory testing: Combining psychometric meta-analysis and structural equations modeling. Personnel Psychology, 48(4), 865-885. 
This is an author-produced, peer-reviewed version of this article. The final, definitive version of this document can be found online at Personnel Psychology, published by Wiley Periodicals, Inc.. Copyright restrictions may apply. doi: 10.1111/peps.12286

Viswesvaran, C., Ones, D. S., \& Schmidt, F. L. (1996). Comparative analysis of the reliability of job performance ratings. Journal of Applied Psychology, 81(5), 557-574.

Vogel, R. M., \& Mitchell, M. S. (2017). The motivational effects of diminished self-esteem for employees who experience abusive supervision. Journal of Management, 43(7) 2218-2251.

Walter, F., Lam, C. K., van der Vegt, G. S., Huang, X., \& Miao, Q. (2015). Abusive supervision and subordinate performance: Instrumentality considerations in the emergence and consequences of abusive supervision. Journal of Applied Psychology, 100(4), 1056-1072.

Wang, G., Harms, P. D., \& Mackey, J. D. (2015). Does it take two to tangle? Subordinates’ perceptions of and reactions to abusive supervision. Journal of Business Ethics, 131(2), 487-503.

Wang, L., Zhang, Z., McArdle, J. J., \& Salthouse, T. A. (2008). Investigating ceiling effects in longitudinal data analysis. Multivariate Behavioral Research, 43, 476-496.

Wood, J. A. (2008). Methodology for dealing with duplicate study effects in a meta-analysis. Organizational Research Methods, 11(1), 79-95.

Yu, J. J., Downes, P. E., Carter, K. M., \& O’Boyle, E. H. (2016). The problem of effect size heterogeneity in metaanalytic structural equation modeling. Journal of Applied Psychology, 101(10), 1457-1473.

Zhang, H., Kwan, H. K., Zhang, X., \& Wu, L.-Z. (2014). High core self-evaluators maintain creativity: A motivational model of abusive supervision. Journal of Management, 40(4), 1151-1174. 
This is an author-produced, peer-reviewed version of this article. The final, definitive version of this document can be found online at Personnel Psychology, published by Wiley Periodicals, Inc. Copyright restrictions may apply. doi: 10.1111/peps.12286

Table 1

Meta-Analytic Results for Linear Analyses

\begin{tabular}{|c|c|c|c|c|c|c|c|c|c|}
\hline Analysis & $k$ & $N$ & $\bar{r}$ & $S D_{\overline{\mathrm{r}}}$ & $\rho$ & $S D_{\rho}$ & $\begin{array}{l}80 \% \\
\text { Credibility } \\
\text { Interval }(\rho)\end{array}$ & $\begin{array}{l}95 \% \\
\text { Confidence } \\
\text { Interval }(\rho)\end{array}$ & $\begin{array}{l}\% \text { Variance } \\
\text { Attributable } \\
\text { to Artifacts }\end{array}$ \\
\hline Overall Job Performance & 54 & 14,029 & -.19 & .12 & -.23 & .16 & $(-.43,-.03)$ & $(-.27,-.19)$ & $20 \%$ \\
\hline Published Studies & 39 & 10,334 & -.17 & .12 & -.21 & .16 & $(-.41,-.01)$ & $(-.26,-.16)$ & $19 \%$ \\
\hline Other-Rated Performance & 44 & 10,725 & -.19 & .13 & -.24 & .17 & $(-.47,-.02)$ & $(-.30,-.19)$ & $19 \%$ \\
\hline Agreement Scale Studies & 25 & 5,570 & -.20 & .11 & -.25 & .14 & $(-.43,-.08)$ & $(-.31,-.19)$ & $29 \%$ \\
\hline Frequency Scale Studies & 27 & 8,317 & -.18 & .13 & -.22 & .16 & $(-.43,-.01)$ & $(-.28,-.15)$ & $15 \%$ \\
\hline Abusive Supervision Studies & 46 & 11,474 & -.18 & .13 & -.22 & .17 & $(-.44,-.01)$ & $(-.27,-.17)$ & $19 \%$ \\
\hline Overall OCBs & 64 & 16,415 & -.18 & .12 & -.23 & .13 & $(-.40,-.07)$ & $(-.27,-.20)$ & $26 \%$ \\
\hline Published Studies & 46 & 12,782 & -.20 & .10 & -.25 & .10 & $(-.39,-.12)$ & $(-.29,-.22)$ & $34 \%$ \\
\hline Self-Rated OCBs & 23 & 5,991 & -.19 & .13 & -.21 & .13 & $(-.38,-.04)$ & $(-.27,-.15)$ & $20 \%$ \\
\hline Other-Rated OCBs & 39 & 10,038 & -.18 & .11 & -.26 & .13 & $(-.42,-.10)$ & $(-.30,-.21)$ & $32 \%$ \\
\hline Agreement Scale Studies & 33 & 7,370 & -.24 & .11 & -.32 & .12 & $(-.48,-.17)$ & $(-.37,-.27)$ & $33 \%$ \\
\hline Frequency Scale Studies & 30 & 8,922 & -.14 & .10 & -.18 & .10 & $(-.31,-.05)$ & $(-.22,-.14)$ & $32 \%$ \\
\hline Abusive Supervision Studies & 57 & 14,760 & -.18 & .11 & -.22 & .13 & $(-.39,-.06)$ & $(-.26,-.19)$ & $27 \%$ \\
\hline OCB-Organization (OCB-O) & 37 & 9,331 & -.18 & .11 & -.24 & .14 & $(-.41,-.07)$ & $(-.29,-.19)$ & $27 \%$ \\
\hline Published Studies & 27 & 7,236 & -.17 & .10 & -.24 & .12 & $(-.39,-.08)$ & $(-.29,-.18)$ & $30 \%$ \\
\hline Other-Rated OCBs & 22 & 6,117 & -.18 & .11 & -.27 & .15 & $(-.46,-.08)$ & $(-.33,-.20)$ & $25 \%$ \\
\hline Agreement Scale Studies & 23 & 5,664 & -.21 & .12 & -.30 & .15 & $(-.48,-.11)$ & $(-.36,-.23)$ & $26 \%$ \\
\hline Abusive Supervision Studies & 33 & 8,353 & -.18 & .11 & -.23 & .13 & $(-.40,-.06)$ & $(-.28,-.18)$ & $27 \%$ \\
\hline OCB-Individual (OCB-I) & 22 & 5,698 & -.19 & .10 & -.25 & .12 & $(-.40,-.10)$ & $(-.31,-.20)$ & $32 \%$ \\
\hline Abusive Supervision Studies & 20 & 4,966 & -.17 & .10 & -.23 & .10 & $(-.35,-.10)$ & $(-.28,-.18)$ & $43 \%$ \\
\hline
\end{tabular}


This is an author-produced, peer-reviewed version of this article. The final, definitive version of this document can be found online at Personnel Psychology, published by Wiley Periodicals, Inc.. Copyright restrictions may apply. doi: 10.1111/peps.12286

Table 1 (Continued)

\begin{tabular}{|c|c|c|c|c|c|c|c|c|c|}
\hline Analysis & $k$ & $N$ & $\bar{r}$ & $S D_{\overline{\mathrm{r}}}$ & $\rho$ & $S D_{\rho}$ & $\begin{array}{l}80 \% \\
\text { Credibility } \\
\text { Interval }(\rho)\end{array}$ & $\begin{array}{l}95 \% \\
\text { Confidence } \\
\text { Interval }(\rho)\end{array}$ & $\begin{array}{l}\% \text { Variance } \\
\text { Attributable } \\
\text { to Artifacts }\end{array}$ \\
\hline Overall Workplace Deviance & 83 & 22,759 & .39 & .15 & .45 & .14 & $(.26, .63)$ & $(.42, .48)$ & $14 \%$ \\
\hline Published Studies & 55 & 16,993 & .40 & .14 & .46 & .14 & $(.28, .64)$ & $(.42, .50)$ & $13 \%$ \\
\hline Unpublished Studies & 28 & 5,766 & .37 & .16 & .43 & .15 & $(.23, .62)$ & $(.37, .49)$ & $17 \%$ \\
\hline Self-Rated Deviance & 63 & 18,359 & .41 & .15 & .46 & .14 & $(.27, .64)$ & $(.42, .50)$ & $12 \%$ \\
\hline Frequency Scale Studies & 67 & 18,123 & .39 & .15 & .45 & .14 & $(.26, .64)$ & $(.41, .49)$ & $14 \%$ \\
\hline Abusive Supervision Studies & 78 & 20,661 & .40 & .15 & .46 & .14 & $(.28, .64)$ & $(.43, .49)$ & $15 \%$ \\
\hline Organization-Directed Deviance & 55 & 15,859 & .35 & .15 & .40 & .15 & $(.21, .59)$ & $(.36, .44)$ & $14 \%$ \\
\hline Published Studies & 32 & 11,313 & .37 & .14 & .42 & .14 & $(.24, .60)$ & $(.37, .47)$ & $12 \%$ \\
\hline Unpublished Studies & 23 & 4,546 & .29 & .15 & .35 & .15 & $(.17, .54)$ & $(.29, .42)$ & $22 \%$ \\
\hline Self-Rated Deviance & 42 & 12.992 & .36 & .15 & .40 & .15 & $(.21, .59)$ & $(.36, .45)$ & $12 \%$ \\
\hline Frequency Scale Studies & 42 & 11,845 & .35 & .15 & .41 & .14 & $(.23, .59)$ & $(.36, .45)$ & $15 \%$ \\
\hline Abusive Supervision Studies & 51 & 14,118 & .35 & .15 & .41 & .15 & $(.22, .61)$ & $(.37, .46)$ & $14 \%$ \\
\hline Interpersonal-Directed Deviance & 31 & 8,297 & .32 & .12 & .38 & .11 & $(.23, .52)$ & $(.33, .42)$ & $24 \%$ \\
\hline Self-Rated Deviance & 24 & 6,763 & .32 & .11 & .36 & .09 & $(.25, .48)$ & $(.32, .41)$ & $31 \%$ \\
\hline Frequency Scale Studies & 26 & 6,952 & .33 & .12 & .39 & .12 & $(.24, .55)$ & $(.34, .44)$ & $23 \%$ \\
\hline Abusive Supervision Studies & 29 & 7,471 & .32 & .12 & .38 & .12 & $(.22, .53)$ & $(.33, .42)$ & $23 \%$ \\
\hline Leader-Directed Deviance & 31 & 9,490 & .49 & .16 & .56 & .13 & $(.39, .73)$ & $(.51, .61)$ & $12 \%$ \\
\hline Published Studies & 22 & 7,416 & .51 & .15 & .58 & .13 & $(.42, .74)$ & $(.52, .63)$ & $11 \%$ \\
\hline Self-Rated Deviance & 25 & 8,175 & .52 & .13 & .58 & .12 & $(.42, .74)$ & $(.53, .63)$ & $11 \%$ \\
\hline Frequency Scale Studies & 25 & 7,124 & .48 & .16 & .56 & .14 & $(.38, .74)$ & $(.50, .61)$ & $12 \%$ \\
\hline Abusive Supervision Studies & 31 & 9,490 & .49 & .16 & .56 & .13 & $(.39, .73)$ & $(.51, .61)$ & $12 \%$ \\
\hline
\end{tabular}

Note. $k=$ number of studies included in the analysis. $N=$ total sample size of all studies included in the analysis. $\bar{r}=$ average weighted bivariate correlation across studies. $S D_{\overline{\mathrm{r}}}=$ standard deviation of the average weighted bivariate correlations across studies. $\rho=$ the population estimate that corrects the zeroorder bivariate correlation for measurement and sampling error across studies. $S D_{\rho}=$ standard deviation of the population correlation estimate across studies. 
This is an author-produced, peer-reviewed version of this article. The final, definitive version of this document can be found online at Personnel Psychology, published by Wiley Periodicals, Inc..

Copyright restrictions may apply. doi: 10.1111/peps.12286

Table 2

Meta-Analytic Estimates for the Curvilinear Regression Analyses

\begin{tabular}{lllllll}
\hline Analysis & $k$ & Adjusted $N$ & $B_{\mathrm{DL}}$ & $\begin{array}{l}95 \% \mathrm{CI} \\
B_{\mathrm{DL}}\end{array}$ & $B_{\mathrm{DL}}{ }^{2}$ & $\begin{array}{l}95 \% \mathrm{CI} \\
B_{\mathrm{DL}}{ }^{2}\end{array}$ \\
\hline Overall Job Performance & 31 & 4,933 & -.307 & $(-.344,-.270)$ & .099 & $(.062, .136)$ \\
$\quad$ Published Studies & 27 & 4,467 & -.280 & $(-.319,-.241)$ & .086 & $(.047, .125)$ \\
$\quad$ Other-Rated Performance & 28 & 3,447 & -.269 & $(-.312,-.226)$ & .045 & $(.002, .088)$ \\
$\quad$ Abusive Supervision Studies & 26 & 3,370 & -.233 & $(-.280,-.186)$ & .017 & $(-.030, .064)$ \\
& & & & & & \\
Overall OCBs & 32 & 4,904 & -.337 & $(-.372,-.302)$ & .122 & $(.087, .157)$ \\
$\quad$ Published Studies & 25 & 4,066 & -.336 & $(-.373,-.299)$ & .138 & $(.101, .175)$ \\
$\quad$ Other-Rated OCBs & 23 & 2,449 & -.360 & $(-.405,-.315)$ & .072 & $(.027, .117)$ \\
$\quad$ Abusive Supervision Studies & 29 & 4,509 & -.320 & $(-.357,-.283)$ & .121 & $(.084, .158)$ \\
& & & & & & \\
Overall Workplace Deviance & 32 & 7,547 & .637 & $(.602, .672)$ & -.175 & $(-.210,-.140)$ \\
$\quad$ Published Studies & 22 & 6,536 & .648 & $(.609, .687)$ & -.164 & $(-.203,-.125)$ \\
$\quad$ Self-Rated Deviance & 26 & 6,982 & .671 & $(.634, .708)$ & -.204 & $(-.241,-.167)$ \\
$\quad$ Frequency Scale Studies & 21 & 5,148 & .620 & $(.577, .663)$ & -.145 & $(-.188,-.102)$ \\
$\quad$ Abusive Supervision Studies & 31 & 7,199 & .596 & $(.557, .635)$ & -.137 & $(-.176,-.098)$ \\
$\quad$ Organization-Directed Deviance & 23 & 5,504 & .611 & $(.566, .656)$ & -.189 & $(-.234,-.144)$ \\
\hline
\end{tabular}

Note. $k=$ number of studies included in the analysis. Adjusted $N=$ sample size of all studies included in the analysis that was adjusted for unreliability in measurement. $\mathrm{DL}=$ destructive leadership. $\mathrm{OCB}=$ organizational citizenship behavior. $B_{\mathrm{DL}}=$ standardized effect size for the linear destructive leadership term on the behavior. $B_{\mathrm{DL}}{ }^{2}=$ standardized effect size for the non-linear destructive leadership term on the behavior. $95 \% \mathrm{CI}=95 \%$ confidence interval. 
Table 3

Results of Relative Weight Analyses for the Curvilinear Regression Analyses

\begin{tabular}{|c|c|c|c|c|c|c|c|}
\hline Analysis & $k$ & Adjusted N & $R W_{\mathrm{DL}}$ & $R W_{\mathrm{DL}}^{2}$ & $\begin{array}{l}\text { Model } \\
R^{2}\end{array}$ & $\begin{array}{l}\% R^{2} \\
\mathrm{DL}\end{array}$ & $\begin{array}{l}\% R^{2} \\
\mathrm{DL}^{2}\end{array}$ \\
\hline Overall Job Performance & 31 & 4,933 & .054 & .009 & .063 & .862 & .138 \\
\hline Published Studies & 27 & 4,467 & .044 & .008 & .052 & .848 & .152 \\
\hline Other-Rated Performance & 28 & 3,447 & .050 & .009 & .059 & .846 & .154 \\
\hline Abusive Supervision Studies & 26 & 3,370 & .037 & .011 & .049 & .767 & .233 \\
\hline Overall OCBs & 32 & 4,904 & .068 & .009 & .077 & .888 & .112 \\
\hline Published Studies & 25 & 4,066 & .066 & .008 & .074 & .888 & .112 \\
\hline Other-Rated OCBs & 23 & 2,449 & .096 & .010 & .106 & .904 & .096 \\
\hline Abusive Supervision Studies & 29 & 4,509 & .058 & .008 & .066 & .876 & .124 \\
\hline Overall Workplace Deviance & 32 & 7,547 & .180 & .069 & .249 & .722 & .278 \\
\hline Published Studies & 22 & 6,536 & .192 & .076 & .268 & .716 & .284 \\
\hline Self-Rated Deviance & 26 & 6,982 & .191 & .071 & .262 & .730 & .270 \\
\hline Frequency Scale Studies & 21 & 5,148 & .185 & .072 & .257 & .720 & .280 \\
\hline Abusive Supervision Studies & 31 & 7,199 & .165 & .071 & .236 & .698 & .302 \\
\hline Organization-Directed Deviance & 23 & 5,504 & .153 & .059 & .212 & .720 & .280 \\
\hline
\end{tabular}

Note. $k=$ number of studies included in the analysis. Adjusted $N=$ sample size of all studies included in the analysis that was adjusted for unreliability in measurement. $\mathrm{DL}=$ destructive leadership. $\mathrm{OCB}=$ organizational citizenship behavior. $R W_{\mathrm{DL}}=$ the relative weight of the linear destructive leadership term on the behavior. $R W_{\mathrm{DL}}{ }^{2}=$ the relative weight of the non-linear destructive leadership term on the behavior. Model $R^{2}=$ the amount of variance explained in the behavior. $\% R^{2} \mathrm{DL}=$ the amount of the explained variance in the behavior accounted for by the linear destructive leadership term. $\% R^{2} \mathrm{DL}^{2}=$ the amount of the explained variance in the behavior accounted for by the curvilinear destructive leadership term. 
This is an author-produced, peer-reviewed version of this article. The final, definitive version of this document can be found online at Personnel Psychology, published by Wiley Periodicals, Inc.. Copyright restrictions may apply. doi: 10.1111/peps.12286

Table 4

Meta-Analytic Estimates for the Curvilinear Semipartial Correlation Analyses

\begin{tabular}{|c|c|c|c|c|}
\hline Analysis & $k$ & $\begin{array}{l}\text { Adjusted } \\
\text { Weight }(N)\end{array}$ & $S r_{\mathrm{DL}}^{2}$ & $\begin{array}{l}95 \% \mathrm{CI} \\
S r_{\mathrm{DL}}^{2}\end{array}$ \\
\hline Overall Job Performance & 31 & 3,997 & .033 & $(-.001, .067)$ \\
\hline Published Studies & 27 & 3,359 & .041 & $(.004, .079)$ \\
\hline Other-Rated Performance & 28 & 3,195 & .007 & $(-.027, .042)$ \\
\hline Abusive Supervision Studies & 26 & 2,717 & .005 & $(-.033, .042)$ \\
\hline Overall OCBs & 32 & 3,898 & .054 & $(.015, .093)$ \\
\hline Published Studies & 25 & 3,135 & .061 & $(.021, .101)$ \\
\hline Other-Rated OCBs & 22 & 2,636 & .041 & $(-.003, .086)$ \\
\hline Abusive Supervision Studies & 29 & 3,328 & .058 & $(.014, .101)$ \\
\hline Overall Workplace Deviance & 32 & 4,205 & -.041 & $(-.091, .009)$ \\
\hline Published Studies & 22 & 3,645 & -.036 & $(-.097, .024)$ \\
\hline Self-Rated Deviance & 26 & 3,863 & -.050 & $(-.106, .007)$ \\
\hline Frequency Scale Studies & 21 & 3,059 & -.047 & $(-.116, .022)$ \\
\hline Abusive Supervision Studies & 31 & 3,834 & -.024 & $(-.069, .022)$ \\
\hline Organization-Directed Deviance & 23 & 3,048 & -.034 & $(-.096, .029)$ \\
\hline
\end{tabular}

Note. $k=$ number of studies included in the analysis. Adjusted Weight $(N)=$ sample size of all studies included in the analysis that was adjusted for explained variance and unreliability in measurement. $S r_{\mathrm{DL}}{ }^{2}$ = semipartial correlation for the curvilinear destructive leadership term. DL = destructive leadership. OCB = organizational citizenship behavior. 95\% CI = 95\% confidence interval. 
This is an author-produced, peer-reviewed version of this article. The final, definitive version of this document can be found online at Personnel Psychology, published by Wiley Periodicals, Inc.. Copyright restrictions may apply. doi: 10.1111/peps.12286

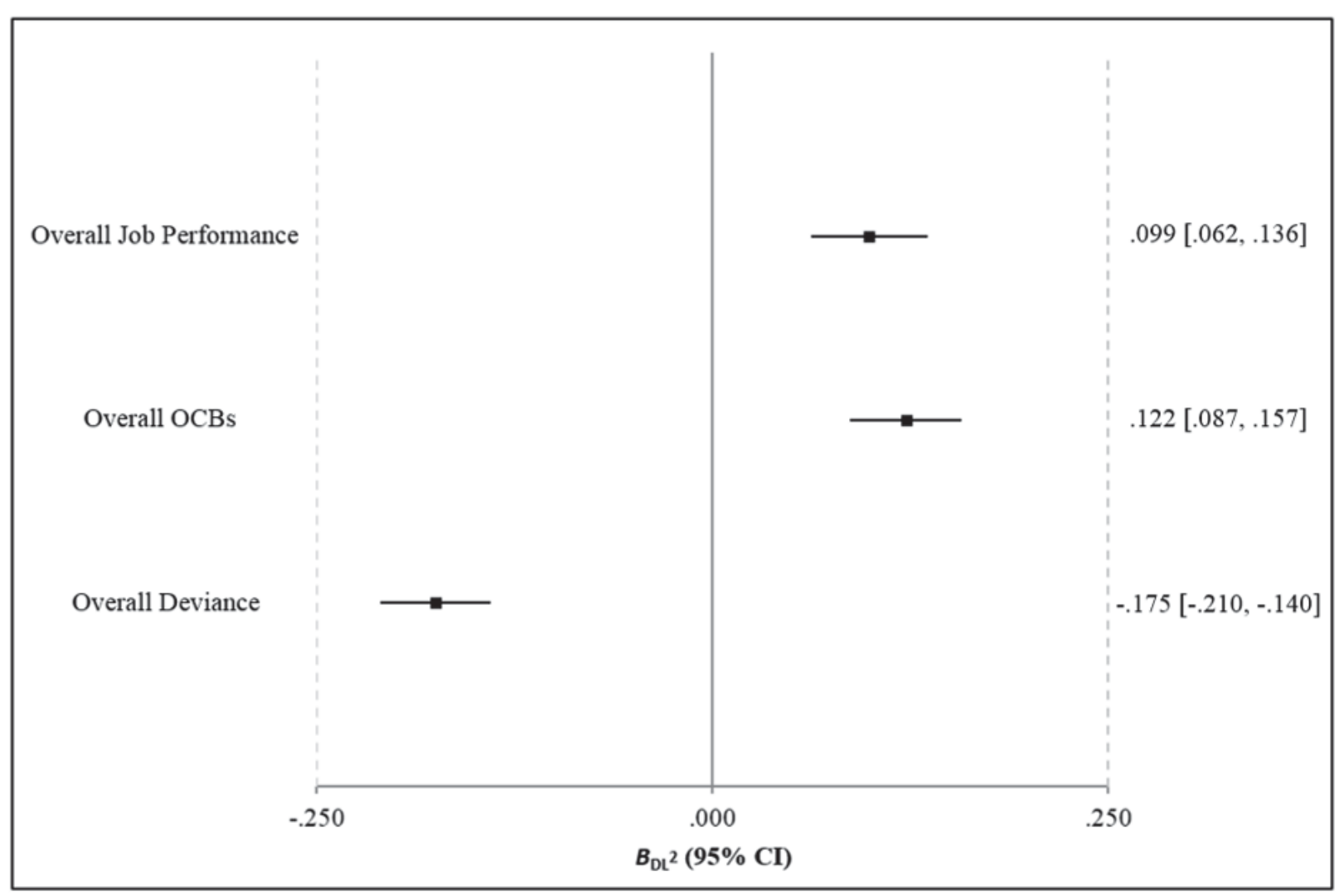

Figure 1. Forest plot of the effects of the curvilinear destructive leadership term on followers' workplace behaviors from the regression analyses. 
This is an author-produced, peer-reviewed version of this article. The final, definitive version of this document can be found online at Personnel Psychology, published by Wiley Periodicals, Inc.. Copyright restrictions may apply. doi: 10.1111/peps.12286

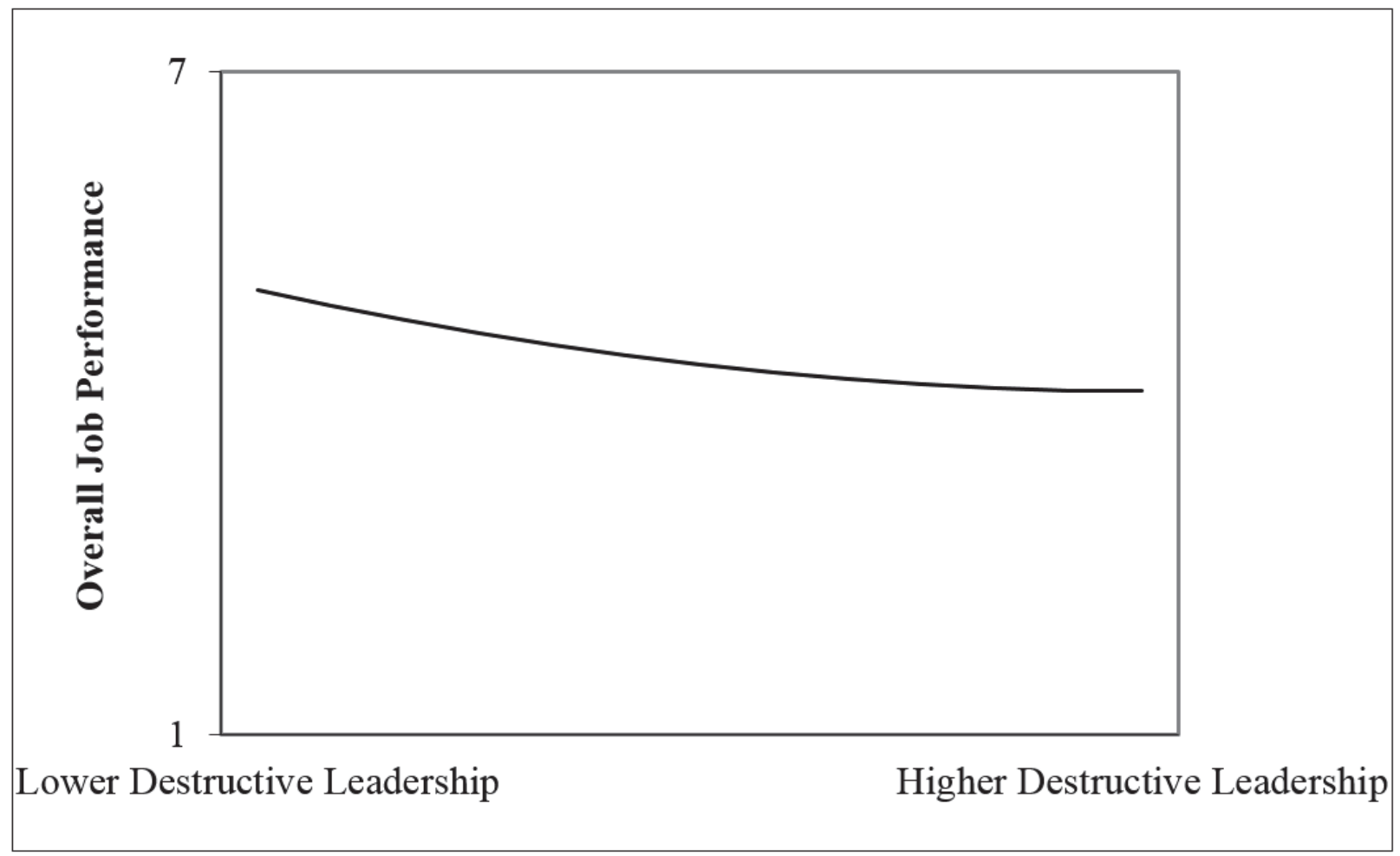

Figure 2. A plot of the curvilinear effect of destructive leadership on overall job performance at one standard deviation below and above the mean of destructive leadership. 
This is an author-produced, peer-reviewed version of this article. The final, definitive version of this document can be found online at Personnel Psychology, published by Wiley Periodicals, Inc.. Copyright restrictions may apply. doi: 10.1111/peps.12286

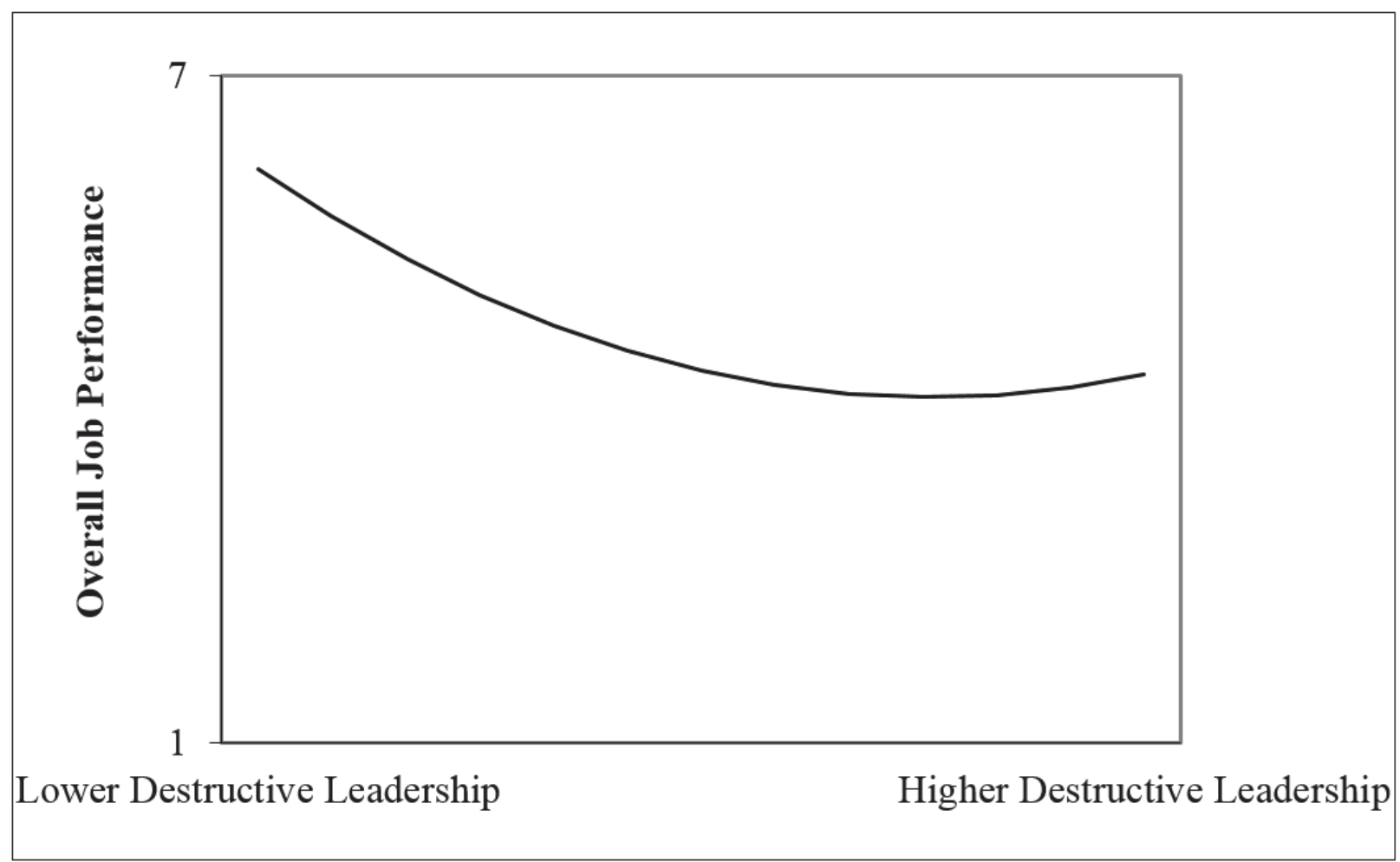

Figure 3. A plot of the curvilinear effect of destructive leadership on overall job performance at two standard deviations below and above the mean of destructive leadership. 
This is an author-produced, peer-reviewed version of this article. The final, definitive version of this document can be found online at Personnel Psychology, published by Wiley Periodicals, Inc.. Copyright restrictions may apply. doi: 10.1111/peps.12286

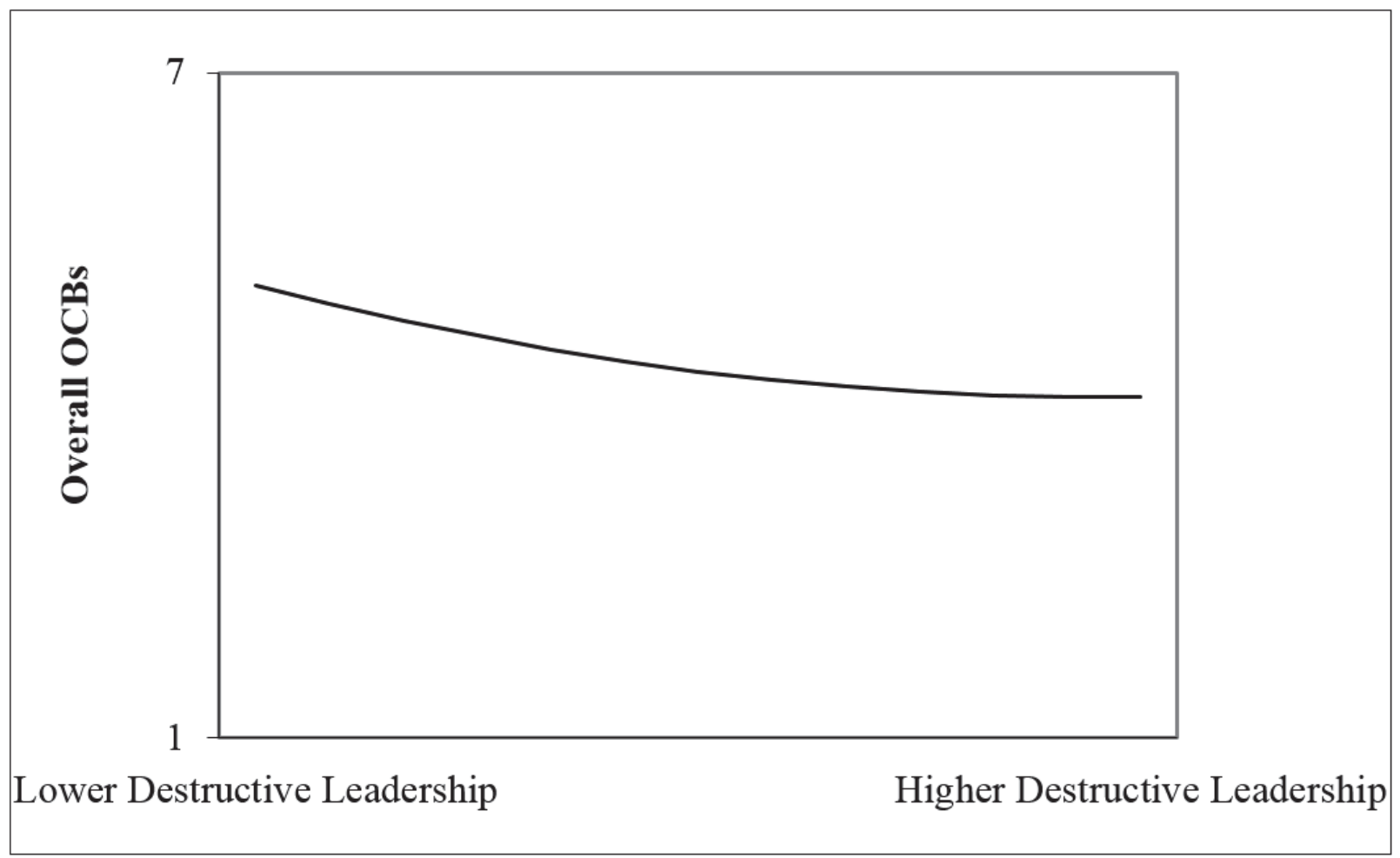

Figure 4. A plot of the curvilinear effect of destructive leadership on overall organizational citizenship behaviors (OCBs) at one standard deviation below and above the mean of destructive leadership. 
This is an author-produced, peer-reviewed version of this article. The final, definitive version of this document can be found online at Personnel Psychology, published by Wiley Periodicals, Inc.. Copyright restrictions may apply. doi: 10.1111/peps.12286

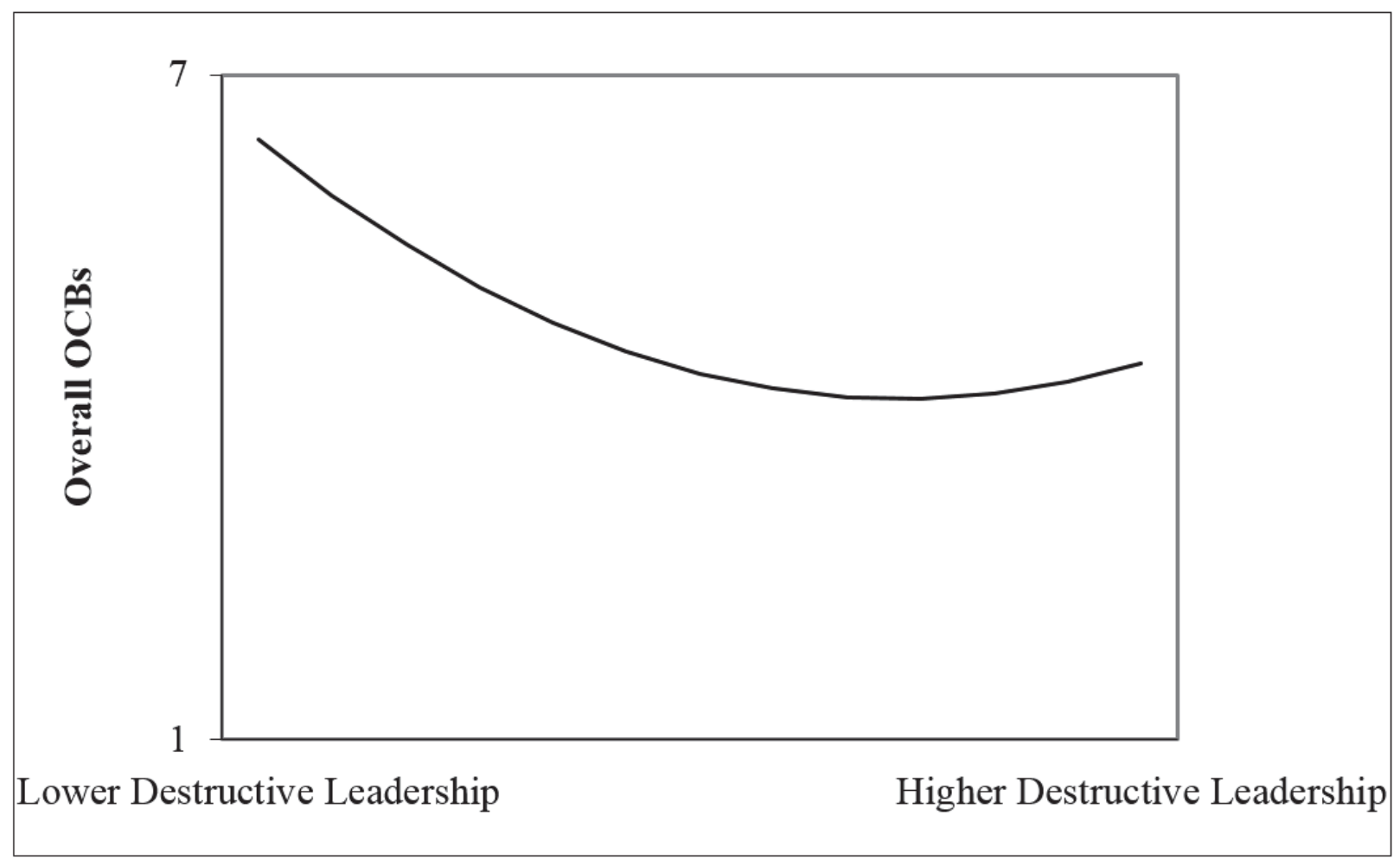

Figure 5. A plot of the curvilinear effect of destructive leadership on overall organizational citizenship behaviors (OCBs) at two standard deviations below and above the mean of destructive leadership. 
This is an author-produced, peer-reviewed version of this article. The final, definitive version of this document can be found online at Personnel Psychology, published by Wiley Periodicals, Inc.. Copyright restrictions may apply. doi: 10.1111/peps.12286

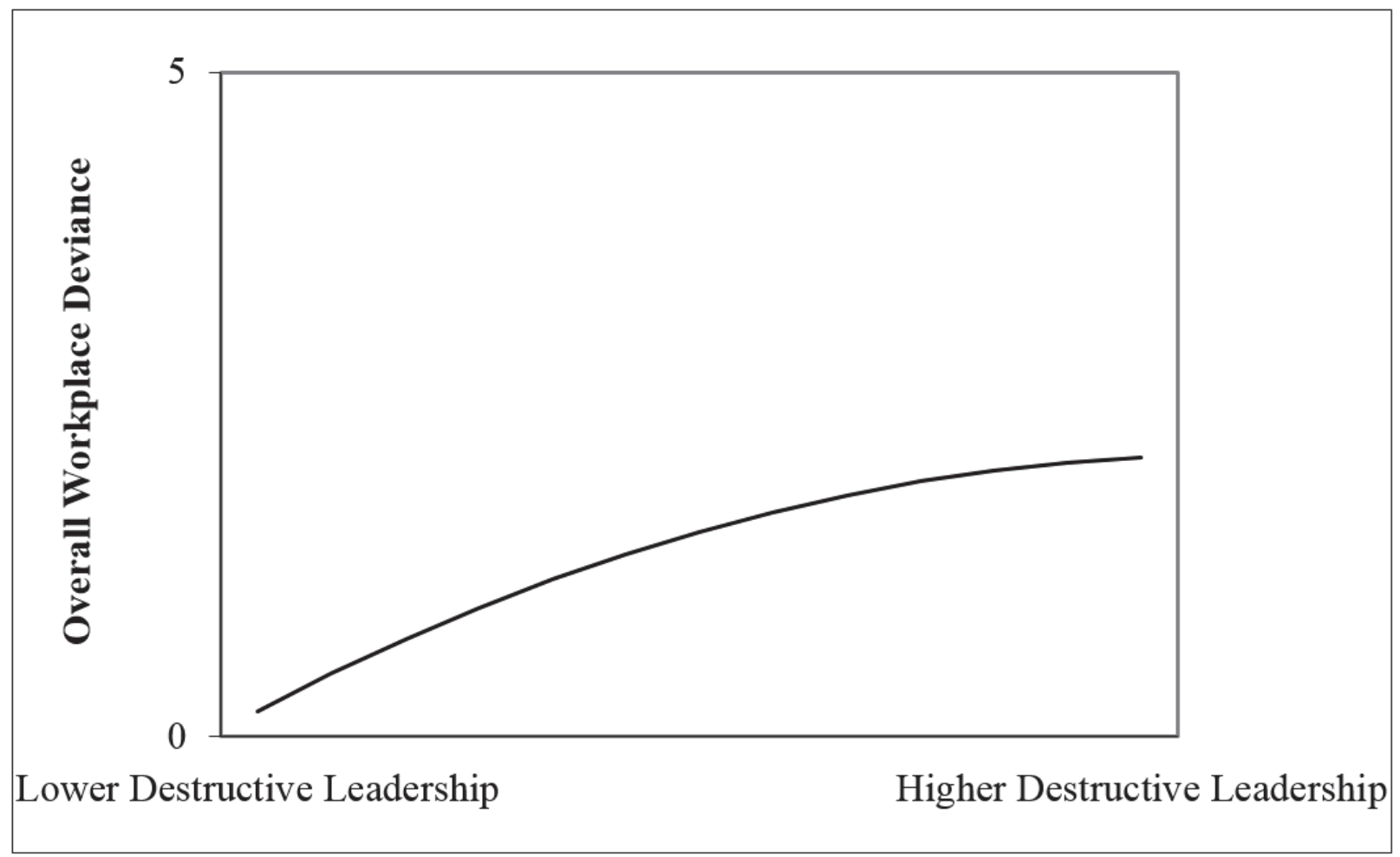

Figure 6. A plot of the curvilinear effect of destructive leadership on overall workplace deviance at one standard deviation below and above the mean of destructive leadership. 
This is an author-produced, peer-reviewed version of this article. The final, definitive version of this document can be found online at Personnel Psychology, published by Wiley Periodicals, Inc.. Copyright restrictions may apply. doi: 10.1111/peps.12286

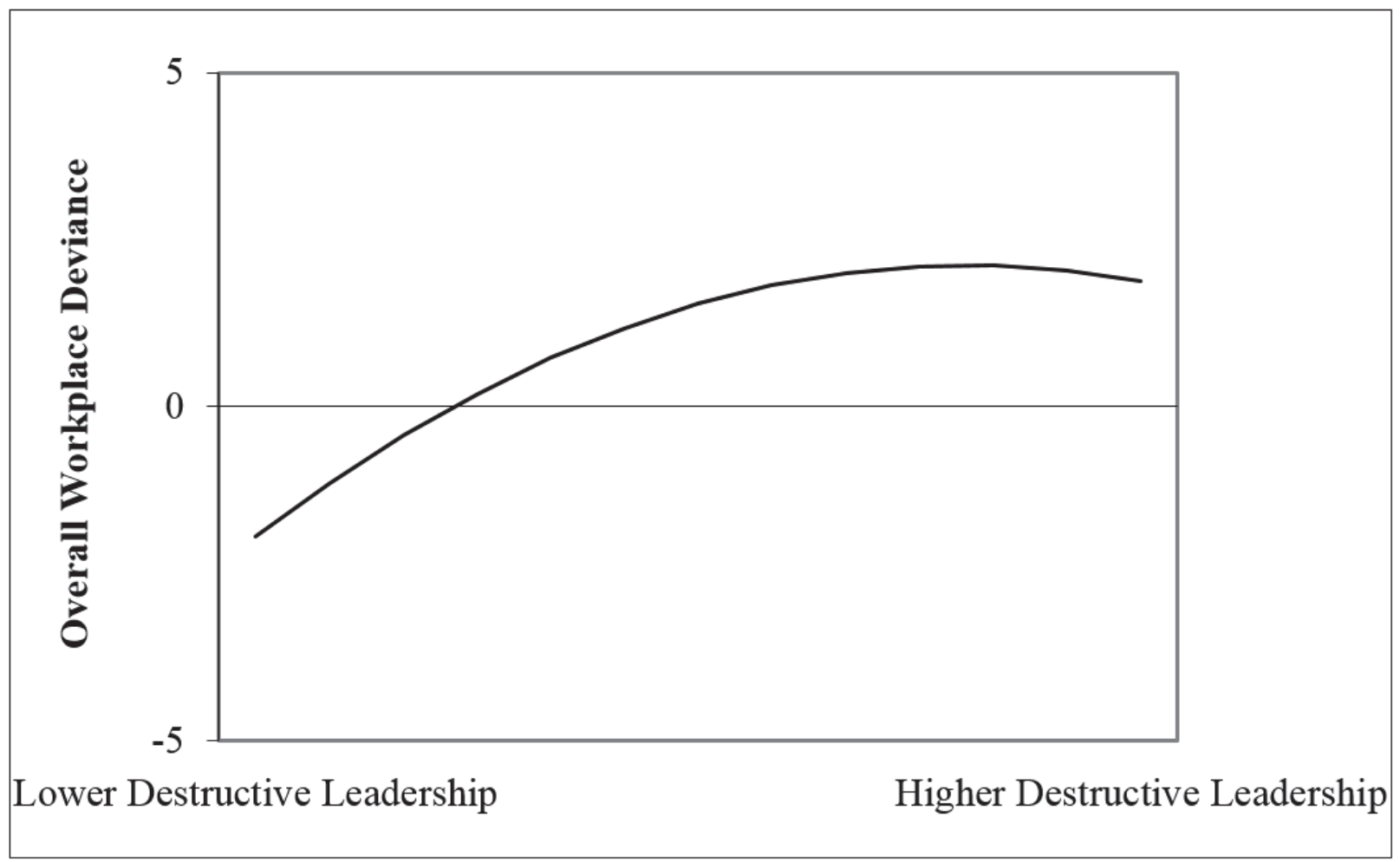

Figure 7. A plot of the curvilinear effect of destructive leadership on overall workplace deviance at two standard deviations below and above the mean of destructive leadership.

\section{Appendix A}

\section{Studies Included in the Meta-Analysis}

Alexander, K. (2011). Abusive supervision as a predictor of deviance and health outcomes: The exacerbating role of narcissism and social support (Unpublished doctoral dissertation). Bowling Green State University, Bowling Green, Ohio.

Aryee, S., Chen, Z. X., Sun, L.-Y., \& Debrah, Y. A. (2007). Antecedents and outcomes of abusive supervision: Test of a trickle-down model. Journal of Applied Psychology, 92(3), 191-201.

Aryee, S., Sun, L. Y., Chen, Z. X. G., \& Debrah, Y. A. (2008). Abusive supervision and contextual performance: The mediating role of emotional exhaustion and the moderating role of work unit structure. Management and Organization Review, 4(3), 393-411.

Ashforth, B. (1997). Petty tyranny in organizations: A preliminary examination of antecedents and consequences. Canadian Journal of Administrative Sciences, 14, 126-140.

Avey, J. B., Wu, K., \& Holley, E. (2015). The influence of abusive supervision and job embeddedness on citizenship and deviance. Journal of Business Ethics, 129, 721-731.

Biron, M. (2010). Negative reciprocity and the association between perceived organizational ethical values and organizational deviance. Human Relations, 63(6), 875-897.

Bligh, M. C., Kohles, J. C., Pearce, C. L., Justin, J. E., \& Stovall, J. F. (2007). When the romance is over: Follower perspectives of aversive leadership. Applied Psychology, 56(4), 528-557.

Bowling, N. A., \& Michel, J. S. (2011). Why do you treat me badly? The role of attributions regarding the cause of abuse in subordinates' responses to abusive supervision. Work \& Stress, 25(4), 309-320.

Bozeman, J. (2016). Precipitating abusive supervision: Target factors and supervisor blame attributions (Unpublished doctoral dissertation). University of Manitoba, Winnipeg, Canada.

Burris, E. R., Detert, J. R., \& Chiaburu, D. S. (2008). Quitting before leaving: The mediating effects of psychological attachment and detachment on voice. Journal of Applied Psychology, 93(4), 912-922. 
This is an author-produced, peer-reviewed version of this article. The final, definitive version of this document can be found online at Personnel Psychology, published by Wiley Periodicals, Inc.. Copyright restrictions may apply. doi: 10.1111/peps.12286

Camps, J. (2015). Once upon a jerk... a follower-centered perspective on the emergence and maintenance of abusive supervision (Unpublished doctoral dissertation). Ghent University, Ghent, Belgium.

Chang, K., Kuo, C.-C., Su, M., \& Taylor, J. (2013). Dis-identification in organizations and its role in the workplace. Industrial Relations, 68(3), 479-506.

Chen, H. (2011). Work ethic and workplace behavior: Essays on direct and moderated relationships across national cultures (Unpublished doctoral dissertation). University of Texas, Dallas, Texas.

Chi, N.-W., Wang, A.-C., \& Farh, C. I. C. (2016). Turn the other cheek: The role of morality in promoting prosocial responses to abusive supervision. Manuscript presented at the Academy of Management annual meeting in Anaheim, California.

Childers, O., Witt, L., Campion, J., Virgets, A., Johnson, L., \& Romay, S. (2014). Because nice matters: The effects of abusive supervision on deviance. Manuscript presented at the Society for Industrial and Organizational Psychology annual meeting in Honolulu, Hawaii.

Choi, J. N., Anderson, T. A., \& Veillette, A. (2009). Contextual inhibitors of employee creativity in organizations the insulating role of creative ability. Group \& Organization Management, 34(3), 330-357.

Chu, L.-C. (2014). Mediating toxic emotions in the workplace - the impact of abusive supervision. Journal of Nursing Management, 22(8), 953-963.

Daniels, M. A. (2015). Shame as an alternate mechanism for the abusive supervision-performance relation and the role of power distance values (Unpublished doctoral dissertation). Bowling Green State University, Bowling Green, Ohio.

Decoster, S., Camps, J., \& Stouten, J. (2014). The mediating role of LMX between abusive supervision and work behaviors: A replication and extension. American Journal of Business, 29(1), 61-75.

Duffy, M. K., Ganster, D. C., \& Pagon, M. (2002). Social undermining at work. Academy of Management Journal, 45, 331-351.

Duffy, M. K., Ganster, D. C., Shaw, J. D., Johnson, J. L., \& Pagon, M. (2006). The social context of undermining behavior at work. Organizational Behavior and Human Decision Processes, 101, 105-126.

Duniewicz, K. (2015). Don't get mad, get even: How employees abused by their supervisor retaliate against the organization and undermine their spouses (Unpublished doctoral dissertation). Florida International University, Miami, Florida.

Eissa, G., Chinchanachokchai, S., \& Wyland, R. (2017). The influence of supervisor undermining on self-esteem, creativity, and overall job performance: A multiple mediation model. Organization Management Journal, 14(4), 185-197.

Ellen III, B. P., Kiewitz, C., Garcia, P. R. J. M., \& Hochwarter, W. A. (in press). Dealing with the full-of-self-boss: Interactive effects of supervisor narcissism and subordinate resource management ability on work outcomes. Journal of Business Ethics. doi: 10.1007/s10551-017-3666-4

Eschleman, K. J., Bowling, N. A., Michel, J. S., \& Burns, G. N. (2014). Perceived intent of supervisor as a moderator of the relationships between abusive supervision and counterproductive work behaviors. Work \& Stress, 28(4), 362-375.

Ferris, D. L., Yan, M., Lim, V. K. G., Chen, Y., \& Fatimah, S. (2016). An approach-avoidance framework of workplace aggression. Academy of Management Journal, 59(5), 1777-1800.

Frieder, R. E., Mackey, J. D., \& Perrewé, P. L. (2014). Attenuating the negative effects of abusive supervision: Resilience in the face of adversity and punishment to dissuade deviance. In P. L. Perrewé \& P. Spector (CoChairs): Mistreatment in organizations: The role of abusive supervision. Symposium presented at the Southern Management Association annual meeting in Savannah, Georgia.

Frieder, R. E., Hochwarter, W. A., \& DeOrtentiis, P. S. (2015). Attenuating the negative effects of abusive supervision: The role of proactive voice behavior and resource management ability. The Leadership Quarterly, 26, 821-837.

Garcia, P. R. J. M., Wang, L., Lu, V., Kiazad, K., \& Restubog, S. L. D. (2015). When victims become culprits: The role of subordinates' neuroticism in the relationship between abusive supervision and workplace deviance. Personality and Individual Differences, 72, 225-229.

Gardner, D., O’Driscoll, M., Cooper-Thomas, H. D., Roche, M., Bentley, T., Catley, B., Teo, S.T. \& Trenberth, L. (2016). Predictors of workplace bullying and cyber-bullying in New Zealand. International Journal of Environmental Research and Public Health, 13(5), 448-462.

Gregory, B. T., Osmonbekov, T., Gregory, S. T., Albritton, M. D., \& Carr, J. C. (2013). Abusive supervision and citizenship behaviors: Exploring boundary conditions. Journal of Managerial Psychology, 28(6), 628-644. 
This is an author-produced, peer-reviewed version of this article. The final, definitive version of this document can be found online at Personnel Psychology, published by Wiley Periodicals, Inc.. Copyright restrictions may apply. doi: 10.1111/peps.12286

Gu, J., Song, J., \& Wu, J. (2016). Abusive supervision and employee creativity in China: Departmental identification as mediator and face as moderator. Leadership \& Organization Development Journal, 37(8), 1187-1204.

Hamid, R. A., Juhdi, N. H., Ismail, M. D., \& Abdullah, N. A. (2016). Abusive supervision and workplace deviance as moderated by spiritual intelligence: An empirical study of Selangor employees. Malaysian Journal of Society and Space, 12(2), 191-202.

Han, G. H., Harms, P. D., \& Bai, Y. (2017). Nightmare bosses: The impact of abusive supervision on employees' sleep, emotions, and creativity. Journal of Business Ethics, 145(1), 21-31.

Hanig, S. (2013). Losing your calm or losing control: Two paths to retaliatory deviance in response to abusive supervision (Unpublished master's thesis). University of Waterloo, Ontario, Canada.

Harris, K. J., Harvey, P., \& Kacmar, K. M. (2011). Abusive supervisory reactions to coworker relationship conflict. The Leadership Quarterly, 22, 1010-1023.

Harris, K. J., \& Kacmar, K. M. (2013). What really makes abusive supervision bad? When the abuser is also viewed as promotable. Manuscript presented at the Southern Management Association annual meeting in New Orleans, Louisiana.

Harris, K. J., Kacmar, K. M., \& Zivnuska, S. (2007). An investigation of abusive supervision as a predictor of performance and the meaning of work as a moderator of the relationship. The Leadership Quarterly, 18(3), 252-263.

Harvey, P., Harris, K. J., Gillis, W. E., \& Martinko, M. J. (2014). Abusive supervision and the entitled employee. The Leadership Quarterly, 25(2), 204-217.

Hon, A. H. Y., \& Lu, L. (2016). When will the trickle-down effect of abusive supervision be alleviated? The moderating roles of power distance and traditional cultures. Cornell Hospitality Quarterly, 57(4), 421-433.

Hoobler, J., \& Brass, D. (2006). Abusive supervision and family undermining as displaced aggression. Journal of Applied Psychology, 91(5), 1125-1133.

Hussain, I., \& Sia, S. K. (2017). Power distance orientation dilutes the effect of abusive supervision on workplace deviance. Management and Labour Studies, 42(4), 293-305.

Jian, Z., Kwan, H. K., Qiu, Q., Liu, Z. Q., \& Kim, F. H.-K. (2012). Abusive supervision and frontline employees' service performance. The Service Industries Journal, 32(5), 683-698.

Jiang, W., \& Gu, Q. (2016). How abusive supervision and abusive supervisory climate influence salesperson creativity and sales team effectiveness in China. Management Decision, 54(2), 456-475.

Jiang, W., Gu, X., Tang, T., L.-P. (2016). Abusive supervision and poor creativity: The social cognitive and social comparison perspectives. Manuscript presented at the Academy of Management annual meeting in Anaheim, California.

Johnson, M. A., \& Griffith, M. D. (2016). Heavy is the head that wears the crown? Employee reactions to a supervisor's adiposity. Manuscript presented at the Academy of Management annual meeting in Anaheim, California.

Joo, M. K., \& Witt, L. (2015). Effects of abusive supervision and emotional exhaustion on production deviance. Manuscript presented at the Society for Industrial and Organizational Psychology annual meeting in Philadelphia, Pennsylvania.

Kacmar, K. M., Tillman, C. J., Harris, K. J., \& Whitman, M. V. (2016). Perceptions of ethical leadership as a mediator of the relationship between abusive supervision and work behaviors. Journal of Behavioral and Applied Management, 16(1), 2-19.

Kacmar, K. M., Whitman, M. V., \& Harris, K. J. (2013). The lingering impact of abusive supervision. The Journal of Applied Management and Entrepreneurship, 18(3), 51-71.

Kane, R. E., \& Perrewé, P. L. (2012). Disentangling reactions to abusive supervision: The role of supervisor organizational embodiment. Manuscript presented at the Southern Management Association annual meeting in Fort Lauderdale, Florida.

Kane-Frieder, R. E., Mackey, J. D., Perrewé, P. L., \& Gallagher, V. C. (2013). Reactions to perceived abusive supervision: Knee-jerk reactions or judicious reactions to a jerk? In P. Spector \& P. L. Perrewé \& (CoChairs): Employee mistreatment in the workplace. Symposium presented at the Southern Management Association annual meeting in New Orleans, Louisiana.

Kedharnath, U. (2014). Abusive supervision and employee perceptions of leaders' implicit leadership theories (Unpublished doctoral dissertation). Colorado State University, Fort Collins, Colorado.

Khan, A. K., Moss, S., Quratulain, S., \& Hameed, I. (in press). When and how subordinate performance leads to abusive supervision: A social dominance perspective. Journal of Management. doi: 10.1177/0149206316653930 
This is an author-produced, peer-reviewed version of this article. The final, definitive version of this document can be found online at Personnel Psychology, published by Wiley Periodicals, Inc.. Copyright restrictions may apply. doi: 10.1111/peps.12286

Khan, A. K., Quratulain, S., \& Crawshaw, J. R. (2017). Double jeopardy: Subordinates' worldviews and poor performance as predictors of abusive supervision. Journal of Business and Psychology, 32(2), 165-178.

Kim, S. L., \& Yun, S. (2015). The effect of coworker knowledge sharing on performance and its boundary conditions: An interactional perspective. Journal of Applied Psychology, 100(2), 575-582.

Lam, C. K., Walter, F., \& Huang, X. (2017). Supervisors' emotional exhaustion and abusive supervision: The moderating roles of perceived subordinate performance and supervisor self-monitoring. Journal of Organizational Behavior, 38(8), 1151-1166.

Lee, J., \& Wang, G. (2015). Interactive effects of charismatic leadership and abusive supervision. Poster presented at the annual conference of the Society for Industrial and Organizational Psychology, Philadelphia, PA.

Lee, S., Yun, S., \& Srivastava, A. (2013). Evidence for a curvilinear relationship between abusive supervision and creativity in South Korea. The Leadership Quarterly, 24(5), 724-731.

Li, Y. N., Zhang, M. J., Law, K. S., \& Yan, M. N. (2015). Subordinate performance and abusive supervision: The role of envy and anger. Manuscript presented at the Academy of Management annual meeting in Vancouver, Canada.

Lian, H., Ferris, D. L., Morrison, R., \& Brown, D. J. (2014). Blame it on the supervisor or the subordinate? Reciprocal relations between abusive supervision and organizational deviance. Journal of Applied Psychology, 99(4), 651-664.

Lian, H., Ferris, D. L., \& Brown, D. J. (2012). Does power distance exacerbate or mitigate the effects of abusive supervision? It depends on the outcome. Journal of Applied Psychology, 97(1), 107-123.

Liang, L. H., Lian, H., Brown, D. J., Ferris, D. L., Hanig, S., \& Keeping, L. M. (2016). Why are abusive supervisors abusive? A dual-system self-control model. Academy of Management Journal, 59(4), 1385-1406.

Liang, L., Valdron, J., Skyvington, S., Brown, D., Ferris, L., \& Lian, H. (2016). Organizational citizenship behavior licenses deviant reactions to abusive supervision. Manuscript presented at the Society for Industrial and Organizational Psychology annual meeting in Anaheim, California.

Lim, V. K. G., \& Teo, T. S. H. (2009). Mind your e-manners: Impact of cyber incivility on employees' work attitude and behavior. Information \& Management, 46, 419-425.

Liu, D., Liao, H., \& Loi, R. (2012). The dark side of leadership: A three-level investigation of the cascading effect of abusive supervision on employee creativity. Academy of Management Journal, 55(5), 1187-1212.

Liu, J., Kwan, H. K., Wu, L., \& Wu, W. (2010). Abusive supervision and subordinate supervisor-directed deviance: The moderating role of traditional values and the mediating role of revenge cognitions. Journal of Occupational and Organizational Psychology, 83, 835-856.

Liu, W., Zhang, P., Liao, J., Hao, P., \& Mao, J. (2016). Abusive supervision and employee creativity: The mediating role of psychological safety and organizational identification. Management Decision, 54(1), 130-147.

Liu, X.-Y., \& Wang, J. (2013). Abusive supervision and organizational citizenship behaviour: Is supervisorsubordinate guanxi a mediator? The International Journal of Human Resource Management, 24(7), 14711489.

Lyu, Y., Zhou, X., Li, W., Wan, J., Zhang, J., \& Qiu, C. (2016). The impact of abusive supervision on service employees' proactive customer service performance in the hotel industry. International Journal of Contemporary Hospitality Management, 28(9), 1992-2012.

Lyu, Y., Zhu, H., Zhong, H.-J., \& Hu, L. (2016). Abusive supervision and customer-oriented organizational citizenship behavior: The roles of hostile attribution bias and work engagement. International Journal of Hospitality Management, 53, 69-80.

Mackey, J. D., Frieder, R. E., Perrewé, P. L., Gallagher, V. C., \& Brymer, R. A. (2015). Empowered employees as social deviants: The role of abusive supervision. Journal of Business and Psychology, 30(1), 149-162.

Mackey, J. D., McAllister, C. P., \& Brees, J. R. (2015). Oh behave! Perceptions of abusive supervision and OCB: A social exchange perspective. Manuscript presented at the Academy of Management annual meeting in Vancouver, Canada.

Mathe, K., \& Slevitch, L. (2013). An exploratory examination of supervisor undermining, employee involvement climate, and the effects on customer perceptions of service quality in quick-service restaurants. Journal of Hospitality \& Tourism Research, 37(1), 29-50.

Mawritz, M. B., Mayer, D. M., Hoobler, J. M., Wayne, S. J., \& Marinova, S. V. (2012). A trickle-down model of abusive supervision. Personnel Psychology, 65, 325-357.

Mawritz, M. B., Dust, S. B., \& Resick, C. J. (2014). Hostile climate, abusive supervision, and employee coping: Does conscientiousness matter? Journal of Applied Psychology, 99(4), 737-747.

Mawritz, M. B., Greenbaum, R. L., Butts, M. M., \& Graham, K. (2017). I just can't control myself: A self-regulation perspective on the abuse of deviant employees. Academy of Management Journal, 60(4), 1482-1503. 
This is an author-produced, peer-reviewed version of this article. The final, definitive version of this document can be found online at Personnel Psychology, published by Wiley Periodicals, Inc.. Copyright restrictions may apply. doi: 10.1111/peps.12286

McAllister, C. P., \& Mackey, J. D. (2014). Workplace reactions to perceptions of abusive supervision: The role of self-regulation. In P. L. Perrewé \& P. Spector (Co-Chairs): Mistreatment in organizations: The role of abusive supervision. Symposium presented at the Southern Management Association annual meeting in Savannah, Georgia.

Meng, Y., Tan, J. \& Li, J. (2017). Abusive supervision by academic supervisors and postgraduate research students' creativity: The mediating role of leader-member exchange and intrinsic motivation. International Journal of Leadership in Education, 20(5), 605-617.

Michel, J. S., Newness, K., \& Duniewicz, K. (2016). How abusive supervision affects workplace deviance: A moderated-mediation examination of aggressiveness and work-related negative affect. Journal of Business and Psychology, 31(1), 1-22.

Mitchell, M. S., \& Ambrose, M. L. (2007). Abusive supervision and workplace deviance and the moderating effects of negative reciprocity beliefs. Journal of Applied Psychology, 92(4), 1159-1168.

Mitchell, M. S., \& Ambrose, M. L. (2012). Employees' behavioral reactions to supervisor aggression: An examination of individual and situational factors. Journal of Applied Psychology, 97(6), 1148-1170.

Nandkeolyar, A. K., O’Reilly, J., Ekkirala, S., \& Srivastava, N. K. (2016). Whose deviance provokes abuse? Role of social skills and self-evaluations in abusive supervision. Manuscript presented at the Academy of Management annual meeting in Anaheim, California.

Nandkeolyar, A. K., Shaffer, J. A., Li, A., Ekkirala, S., \& Bagger, J. (2014). Surviving an abusive supervisor: The joint roles of conscientiousness and coping strategies. Journal of Applied Psychology, 99(1), 138-150.

Naseer, S., Raja, U., Syed, F., Donia, M. B., \& Darr, W. (2016). Perils of being close to a bad leader in a bad environment: Exploring the combined effects of despotic leadership, leader member exchange, and perceived organizational politics on behaviors. The Leadership Quarterly, 27(1), 14-33.

Neves, P. (2014). Taking it out on survivors: Submissive employees, downsizing, and abusive supervision. Journal of Occupational and Organizational Psychology, 87(3), 507-534.

Ogunfowora, B. (2009). The consequences of ethical leadership: Comparisons with transformational leadership and abusive supervision (Unpublished doctoral dissertation). University of Calgary, Alberta, Canada.

Ogunfowora, B. (2013). When the abuse is unevenly distributed: The effects of abusive supervision variability on work attitudes and behaviors. Journal of Organizational Behavior, 34, 1105-1123.

Onyishi, I. E. (2012). Abusive supervision and prosocial organizational behavior: A study of workers in the banking industry in Nigeria. The African Symposium, 12(2), 96-103.

Onyishi, I. E., Ugwu, F. O., \& Anike, P. N. (2011). What goes around comes around: The contributions of abusive supervision and equity sensitivity to counterproductive work behaviour. Nigerian Journal of Psychological Research, 7(1), 73-88.

Ouyang, K., Lam, W., \& Wang, W. (2015). Roles of gender and identification on abusive supervision and proactive behavior. Asia Pacific Journal of Management, 32, 671-691.

Peng, A. C. (2013). Psychological mechanisms linking direct and vicarious experiences of abusive supervision to employee deviance (Unpublished doctoral dissertation). Michigan State University, East Lansing, Michigan.

Peng, A. C., Schaubroeck, J. M., \& Li, Y. (2014). Social exchange implications of own and coworkers' experiences of supervisory abuse. Academy of Management Journal, 57, 1385-1405.

Powell, N. (2013). Responding to abusive supervision: Opposing arguments for the role of social class in predicting workplace deviance (Unpublished master's thesis). University of Waterloo, Ontario, Canada.

Pyc, L. S. (2011). The moderating effects of workplace ambiguity and perceived job control on the relations between abusive supervision and employees' behavioral, psychological, and physical strains (Unpublished doctoral dissertation). Hofstra University, Hempstead, New York.

Rafferty, A. E., \& Restubog, S. L. D. (2011). The influence of abusive supervisors on followers' organizational citizenship behaviours: The hidden costs of abusive supervision. British Journal of Management, 22, 270285.

Restubog, S. L. D., Scott, K. L., \& Zagenczyk, T. J. (2011). When distress hits home: The role of contextual factors and psychological distress in predicting employees' responses to abusive supervision. Journal of Applied Psychology, 96(4), 713-729.

Rice, D., Taylor, R. M., \& Forrester, J. (2016). The noninconclusive experience of abusive supervision. Is it hot or is it cold and why it matters. Manuscript presented at the Academy of Management annual meeting in Anaheim, California.

Schaubroeck, J. M., Peng, A. C., \& Hannah, S. T. (2016). The role of peer respect in linking abusive supervision to follower outcomes: Dual moderation of group potency. Journal of Applied Psychology, 101(2), 267-278. 
This is an author-produced, peer-reviewed version of this article. The final, definitive version of this document can be found online at Personnel Psychology, published by Wiley Periodicals, Inc.. Copyright restrictions may apply. doi: 10.1111/peps.12286

Scott, K. D. (2007). The development and test of an exchange-based model of interpersonal workplace exclusion. (Unpublished doctoral dissertation). University of Kentucky, Lexington, Kentucky.

Shao, P. T., Li, A., \& Mawritz, M. (2016). Motivated by peer abusive supervision? The moderating role of prevention focus. Manuscript presented at the Academy of Management annual meeting in Anaheim, California.

Shao, P., Resick, C. J., \& Hargis, M. B. (2011). Helping and harming others in the workplace: The roles of personal values and abusive supervision. Human Relations, 64(8), 1051-1078.

Shoss, M. K., Eisenberger, R., Restubog, S. L. D., \& Zagenczyk, T. J. (2013). Blaming the organization for abusive supervision: The roles of perceived organizational support and supervisor's organizational embodiment. Journal of Applied Psychology, 98(1), 158-168.

Shum, C., Takeuchi, R., \& Chen, Z. (2014). A non-linear relationship between abusive supervision and subordinates' job performance. Manuscript presented at the Academy of Management annual meeting in Philadelphia, Pennsylvania.

Skyvington, S. (2014). License to misbehave: Organizational citizenship behavior as a moral license for deviant reactions to abusive supervision (Unpublished master's thesis). University of Waterloo, Ontario, Canada.

Steinert, J. K. (2015). Workplace aggression: A reconceptualization of the construct \& an exploration of strain based outcomes. (Unpublished doctoral dissertation). Florida International University, Miami, Florida.

Taylor, M. (2004). The relationships between workplace violence, deviant workplace behavior, ethical climate, organizational justice, and abusive supervision (Unpublished doctoral dissertation). Alliant International University, Los Angeles, California.

Taylor, S. G., \& Kluemper, D. H. (2011). How subordinate core self-evaluations and cognitive ability influence perceptions of and deviant reactions to abusive supervision. Manuscript presented at the Southern Management Association annual meeting in Savannah, Georgia.

Tepper, B. J., Henle, C. A., Lambert, L. S., Giacalone, R. A., \& Duffy, M. K. (2008). Abusive supervision and subordinates' organization deviance. Journal of Applied Psychology, 93(4), 721-732.

Tepper, B. J., Moss, S. E., \& Duffy, M. K. (2011). Predictors of abusive supervision: Supervisor perceptions of deep-level dissimilarity, relationship conflict, and subordinate performance. Academy of Management Journal, 54(2), 279-294.

Thau, S., Bennett, R. J., Mitchell, M. S., \& Marrs, M. B. (2009). How management style moderates the relationship between abusive supervision and workplace deviance: An uncertainty management theory perspective. Organizational Behavior and Human Decision Processes, 108(1), 79-92.

Thau, S., \& Mitchell, M. S. (2010). Self-gain or self-regulation impairment? Tests of competing explanations of the supervisor abuse and employee deviance relationship through perceptions of distributive justice. Journal of Applied Psychology, 95(6), 1009-1031.

Thoroughgood, C. N., Tate, B. W., Sawyer, K. B., \& Jacobs, R. (2012). Bad to the bone: Empirically defining and measuring destructive leader behavior. Journal of Leadership \& Organizational Studies, 19(2), 230-255.

Velez, M. J., \& Neves, P. (2016). Abusive supervision, psychosomatic symptoms, and deviance: Can job autonomy make a difference? Journal of Occupational Health Psychology, 21(3), 322-333.

Vogel, R., Homberg, F., \& Gericke, A. (2016). Abusive supervision, public service motivation, and employee deviance: The moderating role of employment sector. Evidence-Based HRM, 4(3), 214-231.

Vogel, R. M., \& Mitchell, M. S. (2017). The motivational effects of diminished self-esteem for employees who experience abusive supervision. Journal of Management, 43(7), 2218-2251.

Walter, F., Lam, C. K., van der Vegt, G. S., Huang, X., \& Miao, Q. (2015). Abusive supervision and subordinate performance: Instrumentality considerations in the emergence and consequences of abusive supervision. Journal of Applied Psychology, 100(4), 1056-1072.

Wang, C.-Y., \& Hu, C. (2015). Examining the relationship between sub-dimensions of abusive supervision and selfrating. Manuscript presented at the Society for Industrial and Organizational Psychology annual meeting in Philadelphia, Pennsylvania.

Wang, G., Harms, P. D., \& Mackey, J. D. (2015). Does it take two to tangle? Subordinates' perceptions of and reactions to abusive supervision. Journal of Business Ethics, 131(2), 487-503.

Wang, R., \& Jiang, J. (2014). How do narcissistic employees respond to abusive supervision: Two roles of narcissism in decreasing perception and increasing deviance. Psychological Reports: Employment Psychology \& Marketing, 115(2), 1-9.

Wang, R., \& Jiang, J. (2015). How abusive supervisors influence employees' voice and silence: The effects of interactional justice and organizational attribution. The Journal of Social Psychology, 155, 204-220. 
This is an author-produced, peer-reviewed version of this article. The final, definitive version of this document can be found online at Personnel Psychology, published by Wiley Periodicals, Inc.. Copyright restrictions may apply. doi: 10.1111/peps.12286

Wang, W., Mao, J., Wu, W., \& Liu, J. (2012). Abusive supervision and workplace deviance: The mediating role of interactional justice and the moderating role of power distance. Asia Pacific Journal of Human Resources, 50, 43-60.

Wei, F., \& Si, S. (2013). Tit for tat? Abusive supervision and counterproductive work behaviors: The moderating effects of locus of control and perceived mobility. Asia Pacific Journal of Management, 30(1), 281-296.

Wu, J., \& Song, J. (2014). Abusive supervision and employee task performance: A cross-level model. Manuscript presented at the Academy of Management annual meeting in Philadelphia, Pennsylvania.

Xia, Y., Zhang, L., \& Li, M. (in press). Abusive leadership and helping behavior: Capability or mood, which matters? Current Psychology. doi: 10.1007/s12144-017-9583-y

Xu, E., Huang, X., Lam, C. K., \& Miao, Q. (2012). Abusive supervision and work behaviors: The mediating role of LMX. Journal of Organizational Behavior, 33(4), 531-543.

Xu, Q., Zhang, G., \& Chan, A. (in press). Abusive supervision and subordinate proactive behavior: Joint moderating roles of organizational identification and positive affectivity. Journal of Business Ethics. doi: 10.1007/s10551-017-3691-3

Yoo, J. (2013). The influence of social undermining on the service employee's customer-oriented boundary spanning behavior. Journal of Services Marketing, 27(7), 539-550.

Yoo, J., \& Frankwick, G. L. (2013). Exploring the impact of social undermining on salesperson deviance: an integrated model. Journal of Personal Selling \& Sales Management, 33(1), 79-90.

Yu, L., \& Campbell, E. M. (2015). Hidden predictors of bosses' bad behavior: Nonlinear effects of performance on abusive supervision. Manuscript presented at the Academy of Management annual meeting in Vancouver, Canada.

Yu, K., Lin, W., Wang, L., Ma, J., Wei, W., Wang, H., Guo, W., \& Shi, J. (2016). The role of affective commitment and future work self salience in the abusive supervision-job performance relationship. Journal of Occupational and Organizational Psychology, 89, 28-45.

Zellars, K. L., Tepper, B. J., \& Duffy, M. K. (2002). Abusive supervision and subordinates' organizational citizenship behavior. Journal of Applied Psychology, 87(6), 1068-1076.

Zhang, H., Kwan, H. K., Zhang, X., \& Wu, L.-Z. (2014). High core self-evaluators maintain creativity: A motivational model of abusive supervision. Journal of Management, 40(4), 1151-1174.

Zhou, L. (2016). Abusive supervision and work performance: The moderating role of abusive supervision variability. Social Behavior and Personality, 44(7), 1089-1098. 


\section{Appendix B}

Main Codes and Input Values for the Primary Studies Included in the Linear Meta-Analyses

\begin{tabular}{|c|c|c|c|c|c|c|}
\hline Study & Type of DL & Correlate & $n$ & $r$ & $\alpha_{\mathrm{DL}}$ & $\alpha_{\text {Behavior }}$ \\
\hline Alexander (2011) & abusive & organizational deviance & 199 & .21 & .93 & .74 \\
\hline Alexander (2011) & abusive & interpersonal deviance & 199 & .21 & .93 & .76 \\
\hline Alexander (2011) & abusive & leader deviance & 199 & .42 & .93 & .83 \\
\hline Alexander (2011) & abusive & deviance composite & 199 & .33 & .93 & .90 \\
\hline Aryee et al. (2007) & abusive & OCB-O & 178 & -.19 & .89 & .52 \\
\hline Aryee et al. (2007) & abusive & OCB-I & 178 & -.18 & .89 & .52 \\
\hline Aryee et al. (2007) & abusive & OCB composite & 178 & -.20 & .89 & .72 \\
\hline Aryee et al. (2008) & abusive & OCB-O & 285 & -.31 & .88 & .52 \\
\hline Aryee et al. (2008) & abusive & OCB-I & 285 & -.32 & .88 & .52 \\
\hline Aryee et al. (2008) & abusive & OCB composite & 285 & -.35 & .88 & .71 \\
\hline Ashforth (1997) & petty tyranny & performance & 88 & -.25 & .96 & .52 \\
\hline Avey et al. (2015) & abusive & OCB-I & 603 & -.08 & .88 & .52 \\
\hline Avey et al. (2015) & abusive & organizational deviance & 603 & .33 & .88 & .52 \\
\hline Biron (2010) & abusive & organizational deviance & 275 & .24 & .91 & .84 \\
\hline Bligh et al. (2007) & aversive & performance & 342 & -.28 & .84 & .52 \\
\hline Bligh et al. (2007) & aversive & OCB (general) & 342 & -.30 & .84 & .52 \\
\hline Bowling \& Michel (2011) & abusive & organizational deviance & 381 & .66 & .96 & .95 \\
\hline Bowling \& Michel (2011) & abusive & leader deviance & 381 & .72 & .96 & .96 \\
\hline Bowling \& Michel (2011) & abusive & deviance composite & 381 & .71 & .96 & .98 \\
\hline Bozeman (2016) & abusive & performance composite & 211 & -.15 & .94 & .74 \\
\hline Bozeman (2016) & abusive & OCB-O composite & 211 & -.13 & .94 & .73 \\
\hline Bozeman (2016) & abusive & OCB-I composite & 211 & -.03 & .94 & .68 \\
\hline Bozeman (2016) & abusive & OCB composite & 211 & -.09 & .94 & .80 \\
\hline Bozeman (2016) & abusive & organizational dev. comp. & 211 & .26 & .94 & .62 \\
\hline Bozeman (2016) & abusive & interpersonal dev. comp. & 211 & .34 & .94 & .69 \\
\hline
\end{tabular}


This is an author-produced, peer-reviewed version of this article. The final, definitive version of this document can be found online at Personnel Psychology, published by Wiley Periodicals, Inc.

Copyright restrictions may apply. doi: 10.1111/peps.12286

\begin{tabular}{|c|c|c|c|c|c|c|}
\hline Study & Type of DL & Correlate & $n$ & $r$ & $\alpha_{\mathrm{DL}}$ & $\alpha_{\text {Behavior }}$ \\
\hline Bozeman (2016) & abusive & deviance composite & 211 & .35 & .94 & .77 \\
\hline Burris et al. (2008) & abusive & OCB-O & 499 & -.21 & .84 & .52 \\
\hline Camps (2015) Study 4 & abusive & OCB-O & 135 & -.12 & .91 & .42 \\
\hline Camps (2015) Study 4 & abusive & OCB-I & 135 & -.14 & .91 & .42 \\
\hline Camps (2015) Study 4 & abusive & OCB composite & 135 & -.14 & .91 & .64 \\
\hline Chang et al. (2013) & abusive & performance & 304 & .03 & .90 & .87 \\
\hline Chang et al. (2013) & abusive & OCB-O & 304 & .02 & .90 & .89 \\
\hline Chang et al. (2013) & abusive & deviance composite & 304 & .32 & .90 & .81 \\
\hline Chen (2011) Study 4 & abusive & organizational dev. comp. & 137 & .57 & .96 & .72 \\
\hline Chen (2011) Study 4 & abusive & interpersonal deviance & 137 & .48 & .96 & .52 \\
\hline Chen (2011) Study 4 & abusive & deviance composite & 137 & .55 & .96 & .79 \\
\hline Chen (2011) Study 5 & abusive & organizational dev. comp. & 323 & .31 & .91 & .73 \\
\hline Chen (2011) Study 5 & abusive & interpersonal deviance & 323 & .44 & .91 & .52 \\
\hline Chen (2011) Study 5 & abusive & deviance composite & 323 & .39 & .91 & .80 \\
\hline Chi et al. (2016) Study 1 & abusive & OCB-I & 202 & -.08 & .85 & .52 \\
\hline Chi et al. (2016) Study 1 & abusive & leader deviance & 202 & .35 & .85 & .86 \\
\hline Chi et al. (2016) Study 3 & abusive & OCB-I & 417 & -.13 & .87 & .52 \\
\hline Chi et al. (2016) Study 3 & abusive & leader deviance & 417 & .23 & .87 & .85 \\
\hline Childers et al. (2014) & abusive & interpersonal deviance & 115 & .22 & .89 & .65 \\
\hline Choi et al. (2009) & aversive & OCB-O & 123 & -.08 & .74 & .83 \\
\hline Chu (2014) & abusive & OCB (general) & 212 & -.28 & .94 & .92 \\
\hline Daniels (2015) & abusive & performance & 211 & -.27 & .91 & .52 \\
\hline Daniels (2015) & abusive & OCB (general) & 211 & -.15 & .91 & .52 \\
\hline Decoster et al. (2014) & abusive & performance & 101 & -.20 & .94 & .42 \\
\hline Decoster et al. (2014) & abusive & OCB-O & 101 & -.35 & .94 & .52 \\
\hline Decoster et al. (2014) & abusive & OCB-I & 101 & -.26 & .94 & .52 \\
\hline
\end{tabular}

Appendix B (Continued) 
This is an author-produced, peer-reviewed version of this article. The final, definitive version of this document can be found online at Personnel Psychology, published by Wiley Periodicals, Inc. Copyright restrictions may apply. doi: 10.1111/peps. 12286

\begin{tabular}{|c|c|c|c|c|c|c|}
\hline Study & Type of DL & Correlate & $n$ & $r$ & $\alpha_{\mathrm{DL}}$ & $\alpha_{\text {Behavior }}$ \\
\hline Decoster et al. (2014) & abusive & OCB composite & 101 & -.34 & .94 & .71 \\
\hline Duffy et al. (2002) & undermining & organizational dev. comp. & 343 & .24 & .92 & .93 \\
\hline Duffy et al. (2006) Study 1 & undermining & organizational dev & 737 & .22 & .92 & .92 \\
\hline Duniewicz (2015) Study 1 & abusive & organizational deviance & 200 & .29 & .94 & .83 \\
\hline Duniewicz (2015) Study 1 & abusive & leader deviance & 200 & .54 & .94 & .85 \\
\hline Duniewicz (2015) Study 1 & abusive & deviance composite & 200 & .47 & .94 & .90 \\
\hline Duniewicz (2015) Study 2 & abusive & organizational deviance & 144 & .36 & .96 & .89 \\
\hline Duniewicz (2015) Study 2 & abusive & leader deviance & 144 & .42 & .96 & .88 \\
\hline Duniewicz (2015) Study 2 & abusive & deviance composite & 144 & .42 & .96 & .93 \\
\hline Eissa et al. (2017) & undermining & performance & 123 & -.16 & .95 & .52 \\
\hline Eissa et al. (2017) & undermining & $\mathrm{OCB}-\mathrm{O}$ & 123 & -.02 & .95 & .52 \\
\hline Ellen III et al. (in press) Study 2 & narcissism & OCB (general) & 199 & -.20 & .90 & .85 \\
\hline Ellen III et al. (in press) Study 3 & narcissism & performance & 136 & -.16 & .86 & .86 \\
\hline Ellen III et al. (in press) Study 3 & narcissism & OCB (general) & 136 & -.24 & .86 & .86 \\
\hline Eschleman et al. (2014) & abusive & organizational deviance & 268 & .48 & .93 & .94 \\
\hline Eschleman et al. (2014) & abusive & leader deviance & 268 & .45 & .93 & .96 \\
\hline Eschleman et al. (2014) & abusive & deviance composite & 268 & .49 & .93 & .97 \\
\hline Ferris et al. (2016) Study 1 & abusive & interpersonal deviance & 257 & .49 & .96 & .94 \\
\hline Ferris et al. (2016) Study 2 & undermining & interpersonal deviance & 357 & .35 & .98 & .99 \\
\hline Frieder et al. (2014) Study 1 & abusive & organizational deviance & 73 & .34 & .95 & .80 \\
\hline Frieder et al. (2014) Study 2 & abusive & organizational deviance & 172 & .11 & .96 & .76 \\
\hline Frieder et al. (in press) Study 1 & abusive & OCB-O & 143 & -.41 & .88 & .79 \\
\hline Frieder et al. (in press) Study 2 & abusive & OCB-O & 202 & -.15 & .91 & .84 \\
\hline Garcia et al. (2015) & abusive & organizational deviance & 156 & .25 & .91 & 1.00 \\
\hline Gardner et al. (2016) & destructive & performance & 826 & -.16 & .95 & 1.00 \\
\hline Gregory et al. (2013) & abusive & OCB (general) & 357 & -.33 & .70 & .79 \\
\hline
\end{tabular}


This is an author-produced, peer-reviewed version of this article. The final, definitive version of this document can be found online at Personnel Psychology, published by Wiley Periodicals, Inc.

Copyright restrictions may apply. doi: 10.1111/peps.12286

\begin{tabular}{|c|c|c|c|c|c|c|}
\hline Study & Type of DL & Correlate & $n$ & $r$ & $\alpha_{\mathrm{DL}}$ & $\alpha_{\text {Behavior }}$ \\
\hline Gu et al. (2016) & abusive & OCB-O & 213 & -.28 & .89 & .84 \\
\hline Hamid et al. (2016) & abusive & organizational deviance & 136 & .22 & .91 & .90 \\
\hline Hamid et al. (2016) & abusive & interpersonal deviance & 136 & .25 & .91 & .81 \\
\hline Hamid et al. (2016) & abusive & deviance composite & 136 & .25 & .91 & .92 \\
\hline Han et al. (in press) & abusive & OCB-O & 222 & .05 & .89 & .52 \\
\hline Hanig (2013) & abusive & leader deviance & 407 & .61 & .91 & .87 \\
\hline Harris \& Kacmar (2013) & abusive & performance & 142 & -.32 & .93 & .52 \\
\hline Harris et al. (2007) & abusive & performance composite & 154 & -.21 & .91 & .77 \\
\hline Harris et al. (2011) Study 1 & abusive & OCB-I & 121 & -.29 & .90 & .52 \\
\hline Harris et al. (2011) Study 2 & abusive & OCB-I & 134 & -.21 & .92 & .52 \\
\hline Harvey et al. (2014) Study 1 & abusive & organizational deviance & 396 & .49 & .91 & .82 \\
\hline Harvey et al. (2014) Study 2 & abusive & organizational dev. comp. & 81 & .38 & .83 & .64 \\
\hline Hon \& Lu (2016) & abusive & performance & 266 & -.19 & .92 & .52 \\
\hline Hoobler \& Brass (2006) & abusive & performance & 210 & -.17 & .88 & .52 \\
\hline Hussain \& Sia (2017) & abusive & organizational dev & 256 & .44 & .92 & .90 \\
\hline Hussain \& Sia (2017) & abusive & interpersonal deviance & 256 & .43 & .92 & .90 \\
\hline Hussain \& Sia (2017) & abusive & deviance (general) & 256 & .45 & .92 & .90 \\
\hline Jian et al. (2012) & abusive & performance & 324 & -.22 & .93 & .52 \\
\hline Jiang et al. (2016) & abusive & OCB-O & 253 & -.49 & .92 & .52 \\
\hline Johnson \& Griffith (2016) Study 2 & abusive & performance & 94 & .02 & .91 & .52 \\
\hline Joo \& Witt (2015) & abusive & organizational deviance & 279 & .59 & .73 & .70 \\
\hline Kacmar et al. (2013) & abusive & OCB (general) & 111 & -.33 & .91 & .52 \\
\hline Kacmar et al. (2013) & abusive & OCB-I composite & 111 & -.26 & .91 & .70 \\
\hline Kacmar et al. (2016) & abusive & performance & 121 & -.33 & .96 & .52 \\
\hline Kacmar et al. (2016) & abusive & OCB-I & 121 & -.31 & .96 & .52 \\
\hline Kane \& Perrewé (2012) & abusive & organizational deviance & 107 & .16 & .90 & .71 \\
\hline
\end{tabular}


This is an author-produced, peer-reviewed version of this article. The final, definitive version of this document can be found online at Personnel Psychology, published by Wiley Periodicals, Inc..

Copyright restrictions may apply. doi: 10.1111/peps.12286

Appendix B (Continued)

\begin{tabular}{|c|c|c|c|c|c|c|}
\hline Study & Type of DL & Correlate & $n$ & $r$ & $\alpha_{\mathrm{DL}}$ & $\alpha_{\text {Behavior }}$ \\
\hline Kane \& Perrewé (2012) & abusive & interpersonal deviance & 107 & .23 & .90 & .58 \\
\hline Kane \& Perrewé (2012) & abusive & leader deviance & 107 & .54 & .90 & .64 \\
\hline Kane \& Perrewé (2012) & abusive & deviance composite & 107 & .40 & .90 & .80 \\
\hline Kane-Frieder et al. (2013) & abusive & organizational deviance & 130 & .23 & .93 & .63 \\
\hline Kedharnath (2014) Study 1 & abusive & performance & 264 & -.32 & .94 & .88 \\
\hline Kedharnath (2014) Study 2 & abusive & performance & 303 & -.35 & .96 & .91 \\
\hline Khan et al. (2017) & abusive & performance & 173 & -.36 & .78 & .52 \\
\hline Khan et al. (in press) & abusive & performance & 160 & -.36 & .75 & .52 \\
\hline Kim \& Yun (2015) & abusive & performance & 149 & -.27 & .97 & .52 \\
\hline Lam et al. (in press) Study 1 & abusive & performance & 219 & -.23 & .91 & .52 \\
\hline Lam et al. (in press) Study 2 & abusive & performance & 416 & -.04 & .95 & .52 \\
\hline Lee \& Wang (2015) & abusive & performance & 77 & -.14 & .97 & .52 \\
\hline Lee \& Wang (2015) & abusive & OCB (general) & 77 & -.15 & .97 & .52 \\
\hline Lee \& Wang (2015) & abusive & organizational deviance & 77 & .05 & .97 & .52 \\
\hline Lee et al. (2013) & abusive & OCB-O & 203 & -.11 & .98 & .52 \\
\hline Li et al. (2015) Study 2 & abusive & performance & 357 & -.27 & .98 & .52 \\
\hline Lian et al. (2012) Study 1 & abusive & interpersonal deviance & 264 & .36 & .95 & .88 \\
\hline Lian et al. (2012) Study 2 & abusive & interpersonal deviance & 171 & .48 & .96 & .42 \\
\hline Lian et al. (2012) Study 3 & abusive & interpersonal deviance & 198 & .59 & .97 & .94 \\
\hline Lian et al. (2014) Study 1 & abusive & organizational deviance & 151 & .44 & .96 & .93 \\
\hline Lian et al. (2014) Study 2 & abusive & organizational deviance & 125 & .64 & .98 & .94 \\
\hline Liang, Lian, et al. (2016) & abusive & performance & 206 & -.27 & .97 & .52 \\
\hline Liang, Valdron, et al. (2016) Study 1 & abusive & OCB-O & 193 & .03 & .95 & .92 \\
\hline Liang, Valdron, et al. (2016) Study 1 & abusive & organizational deviance & 193 & .31 & .95 & .89 \\
\hline Liang, Valdron, et al. (2016) Study 2 & abusive & OCB-O & 204 & -.27 & .95 & .90 \\
\hline Liang, Valdron, et al. (2016) Study 2 & abusive & organizational deviance & 204 & .45 & .95 & .89 \\
\hline
\end{tabular}


This is an author-produced, peer-reviewed version of this article. The final, definitive version of this document can be found online at Personnel Psychology, published by Wiley Periodicals, Inc..

Copyright restrictions may apply. doi: 10.1111/peps.12286

Appendix B (Continued)

\begin{tabular}{|c|c|c|c|c|c|c|}
\hline Study & Type of DL & Correlate & $n$ & $r$ & $\alpha_{\mathrm{DL}}$ & $\alpha_{\text {Behavior }}$ \\
\hline Lim \& Teo (2009) & incivility & organizational deviance & 192 & .38 & .95 & .97 \\
\hline Liu \& Wang (2013) & abusive & OCB-O & 280 & .05 & .92 & .52 \\
\hline Liu \& Wang (2013) & abusive & OCB-I & 280 & -.19 & .92 & .52 \\
\hline Liu \& Wang (2013) & abusive & OCB composite & 280 & -.09 & .92 & .64 \\
\hline Liu et al. (2010) Study 1 & abusive & leader deviance & 283 & .24 & .95 & .52 \\
\hline Liu et al. (2010) Study 2 & abusive & leader deviance composite & 222 & .26 & .95 & .82 \\
\hline Liu et al. (2012) & abusive & performance & 762 & .03 & .93 & 1.00 \\
\hline Liu et al. (2012) & abusive & $\mathrm{OCB}-\mathrm{O}$ & 762 & -.12 & .93 & .52 \\
\hline Liu et al. (2016) & abusive & OCB-O & 423 & -.19 & .89 & .52 \\
\hline Lyu et al. (2016) & abusive & performance & 198 & -.25 & .94 & .52 \\
\hline Lyu et al. (2016) & abusive & OCB-I & 198 & -.26 & .94 & .42 \\
\hline Mackey, Frieder, et al. (2015) Study 1 & abusive & interpersonal deviance & 96 & .31 & .90 & .85 \\
\hline Mackey, Frieder, et al. (2015) Study 1 & abusive & leader deviance & 96 & .60 & .90 & .89 \\
\hline Mackey, Frieder, et al. (2015) Study 1 & abusive & deviance composite & 96 & .51 & .90 & .92 \\
\hline Mackey, Frieder, et al. (2015) Study 2 & abusive & interpersonal deviance & 130 & .15 & .93 & .74 \\
\hline Mackey, Frieder, et al. (2015) Study 2 & abusive & leader deviance & 130 & .35 & .93 & .89 \\
\hline Mackey, Frieder, et al. (2015) Study 2 & abusive & deviance composite & 130 & .29 & .93 & .87 \\
\hline Mackey, McAllister, et al. (2015) Study 1 & abusive & $\mathrm{OCB}-\mathrm{O}$ & 109 & -.23 & .97 & .93 \\
\hline Mackey, McAllister, et al. (2015) Study 2 & abusive & OCB-O & 228 & -.10 & .84 & .52 \\
\hline Mackey, McAllister, et al. (2015) Study 3 & abusive & OCB-O & 213 & -.33 & .96 & .94 \\
\hline Mathe \& Slevitch (2013) & undermining & performance & 91 & -.26 & .90 & .42 \\
\hline Mawritz et al. (2012) & abusive & interpersonal deviance & 288 & .31 & .98 & .52 \\
\hline Mawritz et al. (2014) & abusive & organizational deviance & 221 & .53 & .94 & .52 \\
\hline Mawritz et al. (in press) Study 1 & abusive & performance & 165 & -.45 & .95 & .52 \\
\hline Mawritz et al. (in press) Study 1 & abusive & leader deviance & 165 & .26 & .95 & .52 \\
\hline Mawritz et al. (in press) Study 2 & abusive & performance & 121 & -.39 & .99 & .52 \\
\hline
\end{tabular}


This is an author-produced, peer-reviewed version of this article. The final, definitive version of this document can be found online at Personnel Psychology, published by Wiley Periodicals, Inc. Copyright restrictions may apply. doi: 10.1111/peps. 12286

Appendix B (Continued)

\begin{tabular}{|c|c|c|c|c|c|c|}
\hline Study & Type of DL & Correlate & $n$ & $r$ & $\alpha_{\mathrm{DL}}$ & $\alpha_{\text {Behavior }}$ \\
\hline Mawritz et al. (in press) Study 2 & abusive & leader deviance composite & 121 & .55 & .99 & .83 \\
\hline McAllister \& Mackey (2014) & abusive & leader deviance & 157 & .59 & .94 & .89 \\
\hline Meng et al. (in press) & abusive & OCB (general) & 857 & -.21 & .98 & .94 \\
\hline Michel et al. (in press) Study 1 & abusive & organizational deviance & 355 & .68 & .96 & .96 \\
\hline Michel et al. (in press) Study 1 & abusive & leader deviance & 355 & .73 & .96 & .96 \\
\hline Michel et al. (in press) Study 1 & abusive & deviance composite & 355 & .73 & .96 & .98 \\
\hline Michel et al. (in press) Study 2 & abusive & organizational deviance & 256 & .22 & .96 & .87 \\
\hline Michel et al. (in press) Study 2 & abusive & leader deviance & 256 & .48 & .96 & .90 \\
\hline Michel et al. (in press) Study 2 & abusive & deviance composite & 256 & .40 & .96 & .92 \\
\hline Mitchell \& Ambrose (2007) & abusive & organizational deviance & 427 & .17 & .89 & .79 \\
\hline Mitchell \& Ambrose (2007) & abusive & interpersonal deviance & 427 & .21 & .89 & .82 \\
\hline Mitchell \& Ambrose (2007) & abusive & leader deviance & 427 & .40 & .89 & .82 \\
\hline Mitchell \& Ambrose (2007) & abusive & deviance composite & 427 & .31 & .89 & .91 \\
\hline Mitchell \& Ambrose (2012) Study 2 & abusive & interpersonal deviance & 278 & .40 & .90 & .85 \\
\hline Mitchell \& Ambrose (2012) Study 2 & abusive & leader deviance & 278 & .61 & .90 & .84 \\
\hline Mitchell \& Ambrose (2012) Study 2 & abusive & deviance composite & 278 & .54 & .90 & .91 \\
\hline Mitchell \& Ambrose (2012) Study 3 & abusive & interpersonal deviance & 243 & .24 & .89 & .81 \\
\hline Mitchell \& Ambrose (2012) Study 3 & abusive & leader deviance & 243 & .32 & .89 & .86 \\
\hline Mitchell \& Ambrose (2012) Study 3 & abusive & deviance composite & 243 & .31 & .89 & .90 \\
\hline Nandkeolyar et al. (2014) Study 1 & abusive & performance & 363 & -.09 & .89 & 1.00 \\
\hline Nandkeolyar et al. (2014) Study 2 & abusive & performance & 105 & .00 & .93 & .52 \\
\hline Nandkeolyar et al. (2016) Study 1 & abusive & organizational deviance & 286 & .17 & .94 & .52 \\
\hline Naseer et al. (2016) & despotic & performance & 480 & -.32 & .92 & .42 \\
\hline Naseer et al. (2016) & despotic & OCB-O & 480 & -.29 & .92 & .42 \\
\hline Naseer et al. (2016) & despotic & OCB-I & 480 & -.34 & .92 & .42 \\
\hline Naseer et al. (2016) & despotic & OCB composite & 480 & -.33 & .92 & .42 \\
\hline
\end{tabular}


This is an author-produced, peer-reviewed version of this article. The final, definitive version of this document can be found online at Personnel Psychology, published by Wiley Periodicals, Inc..

Copyright restrictions may apply. doi: 10.1111/peps.12286

\begin{tabular}{|c|c|c|c|c|c|c|}
\hline Study & Type of DL & Correlate & $n$ & $r$ & $\alpha_{\mathrm{DL}}$ & $\alpha_{\text {Behavior }}$ \\
\hline Neves (2014) & abusive & performance & 193 & -.27 & .90 & .52 \\
\hline Neves (2014) & abusive & OCB-O & 193 & -.25 & .90 & .52 \\
\hline Ogunfowora (2009) & abusive & OCB (general) & 297 & -.17 & .86 & .86 \\
\hline Ogunfowora (2009) & abusive & OCB-O & 297 & -.14 & .86 & .80 \\
\hline Ogunfowora (2009) & abusive & OCB-I & 297 & -.14 & .86 & .82 \\
\hline Ogunfowora (2009) & abusive & organizational deviance & 297 & .09 & .86 & .77 \\
\hline Ogunfowora (2009) & abusive & interpersonal deviance & 297 & .15 & .86 & .84 \\
\hline Ogunfowora (2013) & abusive & deviance (general) & 297 & .09 & .86 & .77 \\
\hline Onyishi (2012) & abusive & OCB (general) & 335 & -.20 & .89 & .92 \\
\hline Onyishi et al. (2017) & abusive & deviance composite & 215 & .51 & .88 & .86 \\
\hline Ouyag et al. (2015) & abusive & OCB composite & 350 & -.16 & .97 & .79 \\
\hline Peng (2013) & abusive & organizational deviance & 241 & .11 & .90 & .42 \\
\hline Peng (2013) & abusive & interpersonal deviance & 241 & .01 & .90 & .42 \\
\hline Peng (2013) & abusive & leader deviance & 241 & .19 & .90 & .42 \\
\hline Peng (2013) & abusive & deviance composite & 241 & .12 & .90 & .73 \\
\hline Peng et al. (2014) & abusive & performance & 358 & -.22 & .92 & .42 \\
\hline Peng et al. (2014) & abusive & OCB-I & 358 & -.12 & .92 & .42 \\
\hline Powell (2013) Study 2A & abusive & organizational deviance & 274 & .21 & .92 & .86 \\
\hline Powell (2013) Study 2A & abusive & interpersonal deviance & 274 & .22 & .92 & .87 \\
\hline Powell (2013) Study 2A & abusive & deviance composite & 274 & .24 & .92 & .91 \\
\hline Powell (2013) Study 2B & abusive & organizational deviance & 200 & .56 & .97 & .95 \\
\hline Powell (2013) Study 2B & abusive & interpersonal deviance & 200 & .59 & .97 & .94 \\
\hline Powell (2013) Study 2B & abusive & deviance composite & 200 & .59 & .97 & .97 \\
\hline Powell (2013) Study 2C & abusive & organizational deviance & 268 & .38 & .95 & .92 \\
\hline Powell (2013) Study 2C & abusive & interpersonal deviance & 268 & .36 & .95 & .89 \\
\hline Powell (2013) Study 2C & abusive & deviance composite & 268 & .39 & .95 & .95 \\
\hline
\end{tabular}


This is an author-produced, peer-reviewed version of this article. The final, definitive version of this document can be found online at Personnel Psychology, published by Wiley Periodicals, Inc.

Copyright restrictions may apply. doi: 10.1111/peps.12286

Appendix B (Continued)

\begin{tabular}{|c|c|c|c|c|c|c|}
\hline Study & Type of DL & Correlate & $n$ & $r$ & $\alpha_{\mathrm{DL}}$ & $\alpha_{\text {Behavior }}$ \\
\hline Pyc (2011) & abusive & performance composite & 232 & .00 & .95 & .73 \\
\hline Rafferty \& Restubog (2011) & abusive & OCB-O composite & 175 & -.28 & .98 & .76 \\
\hline Restubog et al. (2011) Study 1 & abusive & leader deviance & 184 & .58 & .97 & .88 \\
\hline Restubog et al. (2011) Study 2 & abusive & leader deviance & 188 & .53 & .95 & .67 \\
\hline Rice et al. (2016) & abusive & OCB (general) & 123 & -.09 & .94 & .52 \\
\hline Schaubroeck et al. (in press) & abusive & performance & 560 & -.02 & .91 & .52 \\
\hline Scott $(2007)$ & bullying & $\mathrm{OCB}-\mathrm{O}$ & 252 & -.29 & .96 & .75 \\
\hline Scott (2007) & bullying & OCB-I & 252 & -.29 & .96 & .83 \\
\hline Scott (2007) & bullying & OCB composite & 252 & -.30 & .96 & .88 \\
\hline Shao et al. (2011) & abusive & OCB-I & 490 & -.13 & .95 & .89 \\
\hline Shao et al. (2011) & abusive & interpersonal deviance & 490 & .28 & .95 & .85 \\
\hline Shao et al. (2016) Study 1 & abusive & performance & 213 & -.06 & .89 & 1.00 \\
\hline Shao et al. (2016) Study 2 & abusive & performance & 158 & -.22 & .94 & .52 \\
\hline Shoss et al. (2013) Study 2 & abusive & performance & 254 & -.20 & .91 & .52 \\
\hline Shoss et al. (2013) Study 2 & abusive & OCB-O & 254 & -.16 & .91 & .52 \\
\hline Shoss et al. (2013) Study 3 & abusive & performance composite & 187 & -.16 & .87 & .85 \\
\hline Shoss et al. (2013) Study 3 & abusive & OCB-O & 187 & -.17 & .87 & .42 \\
\hline Shum et al. (2014) & abusive & performance & 573 & -.37 & .95 & .52 \\
\hline Skyvington (2014) Study 1 & abusive & OCB (general) & 193 & .03 & .96 & .52 \\
\hline Skyvington (2014) Study 1 & abusive & organizational deviance & 193 & .32 & .96 & .89 \\
\hline Skyvington (2014) Study 2 & abusive & OCB-I & 96 & -.04 & .96 & .86 \\
\hline Steinert (2015) & abusive & OCB (general) & 219 & .20 & .96 & .94 \\
\hline Steinert (2015) & abusive & deviance composite & 219 & .57 & .96 & .97 \\
\hline Taylor (2004) & abusive & organizational deviance & 175 & .30 & .95 & .87 \\
\hline Taylor \& Kluemper (2011) & abusive & organizational deviance & 163 & .25 & .94 & .52 \\
\hline Taylor \& Kluemper (2011) & abusive & interpersonal deviance & 163 & .27 & .94 & .52 \\
\hline
\end{tabular}


This is an author-produced, peer-reviewed version of this article. The final, definitive version of this document can be found online at Personnel Psychology, published by Wiley Periodicals, Inc..

Copyright restrictions may apply. doi: 10.1111/peps.12286

Appendix B (Continued)

\begin{tabular}{|c|c|c|c|c|c|c|}
\hline Study & Type of DL & Correlate & $n$ & $r$ & $\alpha_{\mathrm{DL}}$ & $\alpha_{\text {Behavior }}$ \\
\hline Taylor \& Kluemper (2011) & abusive & deviance composite & 163 & .29 & .94 & .71 \\
\hline Tepper et al. (2008) Study 1 & abusive & organizational deviance & 243 & .28 & .94 & .69 \\
\hline Tepper et al. (2008) Study 2 & abusive & organizational deviance & 247 & .18 & .93 & .75 \\
\hline Tepper et al. (2011) & abusive & performance & 183 & -.39 & .96 & .52 \\
\hline Thau et al. (2009) Study 1 & abusive & organizational deviance & 373 & .32 & .94 & .68 \\
\hline Thau et al. (2009) Study 1 & abusive & interpersonal deviance & 373 & .33 & .94 & .76 \\
\hline Thau et al. (2009) Study 1 & abusive & deviance composite & 373 & .38 & .94 & .81 \\
\hline Thau et al. (2009) Study 2 & abusive & organizational deviance & 1,477 & .47 & .95 & .93 \\
\hline Thau et al. (2009) Study 2 & abusive & leader deviance & 1,477 & .59 & .95 & .93 \\
\hline Thau et al. (2009) Study 2 & abusive & deviance composite & 1,477 & .56 & .95 & .96 \\
\hline Thau \& Mitchell (2010) Study 1 & abusive & organizational deviance & 216 & .07 & .91 & .79 \\
\hline Thau \& Mitchell (2010) Study 1 & abusive & leader deviance & 216 & .57 & .91 & .80 \\
\hline Thau \& Mitchell (2010) Study 1 & abusive & deviance composite & 216 & .39 & .91 & .85 \\
\hline Thau \& Mitchell (2010) Study 2 & abusive & organizational deviance & 371 & .41 & .95 & .89 \\
\hline Thau \& Mitchell (2010) Study 2 & abusive & leader deviance & 375 & .54 & .95 & .93 \\
\hline Thau \& Mitchell (2010) Study 2 & abusive & deviance composite & 371 & .51 & .95 & .95 \\
\hline Thoroughgood et al. (2012) & abusive & organizational deviance & 670 & .34 & .94 & .86 \\
\hline Thoroughgood et al. (2012) & abusive & interpersonal deviance & 670 & .29 & .94 & .81 \\
\hline Thoroughgood et al. (2012) & abusive & deviance composite & 670 & .36 & .94 & .90 \\
\hline Velez \& Neves (2016) & abusive & organizational deviance & 170 & .25 & .87 & .52 \\
\hline Vogel et al. (2016) & abusive & deviance composite & 150 & .22 & .93 & .91 \\
\hline Vogel \& Mitchell (in press) Study 1 & abusive & organizational deviance & 172 & .29 & .93 & .85 \\
\hline Vogel \& Mitchell (in press) Study 2 & abusive & organizational deviance & 221 & .17 & .95 & .87 \\
\hline Vogel \& Mitchell (in press) Study 2 & abusive & leader deviance & 221 & .37 & .95 & .87 \\
\hline Vogel \& Mitchell (in press) Study 2 & abusive & deviance composite & 221 & .30 & .95 & .92 \\
\hline Vogel \& Mitchell (in press) Study 3 & abusive & organizational deviance & 844 & .47 & .94 & .89 \\
\hline
\end{tabular}


This is an author-produced, peer-reviewed version of this article. The final, definitive version of this document can be found online at Personnel Psychology, published by Wiley Periodicals, Inc..

Copyright restrictions may apply. doi: 10.1111/peps.12286

Appendix B (Continued)

\begin{tabular}{|c|c|c|c|c|c|c|}
\hline Study & Type of DL & Correlate & $n$ & $r$ & $\alpha_{\mathrm{DL}}$ & $\alpha_{\text {Behavior }}$ \\
\hline Vogel \& Mitchell (in press) Study 3 & abusive & leader deviance & 844 & .64 & .94 & .91 \\
\hline Vogel \& Mitchell (in press) Study 3 & abusive & deviance composite & 844 & .58 & .94 & .95 \\
\hline Walter et al. (in press) Study 2 & abusive & performance composite & 169 & -.18 & .81 & .82 \\
\hline Wan \& Qinxuan (in press) & abusive & OCB-O & 319 & -.28 & .75 & .52 \\
\hline Wang \& Hu (2015) & abusive & performance composite & 183 & -.15 & .92 & .93 \\
\hline Wang \& Jiang (2014) & abusive & leader deviance & 403 & .35 & .87 & .83 \\
\hline Wang \& Jiang (2015) Study 1 & abusive & OCB-O & 196 & -.21 & .92 & .87 \\
\hline Wang \& Jiang (2015) Study 2 & abusive & OCB-O composite & 379 & -.18 & .86 & .89 \\
\hline Wang et al. (2012) & abusive & organizational deviance & 283 & .23 & .95 & .84 \\
\hline Wang et al. (2012) & abusive & interpersonal deviance & 283 & .22 & .95 & .79 \\
\hline Wang et al. (2012) & abusive & leader deviance & 283 & .24 & .95 & .52 \\
\hline Wang et al. (2012) & abusive & deviance composite & 283 & .28 & .95 & .86 \\
\hline Wang et al. (in press) & abusive & performance & 376 & -.27 & .95 & .89 \\
\hline Wang et al. (in press) & abusive & interpersonal deviance & 376 & .38 & .95 & .84 \\
\hline Wei \& Si (2013) & abusive & organizational deviance & 198 & .23 & .93 & .52 \\
\hline Wu \& Song (2014) & abusive & performance & 255 & -.20 & .97 & .52 \\
\hline Xia et al. (in press) & abusive & OCB-I & 262 & -.41 & .92 & .93 \\
\hline Xu et al. (2012) Study 1 & abusive & performance & 366 & -.11 & .85 & .52 \\
\hline Xu et al. (2012) Study 1 & abusive & OCB-O & 366 & -.17 & .85 & .52 \\
\hline Xu et al. (2012) Study 1 & abusive & OCB-I & 366 & -.13 & .85 & .52 \\
\hline Xu et al. (2012) Study 1 & abusive & OCB composite & 366 & -.16 & .85 & .74 \\
\hline Xu et al. (2012) Study 2 & abusive & performance & 54 & -.06 & .85 & 1.00 \\
\hline Xu et al. (in press) Study 1 & abusive & OCB-O & 165 & -.16 & .84 & .52 \\
\hline Xu et al. (in press) Study 2 & abusive & OCB-O & 226 & -.12 & .87 & .52 \\
\hline Yoo (2013) & undermining & performance & 469 & -.23 & .94 & .87 \\
\hline Yoo \& Frankwick (2013) & undermining & organizational deviance & 469 & .41 & .94 & .72 \\
\hline
\end{tabular}


This is an author-produced, peer-reviewed version of this article. The final, definitive version of this document can be found online at Personnel Psychology, published by Wiley Periodicals, Inc.. Copyright restrictions may apply. doi: 10.1111/peps.12286

Appendix B (Continued)

\begin{tabular}{|c|c|c|c|c|c|c|}
\hline Study & Type of DL & Correlate & $n$ & $r$ & $\alpha_{\mathrm{DL}}$ & $\alpha_{\text {Behavior }}$ \\
\hline Yoo \& Frankwick (2013) & undermining & interpersonal deviance & 469 & .36 & .94 & .75 \\
\hline Yoo \& Frankwick (2013) & undermining & deviance composite & 469 & .49 & .94 & .79 \\
\hline Yu \& Campbell (2015) Study 1 & abusive & performance & 422 & -.19 & .92 & .52 \\
\hline Yu et al. (in press) & abusive & performance & 480 & -.01 & .91 & .52 \\
\hline Zellars et al. (2002) & abusive & OCB (general) & 278 & -.14 & .93 & .52 \\
\hline Zhang et al. (2014) & abusive & OCB-O & 235 & -.19 & .94 & .52 \\
\hline Zhou (2016) & abusive & performance composite & 82 & -.39 & .96 & .90 \\
\hline Zhou (2016) & abusive & OCB composite & 82 & -.42 & .96 & .91 \\
\hline
\end{tabular}

Note. $n=$ sample size. $r=$ zero-order correlation. $\alpha_{\mathrm{DL}}=$ Cronbach's alpha estimate of internal consistency for the measure of destructive leadership. $\alpha_{\mathrm{Behavior}}=$ Cronbach's alpha estimate of internal consistency for the measure of behavior (i.e., job performance, OCBs, or workplace deviance). DL = destructive leadership. OCB $=$ organizational citizenship behaviors. OCB-O $=$ organizational citizenship behaviors directed toward organizations. OCB- $\mathrm{I}=$ organizational citizenship behaviors directed toward individuals. deviance $=$ deviance comp. $=$ composite. 


\section{Appendix C}

Main Codes and Input Values for the Primary Studies Included in the Curvilinear Meta-Analyses

\begin{tabular}{|c|c|c|c|c|c|c|}
\hline Study & Type of DL & Correlate & $n$ & $\begin{array}{l}r_{\mathrm{DL}} \\
\& \mathrm{DL}^{2}\end{array}$ & $\begin{array}{l}r_{\mathrm{DL}} \\
\& \mathrm{~B} \\
\end{array}$ & $\begin{array}{l}r_{\mathrm{DL}}{ }^{2} \\
\& \mathrm{~B}\end{array}$ \\
\hline Bligh et al. (2007) & aversive & performance & 342 & .655 & -.281 & -.242 \\
\hline Bligh et al. (2007) & aversive & OCB (general) & 342 & .655 & -.299 & -.215 \\
\hline Bowling \& Michel (2011) & abusive & organizational deviance & 381 & .788 & .668 & .617 \\
\hline Bowling \& Michel (2011) & abusive & leader deviance & 381 & .788 & .726 & .661 \\
\hline Bowling \& Michel (2011) & abusive & deviance composite & 381 & .788 & .718 & .654 \\
\hline Burris et al. (2008) & abusive & OCB-O & 499 & .766 & -.208 & -.116 \\
\hline Chi et al. (2016) Study 3 & abusive & OCB-I & 417 & .343 & -.130 & -.147 \\
\hline Childers et al. (2014) & abusive & interpersonal deviance & 115 & .735 & .218 & .068 \\
\hline Daniels (2015) & abusive & performance & 211 & .762 & -.269 & -.217 \\
\hline Daniels (2015) & abusive & OCB (general) & 211 & .762 & -.153 & -.152 \\
\hline Decoster et al. (2014) & abusive & performance & 101 & .854 & -.257 & -.170 \\
\hline Decoster et al. (2014) & abusive & OCB-O & 101 & .854 & -.351 & -.325 \\
\hline Decoster et al. (2014) & abusive & OCB-I & 101 & .854 & -.299 & -.255 \\
\hline Decoster et al. (2014) & abusive & OCB composite & 101 & .854 & -.363 & -.327 \\
\hline Eissa et al. (2017) & undermining & performance & 123 & .836 & -.158 & -.068 \\
\hline Eissa et al. (2017) & undermining & OCB-O & 123 & .836 & -.020 & .020 \\
\hline Ferris et al. (2016) Study 1 & abusive & interpersonal deviance & 257 & .705 & .485 & .447 \\
\hline Frieder et al. (2014) Study 1 & abusive & organizational deviance & 73 & .809 & .340 & .085 \\
\hline Frieder et al. (2014) Study 2 & abusive & organizational deviance & 172 & .794 & .107 & -.017 \\
\hline Gardner et al. (2016) & destructive & performance & 826 & .720 & -.124 & -.026 \\
\hline Gu et al. (2016) & abusive & OCB-O & 213 & .657 & -.279 & -.171 \\
\hline Han et al. (in press) & abusive & OCB-O & 222 & -.587 & .052 & .107 \\
\hline Harris et al. (2007) & abusive & performance composite & 154 & .869 & -.183 & -.174 \\
\hline Harris et al. (2011) Study 1 & abusive & OCB-I & 121 & .874 & -.298 & -.256 \\
\hline Harris et al. (2011) Study 2 & abusive & OCB-I & 134 & .779 & -.213 & -.197 \\
\hline
\end{tabular}


This is an author-produced, peer-reviewed version of this article. The final, definitive version of this document can be found online at Personnel Psychology, published by Wiley Periodicals, Inc. Copyright restrictions may apply. doi: 10.1111/peps. 12286

\begin{tabular}{|c|c|c|c|c|c|c|}
\hline Study & Type of DL & Correlate & $n$ & $\begin{array}{l}r_{\mathrm{DL}} \\
\& \mathrm{DL}^{2}\end{array}$ & $\begin{array}{l}r_{\mathrm{DL}} \\
\& \mathrm{~B} \\
\end{array}$ & $\begin{array}{l}r_{\mathrm{DL}}^{2} \\
\& \mathrm{~B} \\
\end{array}$ \\
\hline Harvey et al. (2014) Study 1 & abusive & organizational deviance & 396 & .800 & .472 & .330 \\
\hline Harvey et al. (2014) Study 2 & abusive & organizational dev. comp. & 81 & .697 & .366 & .145 \\
\hline Hon \& Lu (2016) & abusive & performance & 266 & -.147 & .230 & -.048 \\
\hline Hoobler \& Brass (2006) & abusive & performance & 210 & .840 & -.171 & -.159 \\
\hline Jiang et al. (2016) & abusive & OCB-O & 253 & .466 & -.486 & -.076 \\
\hline Johnson \& Griffith (2016) Study 2 & abusive & performance & 94 & .854 & .054 & -.004 \\
\hline Joo \& Witt (2015) & abusive & organizational deviance & 279 & .439 & .585 & .293 \\
\hline Kacmar et al. (2013) & abusive & OCB-I composite & 111 & .819 & -.269 & -.279 \\
\hline Kacmar et al. (2016) & abusive & performance & 121 & .746 & -.329 & -.325 \\
\hline Kacmar et al. (2016) & abusive & OCB-I & 121 & .746 & -.315 & -.308 \\
\hline Kane \& Perrewé (2012) & abusive & organizational deviance & 107 & .853 & .161 & .054 \\
\hline Kane \& Perrewé (2012) & abusive & interpersonal deviance & 107 & .853 & .229 & .093 \\
\hline Kane \& Perrewé (2012) & abusive & leader deviance & 107 & .853 & .523 & .403 \\
\hline Kane \& Perrewé (2012) & abusive & deviance composite & 107 & .853 & .375 & .217 \\
\hline Kane-Frieder et al. (2013) & abusive & organizational deviance & 130 & .809 & .253 & .137 \\
\hline Khan et al. (in press) & abusive & performance & 160 & .278 & -.365 & -.161 \\
\hline Lam et al. (in press) Study 1 & abusive & performance & 219 & .629 & -.197 & -.133 \\
\hline Lam et al. (in press) Study 2 & abusive & performance & 416 & .672 & .011 & -.021 \\
\hline Lee \& Wang (2015) & abusive & performance & 77 & .654 & -.135 & .016 \\
\hline Lee \& Wang (2015) & abusive & OCB (general) & 77 & .654 & -.146 & -.142 \\
\hline Lee \& Wang (2015) & abusive & organizational deviance & 77 & .654 & .053 & .047 \\
\hline Lee et al. (2013) & abusive & OCB-O & 203 & .670 & -.112 & -.204 \\
\hline Liang, Lian, et al. (2016) & abusive & performance & 206 & .809 & -.270 & -.341 \\
\hline Liu et al. (2016) & abusive & OCB-O & 423 & .234 & -.279 & .002 \\
\hline Lyu et al. (2016) & abusive & performance & 198 & .417 & -.254 & -.004 \\
\hline Lyu et al. (2016) & abusive & OCB-I & 198 & .417 & -.261 & -.018 \\
\hline
\end{tabular}


This is an author-produced, peer-reviewed version of this article. The final, definitive version of this document can be found online at Personnel Psychology, published by Wiley Periodicals, Inc.. Copyright restrictions may apply. doi: 10.1111/peps.12286

\begin{tabular}{|c|c|c|c|c|c|c|}
\hline Study & Type of DL & Correlate & $n$ & $\begin{array}{l}r_{\mathrm{DL}} \\
\& \mathrm{DL}^{2}\end{array}$ & $\begin{array}{l}r_{\mathrm{DL}} \\
\& \mathrm{~B} \\
\end{array}$ & $\begin{array}{l}r_{\mathrm{DL}}^{2} \\
\& \mathrm{~B} \\
\end{array}$ \\
\hline Mackey, Frieder, et al. (2015) Study 1 & abusive & interpersonal deviance & 96 & .847 & .307 & .183 \\
\hline Mackey, Frieder, et al. (2015) Study 1 & abusive & leader deviance & 96 & .847 & .597 & .524 \\
\hline Mackey, Frieder, et al. (2015) Study 1 & abusive & deviance composite & 96 & .847 & .486 & .323 \\
\hline Mackey, Frieder, et al. (2015) Study 2 & abusive & interpersonal deviance & 130 & .809 & .145 & .054 \\
\hline Mackey, Frieder, et al. (2015) Study 2 & abusive & leader deviance & 130 & .809 & .345 & .210 \\
\hline Mackey, Frieder, et al. (2015) Study 2 & abusive & deviance composite & 130 & .809 & .305 & .169 \\
\hline Mackey, McAllister, et al. (2015) Study 1 & abusive & OCB-O & 109 & .915 & -.233 & -.163 \\
\hline Mackey, McAllister, et al. (2015) Study 2 & abusive & OCB-O & 228 & .287 & -.104 & .138 \\
\hline Mackey, McAllister, et al. (2015) Study 3 & abusive & OCB-O & 213 & .857 & -.329 & -.299 \\
\hline Mawritz et al. (2014) & abusive & organizational deviance & 221 & .852 & .527 & .504 \\
\hline McAllister \& Mackey (2014) & abusive & leader deviance & 157 & .830 & .589 & .410 \\
\hline Meng et al. (in press) & abusive & OCB (general) & 857 & .861 & -.083 & .046 \\
\hline Michel et al. (in press) Study 1 & abusive & organizational deviance & 355 & .791 & .676 & .641 \\
\hline Michel et al. (in press) Study 1 & abusive & leader deviance & 355 & .791 & .734 & .681 \\
\hline Michel et al. (in press) Study 1 & abusive & deviance composite & 355 & .791 & .727 & .681 \\
\hline Michel et al. (in press) Study 2 & abusive & organizational deviance & 256 & .834 & .224 & .052 \\
\hline Michel et al. (in press) Study 2 & abusive & leader deviance & 256 & .834 & .476 & .337 \\
\hline Michel et al. (in press) Study 2 & abusive & deviance composite & 256 & .834 & .392 & .213 \\
\hline Nandkeolyar et al. (2014) Study 1 & abusive & performance & 363 & .804 & -.094 & -.107 \\
\hline Nandkeolyar et al. (2014) Study 2 & abusive & performance & 105 & .708 & -.004 & .103 \\
\hline Nandkeolyar et al. (2016) Study 1 & abusive & organizational deviance & 286 & .764 & .166 & .192 \\
\hline Naseer et al. (2016) & despotic & performance & 480 & -.106 & -.318 & .077 \\
\hline Naseer et al. (2016) & despotic & OCB-O & 480 & -.106 & -.285 & .062 \\
\hline Naseer et al. (2016) & despotic & OCB-I & 480 & -.106 & -.335 & .062 \\
\hline Naseer et al. (2016) & despotic & OCB composite & 480 & -.106 & -.328 & .067 \\
\hline Neves $(2014)$ & abusive & performance & 193 & .799 & -.273 & -.198 \\
\hline
\end{tabular}


This is an author-produced, peer-reviewed version of this article. The final, definitive version of this document can be found online at Personnel Psychology, published by Wiley Periodicals, Inc..

Copyright restrictions may apply. doi: 10.1111/peps.12286

\begin{tabular}{|c|c|c|c|c|c|c|}
\hline Study & Type of DL & Correlate & $n$ & $\begin{array}{l}r_{\mathrm{DL}} \\
\& \mathrm{DL}^{2}\end{array}$ & $\begin{array}{l}r_{\mathrm{DL}} \\
\& \mathrm{~B} \\
\end{array}$ & $\begin{array}{l}r_{\mathrm{DL}}^{2} \\
\& \mathrm{~B} \\
\end{array}$ \\
\hline Neves (2014) & abusive & OCB-O & 193 & .799 & -.251 & -.161 \\
\hline Peng (2013) & abusive & organizational deviance & 241 & .883 & .111 & .073 \\
\hline Peng (2013) & abusive & interpersonal deviance & 241 & .883 & .024 & .029 \\
\hline Peng (2013) & abusive & leader deviance & 241 & .883 & .205 & .230 \\
\hline Peng (2013) & abusive & deviance composite & 241 & .883 & .122 & .114 \\
\hline Peng et al. (2014) & abusive & performance & 358 & .840 & -.220 & -.098 \\
\hline Peng et al. (2014) & abusive & OCB-I & 358 & .840 & -.117 & .024 \\
\hline Rafferty \& Restubog (2011) & abusive & OCB-O composite & 175 & .794 & -.279 & -.328 \\
\hline Schaubroeck et al. (in press) & abusive & performance & 560 & .682 & -.041 & .004 \\
\hline Shao et al. (2011) & abusive & OCB-I & 490 & .742 & -.131 & -.049 \\
\hline Shao et al. (2011) & abusive & interpersonal deviance & 490 & .742 & .277 & .157 \\
\hline Shoss et al. (2013) Study 2 & abusive & performance & 254 & .568 & -.199 & -.096 \\
\hline Shoss et al. (2013) Study 2 & abusive & OCB-O & 254 & .568 & -.164 & -.098 \\
\hline Shoss et al. (2013) Study 3 & abusive & performance composite & 187 & .454 & -.167 & -.063 \\
\hline Shoss et al. (2013) Study 3 & abusive & OCB-O & 187 & .454 & -.168 & -.021 \\
\hline Shum et al. (2014) & abusive & performance & 573 & .310 & -.360 & -.144 \\
\hline Thau et al. (2009) Study 1 & abusive & organizational deviance & 373 & .718 & .283 & .112 \\
\hline Thau et al. (2009) Study 1 & abusive & interpersonal deviance & 373 & .718 & .295 & .149 \\
\hline Thau et al. (2009) Study 1 & abusive & deviance composite & 373 & .718 & .335 & .151 \\
\hline Thau et al. (2009) Study 2 & abusive & organizational deviance & 1477 & .778 & .470 & .392 \\
\hline Thau et al. (2009) Study 2 & abusive & leader deviance & 1477 & .778 & .591 & .483 \\
\hline Thau et al. (2009) Study 2 & abusive & deviance composite & 1477 & .778 & .563 & .464 \\
\hline Thau \& Mitchell (2010) Study 1 & abusive & organizational deviance & 216 & .868 & .086 & .025 \\
\hline Thau \& Mitchell (2010) Study 1 & abusive & leader deviance & 216 & .868 & .574 & .413 \\
\hline Thau \& Mitchell (2010) Study 1 & abusive & deviance composite & 216 & .868 & .401 & .267 \\
\hline Thau \& Mitchell (2010) Study 2 & abusive & organizational deviance & 371 & .823 & .370 & .367 \\
\hline
\end{tabular}


This is an author-produced, peer-reviewed version of this article. The final, definitive version of this document can be found online at Personnel Psychology, published by Wiley Periodicals, Inc.. Copyright restrictions may apply. doi: 10.1111/peps.12286

\begin{tabular}{|c|c|c|c|c|c|c|}
\hline Study & Type of DL & Correlate & $n$ & $\begin{array}{l}r_{\mathrm{DL}} \\
\& \mathrm{DL}^{2}\end{array}$ & $\begin{array}{l}r_{\mathrm{DL}} \\
\& \mathrm{~B} \\
\end{array}$ & $\begin{array}{l}r_{\mathrm{DL}}^{2} \\
\& \mathrm{~B} \\
\end{array}$ \\
\hline Thau \& Mitchell (2010) Study 2 & abusive & leader deviance & 375 & .823 & .535 & .474 \\
\hline Thau \& Mitchell (2010) Study 2 & abusive & deviance composite & 371 & .823 & .492 & .457 \\
\hline Velez \& Neves (2016) & abusive & organizational deviance & 170 & .671 & .254 & .052 \\
\hline Vogel et al. (2016) & abusive & deviance composite & 150 & .794 & .215 & .080 \\
\hline Vogel \& Mitchell (in press) Study 1 & abusive & organizational deviance & 172 & .799 & .284 & .216 \\
\hline Vogel \& Mitchell (in press) Study 2 & abusive & organizational deviance & 221 & .860 & .171 & .152 \\
\hline Vogel \& Mitchell (in press) Study 2 & abusive & leader deviance & 221 & .860 & .375 & .283 \\
\hline Vogel \& Mitchell (in press) Study 2 & abusive & deviance composite & 221 & .860 & .310 & .244 \\
\hline Vogel \& Mitchell (in press) Study 3 & abusive & organizational deviance & 844 & .762 & .353 & .239 \\
\hline Vogel \& Mitchell (in press) Study 3 & abusive & leader deviance & 844 & .762 & .477 & .279 \\
\hline Vogel \& Mitchell (in press) Study 3 & abusive & deviance composite & 844 & .762 & .444 & .275 \\
\hline Walter et al. (in press) Study 2 & abusive & performance composite & 169 & .562 & -.209 & -.052 \\
\hline Wang \& Jiang (2014) & abusive & leader deviance & 403 & .529 & .355 & .234 \\
\hline Wang \& Jiang (2015) Study 1 & abusive & OCB-O & 196 & .108 & -.151 & .196 \\
\hline Wang \& Jiang (2015) Study 2 & abusive & OCB-O composite & 379 & .481 & -.127 & .003 \\
\hline Wang et al. (in press) & abusive & performance & 376 & .861 & -.274 & -.227 \\
\hline Wang et al. (in press) & abusive & interpersonal deviance & 376 & .861 & .376 & .253 \\
\hline Xia et al. (in press) & abusive & OCB-I & 262 & .099 & -.410 & .014 \\
\hline Xu et al. (2012) Study 2 & abusive & performance & 54 & .582 & -.288 & -.084 \\
\hline Yoo (2013) & undermining & performance & 469 & .530 & -.431 & -.037 \\
\hline Yoo \& Frankwick (2013) & undermining & organizational deviance & 469 & .573 & .427 & .043 \\
\hline Yoo \& Frankwick (2013) & undermining & interpersonal deviance & 469 & .573 & .363 & .101 \\
\hline Yoo \& Frankwick (2013) & undermining & deviance composite & 469 & .573 & .495 & .091 \\
\hline Yu et al. (in press) & abusive & performance & 480 & .756 & .006 & -.006 \\
\hline Zhou (2016) & abusive & performance composite & 82 & .382 & -.393 & -.013 \\
\hline Zhou (2016) & abusive & OCB composite & 82 & .382 & -.412 & -.042 \\
\hline
\end{tabular}


This is an author-produced, peer-reviewed version of this article. The final, definitive version of this document can be found online at Personnel Psychology, published by Wiley Periodicals, Inc.. Copyright restrictions may apply. doi: 10.1111/peps.12286

Appendix C (Continued)

Note. $n=$ sample size. $r=$ zero-order correlation. $\mathrm{DL}=$ destructive leadership. $\mathrm{B}=$ behavior. $\mathrm{OCB}=$ organizational citizenship behaviors. $\mathrm{OCB}-\mathrm{O}=$

organizational citizenship behaviors directed toward organizations. OCB-I = organizational citizenship behaviors directed toward individuals. deviance $=$

deviance. comp. $=$ composite 


\section{Appendix D}

Meta-Analytic Estimates Used as Inputs for the Curvilinear Analyses

\begin{tabular}{|c|c|c|c|c|c|c|c|c|}
\hline Analysis & $k$ & $N$ & $\rho_{\mathrm{DL}} \& \mathrm{DL}^{2}$ & $S D_{\rho \mathrm{DL}} \& \mathrm{DL}^{2}$ & $\rho_{\text {DL } \& B}$ & $S D_{\rho \text { DL } \& \mathrm{~B}}$ & $\rho_{\mathrm{DL}}^{2} \& \mathrm{~B}$ & $S D_{\rho \mathrm{DL}^{2}}^{2} \& \mathrm{~B}$ \\
\hline Overall Job Performance & 31 & 8,427 & .68 & .31 & -.24 & .18 & -.11 & .11 \\
\hline Published Studies & 27 & 7,472 & .70 & .31 & -.22 & .17 & -.11 & .11 \\
\hline Other-Rated Performance & 28 & 6,756 & .65 & .34 & -.24 & .19 & -.13 & .12 \\
\hline Abusive Supervision Studies & 26 & 6,187 & .72 & .27 & -.22 & .18 & -.15 & .10 \\
\hline Overall OCBs & 32 & 8,232 & .63 & .37 & -.26 & .14 & -.09 & .15 \\
\hline Published Studies & 25 & 6,724 & .62 & .40 & -.25 & .13 & -.07 & .15 \\
\hline Other-Rated OCBs & 23 & 5,338 & .56 & .42 & -.32 & .14 & -.13 & .15 \\
\hline Abusive Supervision Studies & 29 & 7,287 & .66 & .34 & -.24 & .13 & -.09 & .15 \\
\hline Overall Workplace Deviance & 32 & 9,542 & .84 & .08 & .49 & .15 & .36 & .17 \\
\hline Published Studies & 22 & 7,905 & .84 & .08 & .51 & .12 & .38 & .17 \\
\hline Self-Rated Deviance & 26 & 8,466 & .84 & .08 & .50 & .13 & .36 & .17 \\
\hline Frequency Scale Studies & 21 & 6,411 & .83 & .09 & .50 & .16 & .37 & .20 \\
\hline Abusive Supervision Studies & 31 & 9.073 & .85 & .07 & .48 & .15 & .37 & .17 \\
\hline Organization-Directed Deviance & 23 & 7,368 & .85 & .08 & .45 & .16 & .33 & .19 \\
\hline
\end{tabular}

Note. $k=$ number of studies included in the analysis. $N=$ total sample size of all studies included in the analysis. $\rho=$ the population estimate that corrects the zero-order bivariate correlation for measurement and sampling error across studies. $S D_{\rho}=$ standard deviation of the population correlation estimate across studies. $\mathrm{DL}=$ destructive leadership. $\mathrm{OCB}=$ organizational citizenship behavior. $\mathrm{B}=$ Behavior. 


\section{Appendix E}

Equations Used to Transform Uncentered Correlations that Included a Curvilinear Term into Mean-Centered Correlations

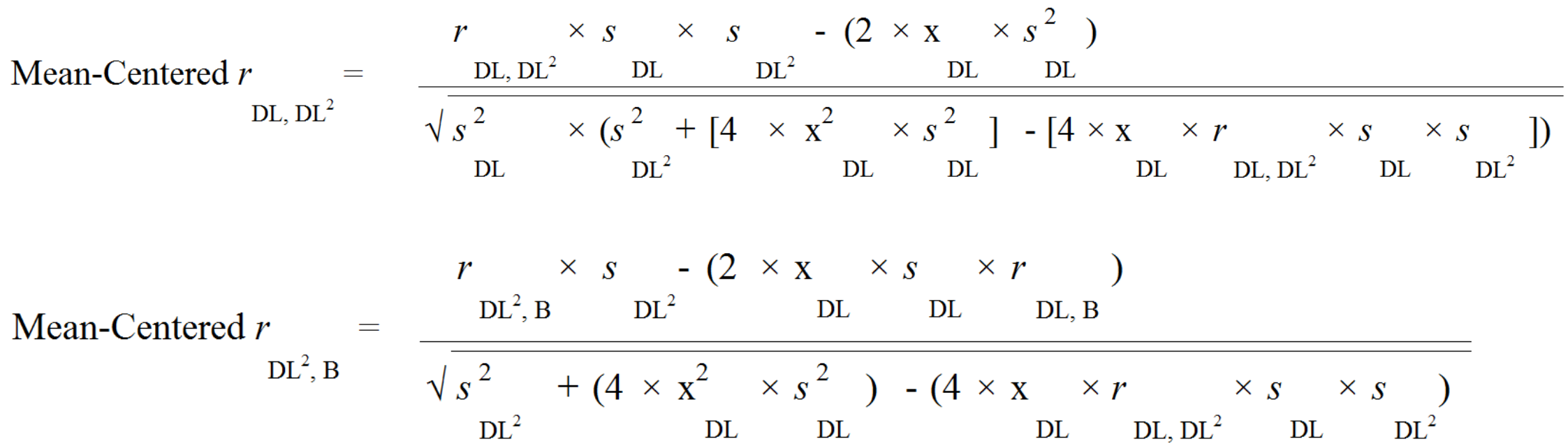

Note. $r=$ uncentered zero-order correlation. $s=$ standard deviation. $s^{2}=$ variance. $\mathrm{x}=$ mean. $\mathrm{DL}=$ destructive leadership. $\mathrm{B}=$ behavior 


\section{Figure 1}

Profiles of Impression Management for Sample 1

\section{Sample 1}

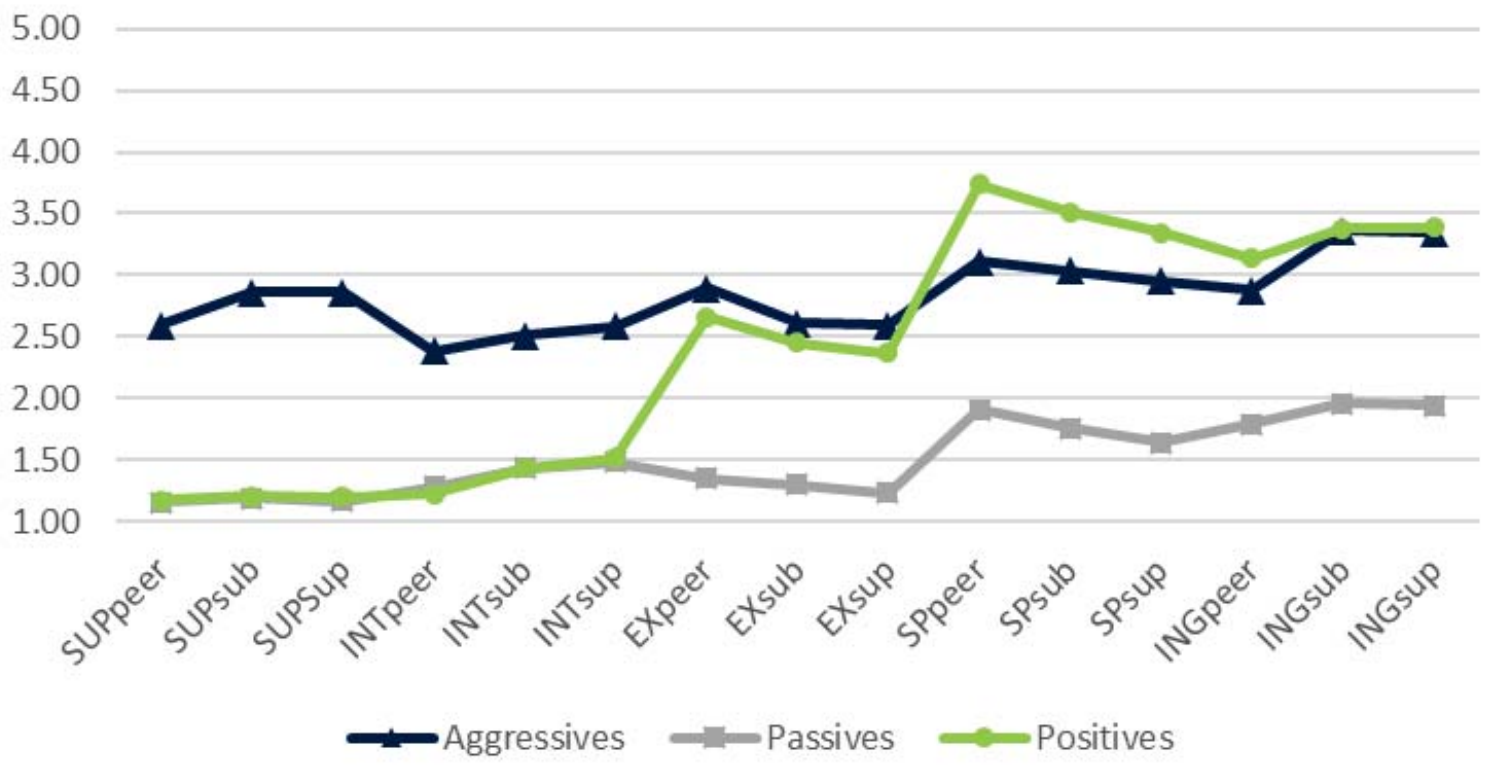

SUP = supplication, INT = intimidation, EX = exemplification, $\mathrm{SP}=$ self-presentation, ING = ingratiation. For subscripts, peer = peers/colleagues, sub = subordinates/support staff, sup = supervisor. 


\section{Figure 2}

Profiles of Impression Management for Sample 2

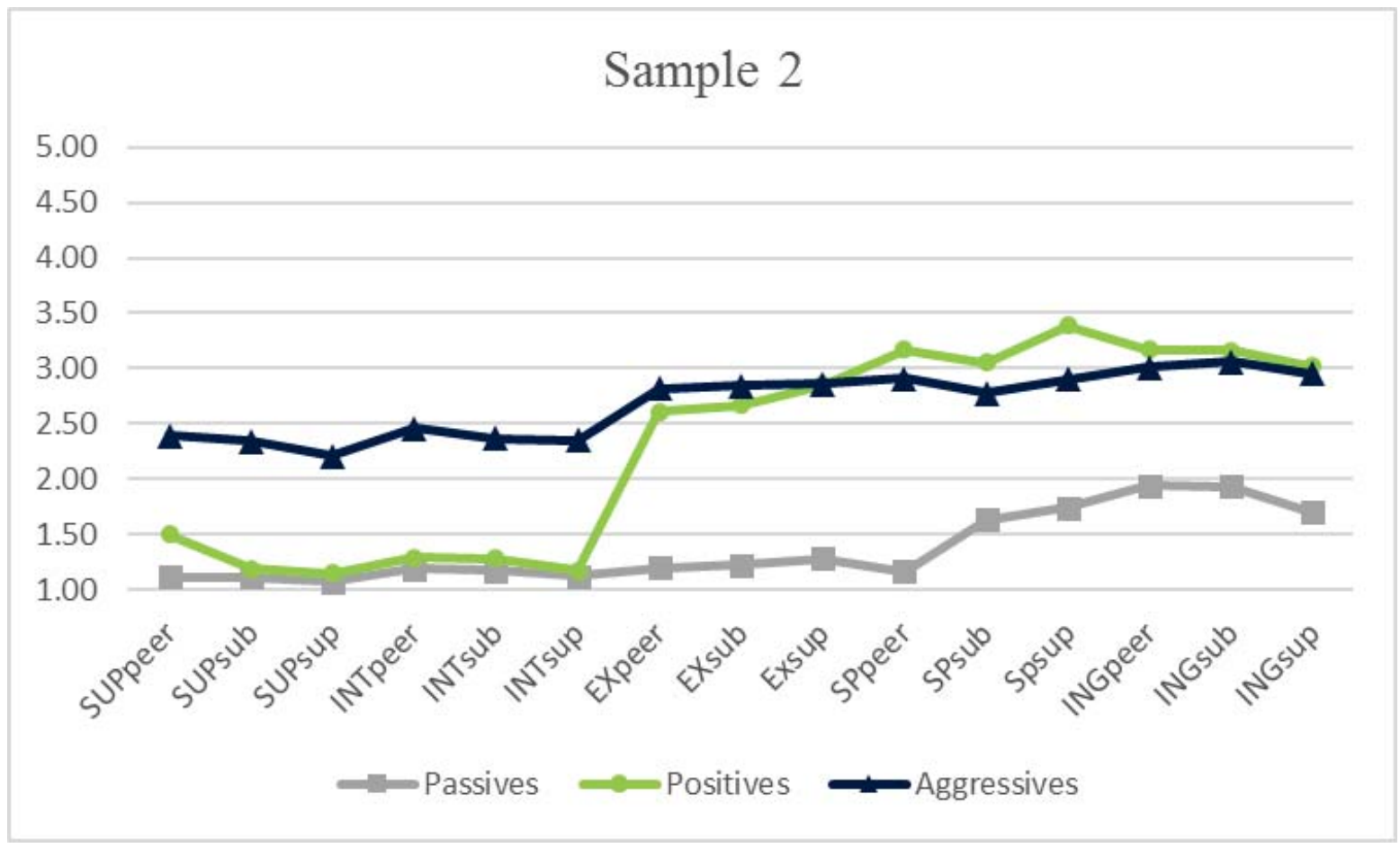

SUP = supplication, INT = intimidation, $\mathrm{EX}=$ exemplification, $\mathrm{SP}=$ self-presentation, $\mathrm{ING}=$ ingratiation. For subscripts, peer = peers/colleagues, sub = subordinates/support staff, sup = supervisor. 
This is an author-produced, peer-reviewed version of this article. The final, definitive version of this document can be found online at Personnel Psychology, published by Wiley Periodicals, Inc.. Copyright restrictions may apply. doi: 10.1111/peps.12286

\section{Figure 3}

Profiles of Impression Management for Sample 3

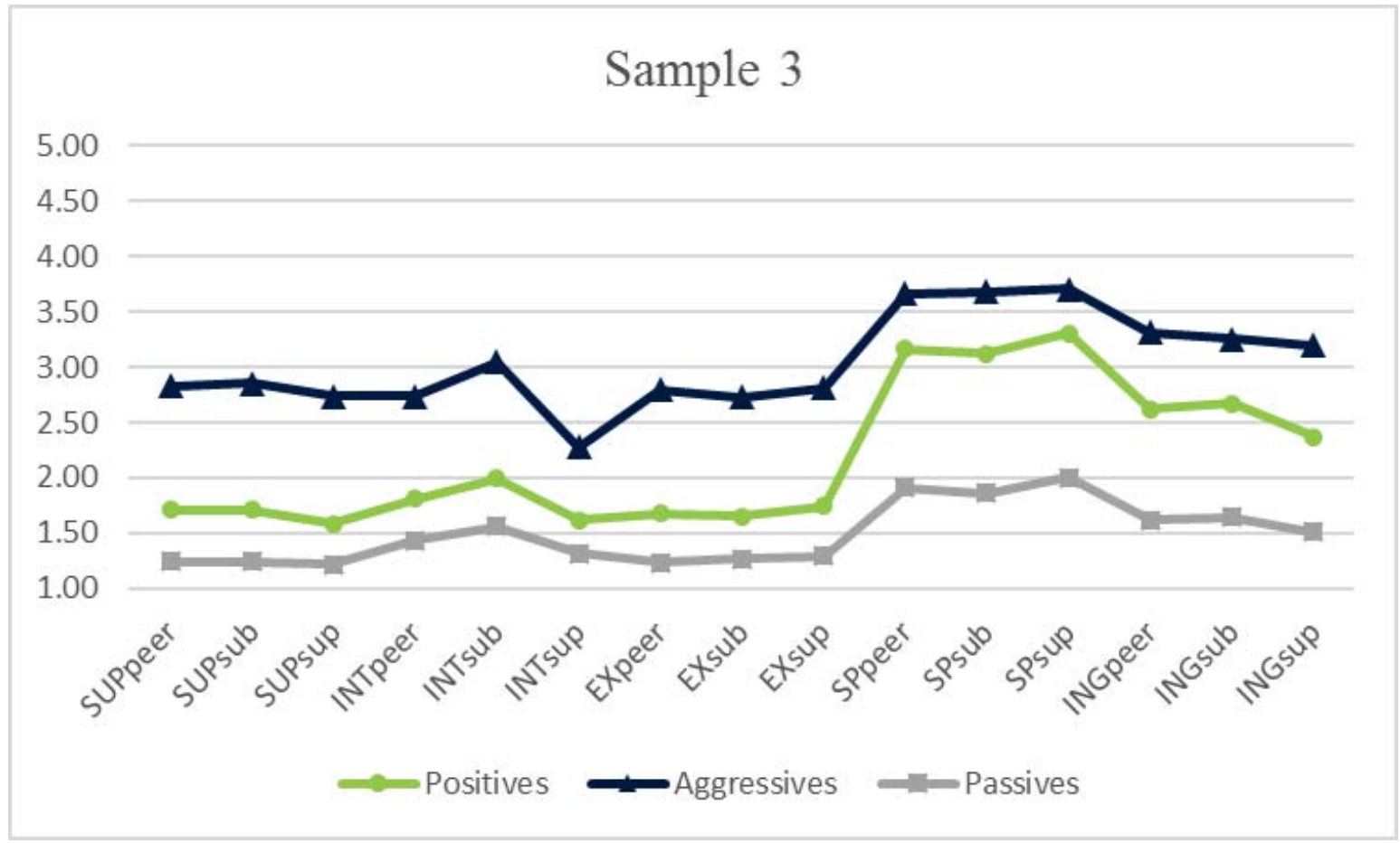

SUP = supplication, INT = intimidation, $\mathrm{EX}=$ exemplification, $\mathrm{SP}=$ self-presentation, $\mathrm{ING}=$ ingratiation. For subscripts, peer = peers/colleagues, sub = subordinates/support staff, sup = supervisor. 


\section{Figure 4}

Profiles of Impression Management for Sample 4

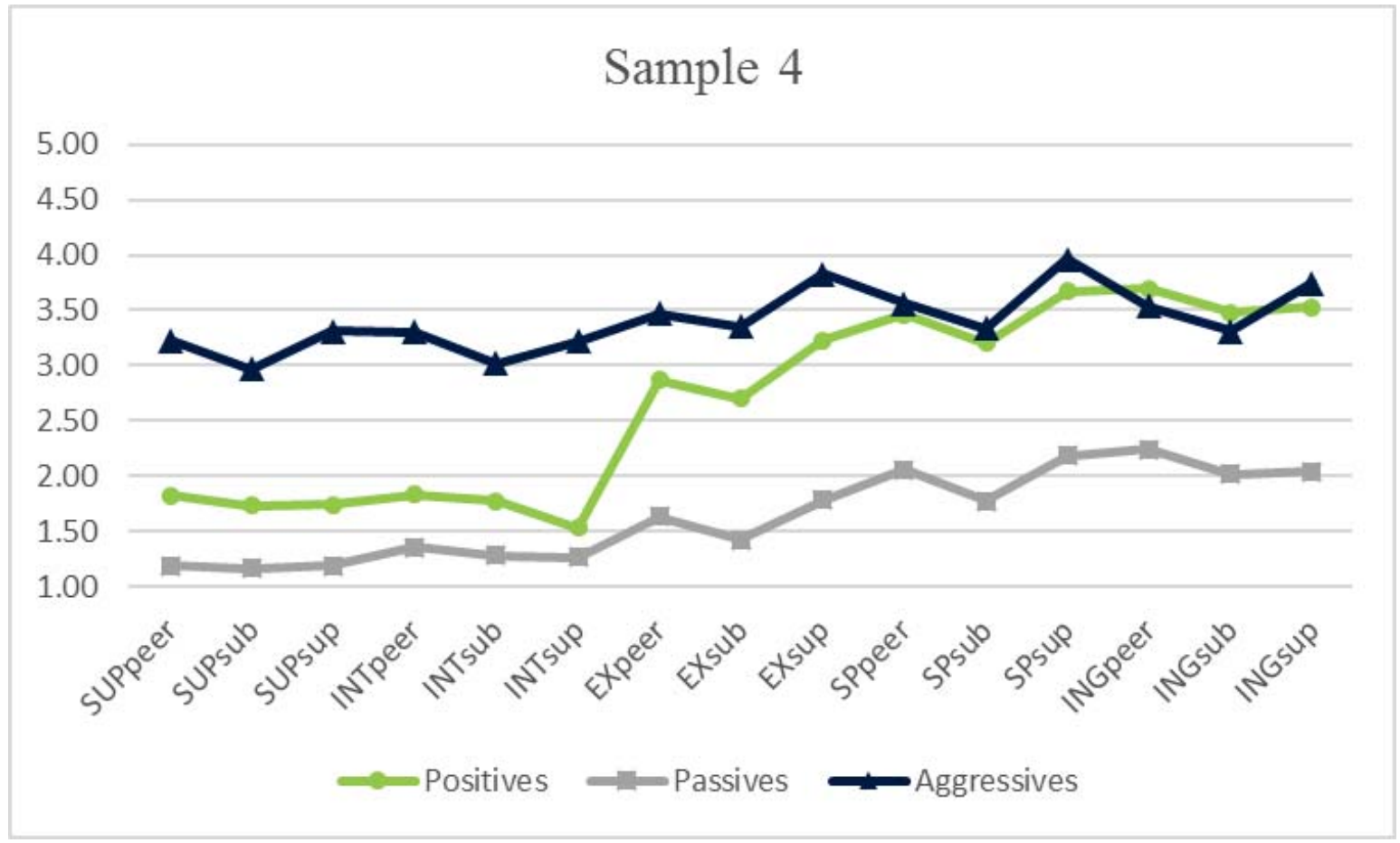

SUP = supplication, INT = intimidation, $\mathrm{EX}=$ exemplification, $\mathrm{SP}=$ self-presentation, $\mathrm{ING}=$ ingratiation. For subscripts, peer = peers/colleagues, sub = subordinates/support staff, sup = supervisor. 